\title{
An Investigation of Controlled Oscillations in a Plasma Torch for Combustion Enhancement
}

\author{
Darius Demetri Sanders
}

Thesis submitted to the faculty of the Virginia Polytechnic Institute and State University in partial fulfillment of the requirements for the degree of

\author{
Master of Science \\ In \\ Mechanical Engineering \\ Dr. Walter F. O’Brien, Chair \\ Dr. Joseph A. Schetz \\ Dr. Pavlos P. Vlachos
}

November 2, 2005

Blacksburg, VA

Keywords: plasma torch, oscillation, unsteady combustion, unsteady shocks 


\title{
An Investigation of Controlled Oscillations in a Plasma Torch for Combustion Enhancement
}

\author{
By \\ Darius D. Sanders \\ Dr. Walter O’Brien, Chair \\ Mechanical Engineering
}

(ABSTRACT)

The oscillating plasma torch is proposed as a potential device that will produce an oscillating shock and resulting control of the supersonic combustion process. This research will capitalize on previous results [Gallimore, 1998] which indicate that the plasma torch oscillations originate from the inherent oscillations of the voltage applied to the torch. The aim of this research is to thoroughly investigate the oscillation behavior of the plasma torch with the plan of ultimately controlling the oscillation at chosen frequencies. A modulating power system used for dynamic control of the plasma torch oscillation was designed and tested in quiescent conditions (no flow), Mach 2.4 cold supersonic flow, and Mach 2 heated supersonic flow conditions. The oscillating plasma torch used nitrogen feedstock and was operated over a frequency range of $2 \mathrm{~Hz}-4 \mathrm{kHz}$. A dynamic torch model using the hybrid Mayr-Cassie electric arc model was developed to predict the plasma torch electric arc response at appropriate frequencies for interaction with supersonic combustion.

In quiescent conditions, the dynamic response of the plasma torch power system and plasma jet were characterized using signal processing techniques and high speed video imaging. High speed Schlieren images were used to determine the behavior of the oscillating plasma jet in Mach 2.4 cross flow and its influence on the induced shock structure. The unsteady nitrogen-fed torch was integrated with the flush walled 4-hole aerodynamic ramp injector using hydrogen and hydrocarbon fuels at the University of Virginia Aerospace Research Lab (ARL) heated Mach 2 supersonic flow. Unsteady pressure variations from the oscillating shock produced by the plasma torch were recorded using recess-mounted Kulite pressure transducers. Also, measurements of the static pressure of the combustion produced by the oscillating plasma torch were obtained.

The oscillating torch system performed well over a range of different flow conditions. It will enable active control input to the combustion process. The controllable unsteady blockage might provide a type shock interaction needed to increase turbulence and mixing augmentation [Kumar, et al. 1987]. 


\section{Acknowledgements}

First and foremost, I would like to thank my family for all their support throughout my whole educational career. Mom thanks for your love and encouragement. Reggie thanks for being a positive male role model. Daphne thanks for you help, advice, and support in anything I needed. Dad thanks for keeping me motivated and supporting me.

I would like to thank my committee for their guidance throughout this research. Special thanks goes to: Dr. O’Brien for serving as great mentor and advisor, Dr. Schetz for challenging me as a graduate student, and Dr. Vlachos for your advice and allowing me to use your lab equipment. Also, special thanks go to Ali Etebari for the work he attributed to the completion of this thesis. The amount of knowledge amongst you is astounding. Also, NASA Langley is appreciated for funding this research.

Also, thanks to all the members of plasma torch research group past and present. Joe thanks for helping me get my feet wet in this research. Melissa thanks for help in the beginning with my research and allowing me to play a role in your research. Cody thanks for advice and

ideas. Ari thanks for your help with this project and I am going to miss all the research trips to UVA. Matt thanks for the help in testing and letting me participate in your research. Hopefully your successful project will make us all rich!

I give credit to Steve for his role in the development of this project. Your knowledge with all the lab equipment is astounding. I appreciate all the help you gave me with LabView. I can’t imagine how long it would have taken to complete my experiments without you.

Thanks to all the Turbolabbers: Kevin, Hoon, Matt, Joe M., Melissa, Tiffany, John, Rob, Dr. King, Katie, Mono, Gautham, Matthew, Joe H., and Mike. Thanks for help in everything, including helping me get my homework done. 
Finally, I would like to thank all my friends and fraternity brothers that have supported me during my time at Virginia Tech. Darrell, Phillip, Mike Terry, Andre, the Theta Psi Chapter, Adria, Lesa, Chanel, Mercedes, Annette, Burthia, and Curtis thanks for the memories past, present, and future. Last but certainly not least, thank you Yvette for your caring, support, and helping me keep a positive attitude throughout the last half of my education. 


\section{Table of Contents}

Acknowledgements.............................................................................................. iii

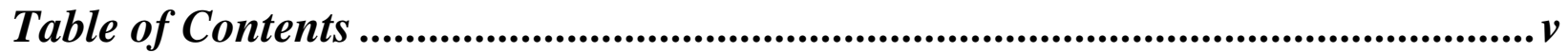

List of Figures ...................................................................................................................vii

List of Tables .............................................................................................................................. ix

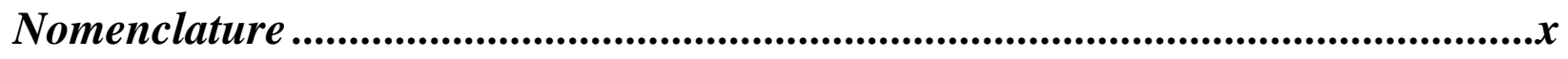

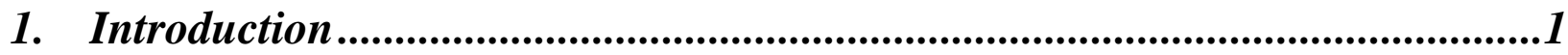

1.1 The First Successful Scramjet Flight ................................................................................. 1

$1.2 \quad$ Scramjet and Ramjet Engine Designs................................................................................. 2

1.2.1 The Ramjet Engine .......................................................................................... 2

1.2.2 The Scramjet Engine ....................................................................................... 2

1.2.3 The Dual Combustor Ramjet .............................................................................. 4

1.3 The Plasma Torch ..................................................................................................................... 4

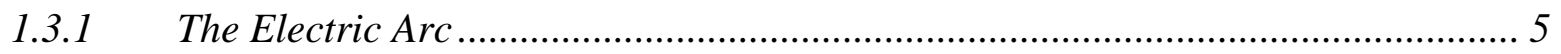

1.3.2 Circuit Behavior of the Electric Arc ……………................................................... 7

1.3.3 Basic Plasma Theory ..................................................................................... 9

1.4 Combustion Enhancement with a Plasma Torch.............................................................. 10

1.4.1 Plasma Torch Radical Production................................................................ 11

1.4.2 Virginia Tech Plasma Torch Ignition and Injection Experiments ......................... 13

$1.5 \quad$ Mixing Enhancement with Unsteady Shock Waves ....................................................... 14

2. Goals and Objectives ..........................................................................................16

3. Experimental Set-up, Facilities, and Operation ............................................18

3.1 Lab Equipment......................................................................................................... 18

3.1.1 Plasma Torch Designs .................................................................................... 18

3.1.2 Oscillating Plasma Torch Power System....................................................... 21

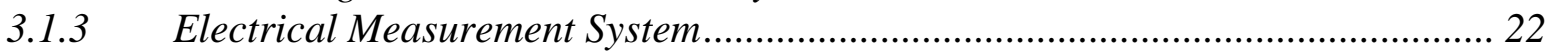

3.1.4 Flow Control System ........................................................................................... 23

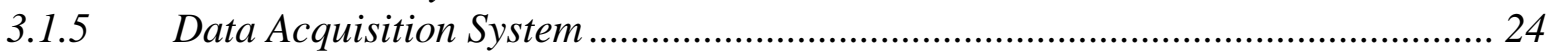

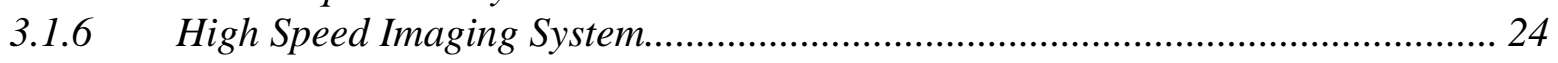

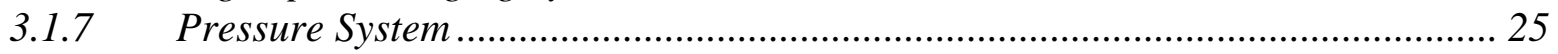

3.1.8 Instrument Isolation System............................................................................ 25

3.2 Experimental Facilities............................................................................................ 26

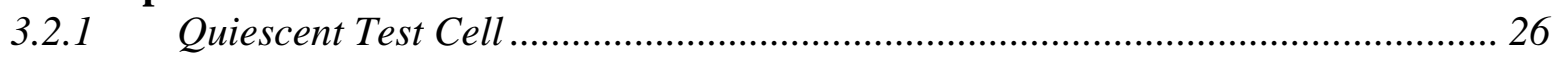

3.2.2 Virginia Tech Unheated Supersonic Wind Tunnel................................................ 27

3.2.3 UVA Supersonic Combustion Tunnel................................................................... 28

3.3 Oscillating Plasma Torch Operation.............................................................................. 29

4. Experimental Testing Procedures ......................................................................32

4.1 Quiescent Testing.......................................................................................................... 32

4.2 Virginia Tech Supersonic Tunnel Testing ....................................................................... 32

4.2.1 High Speed Schlieren Image Set-up..................................................................... 33

4.3 University of Virginia Supersonic Combustion Tunnel Testing ................................ 34

4.3.1 Aerodynamic Ramp Injector ................................................................................ 34

D. Sanders $\quad \mathrm{V}$ 


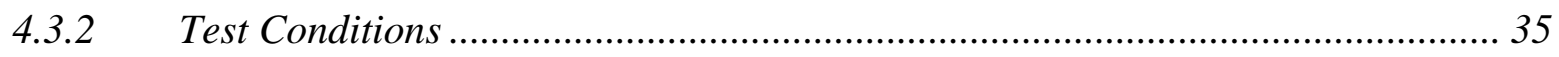

5. Oscillating Plasma Torch System Electrical Response ...................................37

$5.1 \quad$ Electrical Waveform Results ............................................................................................. 37

5.2 Signal Processing Calculations ....................................................................................... 38

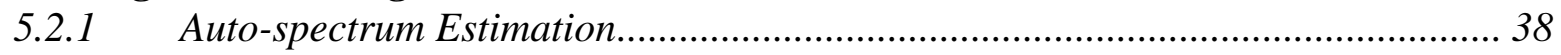

5.2.2 Cross-Spectrum and Coherence Function ...................................................... 39

5.3 Frequency Response Function Investigations ................................................................. 40

5.3.1 Frequency Response of Oscillating Plasma Torch Power System ........................ 40

5.3.2 Frequency Response of the Plasma Torch....................................................... 41

6. High Speed Images of the Oscillating Plasma Torch........................................43

6.1 Quiescent Environment High Speed Images .......................................................................... 43

6.1.1 Area of Intensity Measurement Algorithm ......................................................... 44

6.1.2 Response of the RMS Plasma Torch Brightness ................................................. 45

6.2 High Speed Schlieren Images............................................................................................... 47

6.2.1 Image Analysis of Unsteady Shock Movement.................................................. 49

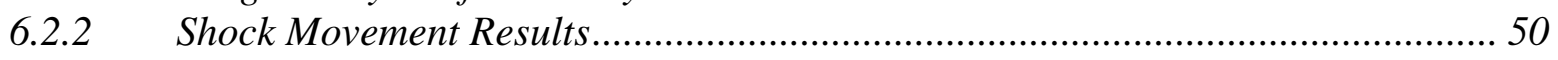

6.2.3 Plasma Torch Shock Animation............................................................................... 52

7. Behavior at Supersonic Combustion Conditions (performed in the University

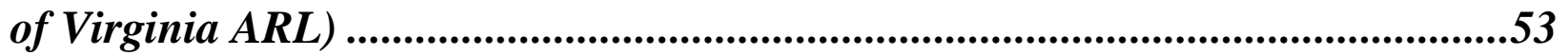

7.1 Combustion Effects Due to Oscillating Plasma Torch .............................................. 53

7.1.1 Unsteady Pressure Measurements with Hydrogen Fuel..................................... 53

7.1.2 Combustor Pressure Profiles with Ethylene Fuel................................................... 56

8. Plasma Torch Electric Arc Model .......................................................................59

8.1 Electric Arc Models from Previous Studies................................................................. 59

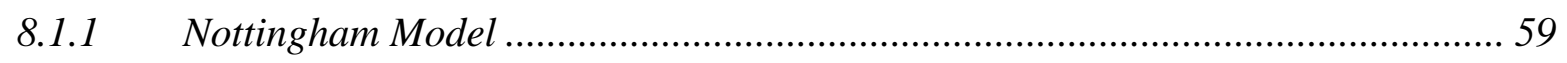

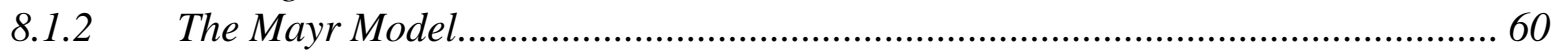

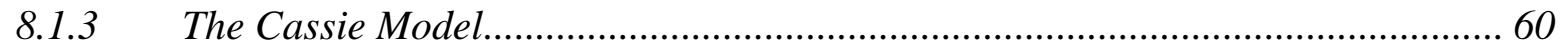

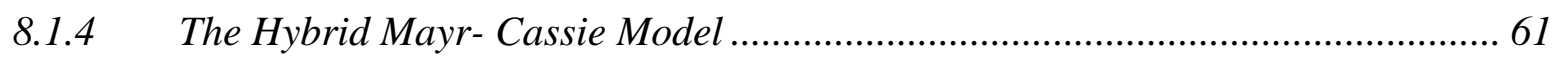

8.2 Plasma Torch Electric Arc Model Development............................................................... 62

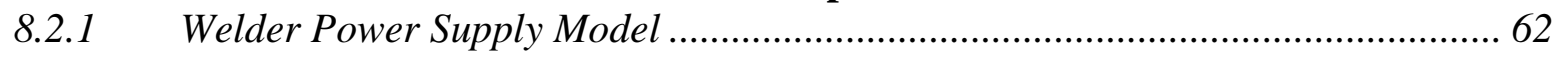

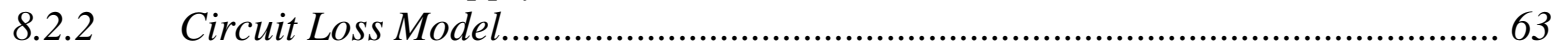

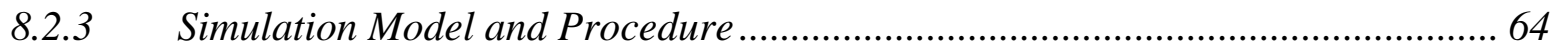

8.3 Frequency Response Investigation of Plasma Torch Electric Arc Model ............... 65

8.3.1 Simulated Experimental Frequency Response Comparison ................................... 66

8.4 Model Predictions at High Frequencies............................................................................ 68

9. Conclusions and Recommendations ................................................................69

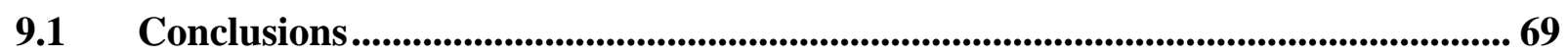

9.2 Recommendations for Future Research ………….......................................................... 71

References ....................................................................................................................................74

Appendix A ..................................................................................................................................77

Audio and Video Media of Oscillating Plasma Torch ............................................................. 77

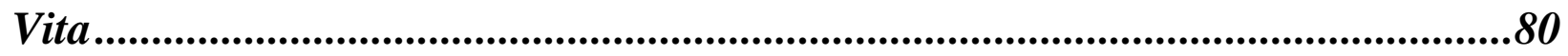

D. Sanders

An Investigation of Controlled Oscillations in a

Plasma Torch for Combustion Enhancement 


\section{List of Figures}

Figure 1.1. Artist rendering (left) and actual picture (right) of X-43A space-plane

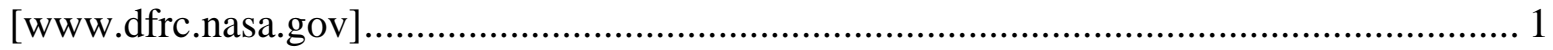

Figure 1.2. Schematic of a Ramjet Engine [www.avaition-history.com] .................................. 2

Figure 1.3. Illustration of a Scramjet Engine [Waltrup et al. 1996] ......................................... 3

Figure 1.4. Illustration of a Dual Combustion Ramjet [Waltrup et al. 1996] ............................. 4

Figure 1.5. Gas and Electron Temperature vs. Pressure [Cobine, 1941] .................................... 6

Figure 1.6. Schematic of an electric arc (left) [Brown, 1984] and voltage potential distribution

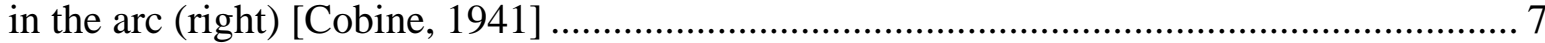

Figure 1.7. Static current-voltage characteristic (right) and the radial temperature distribution

(left) of the electric arc [Brown, 1984] ..................................................................... 8

Figure 1.8. Dynamic characteristics of a low current arc with varying frequency [Brown, 1984] 8

Figure 1.9. Types of plasma as function of temperature and density on a log-log scale

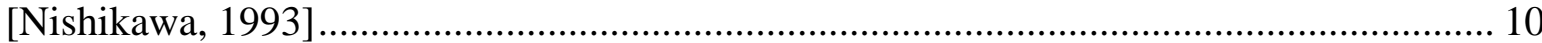

Figure 3.1. The Oscillating Plasma Torch Data Acquisition and Power Supply System........... 19

Figure 3.2. Schematic and Picture of VTPT-3 (A: Anode, B: Torch Body, C: Cathode, D:

Micrometer Drive, E: Cathode Bracket, F: Flow Swirler, G: Support Rod, H: Bolt Jackets, I:

Body Insulator, J: O-Rings, K: Feedstock Lines) ..................................................... 20

Figure 3.3. Schematic of the modified VTPT-3 [Bonanos et al. 2005] ...................................... 20

Figure 3.4. Miller HF Starter (left) and 100XL Thermal Dynamic Welder Power Supply (right)

Figure 3.5. Welder Remote Control Relay Box (left) and G5100 Function Generator (right).... 22

Figure 3.6. Hall Effect Current Sensor .............................................................................. 23

Figure 3.7. Sierra 840M Mass Flow Controller (left) and Dual Channel Digital Display (right) 24

Figure 3.8. Phantom 4.0 SR-CMOS High Speed Camera [www.visionresearch.com] ............... 25

Figure 3.9. Analog Devices Isolation Amplifier............................................................... 26

Figure 3.10. View of Quiescent Test Cell..................................................................... 27

Figure 3.11. Virginia Tech Supersonic Wind Tunnel (left) and illustration of plasma torch in

Virginia Tech Tunnel Setup (right)....................................................................... 28

Figure 3.12. UVA ARL Supersonic Combustion Tunnel Schematic (left) and plasma torch

injector array setup (right). ............................................................................. 28

Figure 3.13. Schematic of UVA Combustion Tunnel Geometry [Bonanos et al. 2005]........... 29

Figure 3.14. Plasma Torch Control Sequence Block Diagram ............................................ 30

Figure 3.15. LabVIEW PT Control Program Front Panel .................................................... 31

Figure 4.1. Oscillating plasma torch operating in quiescent test cell .................................... 32

Figure 4.2. High Speed Schlieren Set-up...................................................................... 34

Figure 4.3. Schematic of 4-holed aerodynamic ramp injector array (left) and the three plasma torch locations tested shown in relation to the aeroramp fuel injector (right) [Bonanos, et al. 2003].

Figure 5.1. Plasma Torch Electrical Waveforms. The Control Oscillator Voltage (left), Plasma

Torch Output Current (top right), and Plasma Torch Output Current (lower right)............ 37

Figure 5.2. The Frequency Response Function of Oscillating Plasma Torch Power System ..... 41

Figure 5.3. The Frequency Response Function of Plasma Torch Output Voltage .................... 42

Figure 6.1. High Speed Images of Oscillating Plasma Jet................................................... 43

D. Sanders vii

An Investigation of Controlled Oscillations in a

Plasma Torch for Combustion Enhancement 
Figure 6.2. Illustration of Area of Intensity Algorithm ............................................................... 44

Figure 6.3. Time Record of Area of Intensity Measurement Oscillating Plasma Jet ................... 45

Figure 6.4. PSD Plot of Area of Intensity Measurement of Plasma Torch Oscillation of $180 \mathrm{~Hz} 46$ Figure 6.5. Graph of Response of RMS Plasma Torch Pixel Area vs. Plasma Torch RMS Power

Figure 6.6. High speed Schlieren image of oscillating plasma torch indicating points of interest

Figure 6.7. High speed Schlieren frame-by-frame display of plasma torch oscillation ............... 48 Figure 6.8. Scaled intensity image of plasma torch with chosen points of the PT shock line

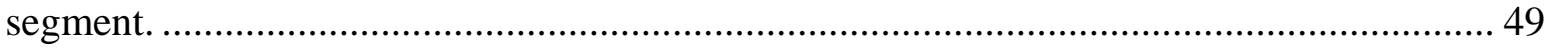

Figure 6.9. Interpolated horizontal intensity profile and surface gradient at the chosen PT shock

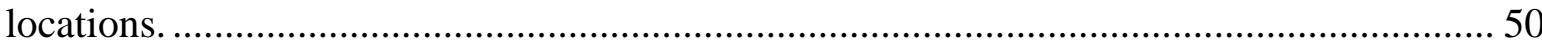

Figure 6.10. Graph of the PT horizontal shock position verses instantaneous power .................. 51

Figure 6.11. Animation of the plasma torch predicted shock motion (Click here to see

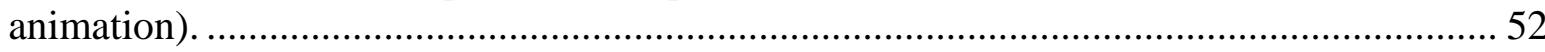

Figure 7.1. Modified Industrial Plasma Torch Electrical Waveforms Oscillating at 2Hz........... 54

Figure 7.2. Kulite Pressure Response to Oscillating Plasma Torch ............................................. 55

Figure 7.3. DFT Calculations of Kulite Pressure Measurements ............................................... 55

Figure 7.4. Video Images Oscillating Plasma Torch Running in Mach 2 Heated Wind Tunnel. 56

Figure 7.5. Ethylene fuel static pressure measurements with DC air plasma torch..................... 58

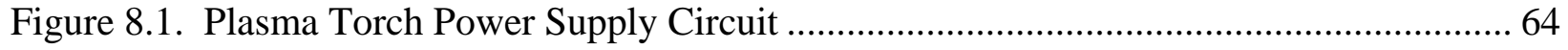

Figure 8.2. Simulink ${ }^{\circledR}$ Model of the Plasma Torch Power Supply System ................................ 64

Figure 8.3. Simulated Plasma Torch Electrical Waveforms Oscillating at 128Hz......................... 65

Figure 8.4. Simulated vs. Experimental FRF Plot of Power Supply .............................................6 66

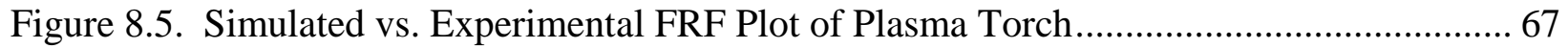

Figure 8.6. Simulated Plasma Torch Response at 50kHz .......................................................... 68

Figure A.1. Nitrogen Plasma Jet Movies Oscillating at 1024Hz (left) and $128 \mathrm{~Hz}$ (right) .......... 77

Figure A.2. High Speed Schlieren Videos of Control Case (left) and Nitrogen PT at $256 \mathrm{~Hz}$.... 78

Figure A.3. Video of Oscillating Plasma Torch Operating at the UVA Supersonic Combustion

Tunnel 79 


\section{List of Tables}

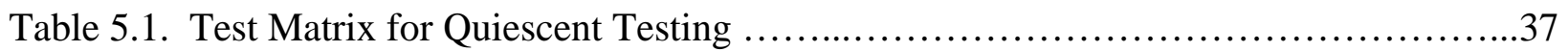

Table 7.1. Static pressure ratio measurements near the beginning of shock train .................... 58

Table 8.1. Simulation parameter inputs for plasma torch electric arc model ............................ 65

D. Sanders 


\section{Nomenclature}

\section{Symbols}

\begin{tabular}{|c|c|c|}
\hline$A$ & $=$ & Spectrum, Material Property \\
\hline$a_{0}$ & $=$ & DC Gain \\
\hline$B$ & $=$ & Material Property \\
\hline$C$ & $=$ & Capacitance \\
\hline$C_{P}$ & $=$ & Specific Heat at Constant Pressure \\
\hline$C_{m}$ & $=$ & Discrete Fourier Transform \\
\hline$d_{j e t}$ & $=$ & Jet Diameter \\
\hline$d_{e q}$ & $=$ & Equivalent Diameter \\
\hline$e$ & $=$ & Elementary Charge \\
\hline$E_{0}$ & $=$ & Steady State Arc Voltage \\
\hline$f$ & $=$ & Frequency \\
\hline$G$ & $=$ & Conductance \\
\hline$G_{\min }$ & $=$ & Minimum Arc Conductance \\
\hline$H$ & $=$ & Frequency Response Function \\
\hline$I_{0}$ & $=$ & Transition Current \\
\hline$i$ & $=$ & Current \\
\hline$K$ & $=$ & Flow Calibration Factor \\
\hline$L$ & $=$ & Inductance \\
\hline$m$ & $=$ & Frequency Index \\
\hline$N$ & $=$ & Total Number of Samples \\
\hline$n$ & $=$ & Number of Jets, Sample Index \\
\hline$n_{0}$ & $=$ & Average Number of Electrons \\
\hline$P_{0}$ & $=$ & Constant Power Loss \\
\hline$P T$ & $=$ & Plasma Torch \\
\hline$Q$ & $=$ & Volumetric Flow Rate \\
\hline$R$ & $=$ & Resistance \\
\hline$T$ & $=$ & Temperature \\
\hline$t$ & $=$ & Time \\
\hline
\end{tabular}

D. Sanders 


$$
\begin{array}{lll}
v & = & \text { Voltage } \\
x, X & = & \text { Time Signal }
\end{array}
$$

\section{Greek Symbols}

$$
\begin{array}{lll}
\alpha & = & \text { Arc Damping Constant } \\
\gamma^{2} & = & \text { Coherence Function } \\
\varepsilon_{0} & = & \text { Permittivity in a Vacuum } \\
\theta & = & \text { Arc Damping Function } \\
\theta_{0} & = & \text { Calibration Constant } \\
\theta_{1} & = & \text { Calibration Constant } \\
\lambda_{D} & = & \text { Debye Length } \\
\rho & = & \text { Density } \\
\omega_{0} & = & \text { Frequency in Radians }
\end{array}
$$

\section{Subscripts}

$$
\begin{array}{lll}
e & = & \text { Electron } \\
X & = & \text { Input Signal } \\
Y & = & \text { Output Signal } \\
S C & = & \text { Short Circuit } \\
\text { OC } & = & \text { Open Circuit }
\end{array}
$$

\section{Superscripts}

* $\quad=\quad$ Conjugate 


\section{CHAPTER ONE}

\section{Introduction}

\subsection{The First Successful Scramjet Flight}

Recently NASA made history with two record breaking flights of the unmanned (Figure 1.1) high speed airplane or space-plane called the $X-43 A$. On March 27, 2004, the $X-43 A$ made aviation history with its first flight using a scramjet engine at Mach 7 or nearly 5,000 $\mathrm{mph}$. The X-43A set a new mark by breaking its own world record again on November 16, 2004 flying at Mach 10 or $7,000 \mathrm{mph}$. The scramjet or supersonic combustion ramjet is a candidate to replace rocket-powered aircraft for use in high speed flight. Scramjets have the advantage of obtaining oxygen needed for combustion and thrust from the atmosphere and do not need to carry a heavy oxidizer, as rockets must. This allows for airplane like operation with increased safety, flexibility, and affordability. The ramjet engine, another type of engine used for high speed flight, is similar to the scramjet engine but it operates by subsonic combustion of fuel. Details of both ramjet and scramjet engines are discussed in the following sections.

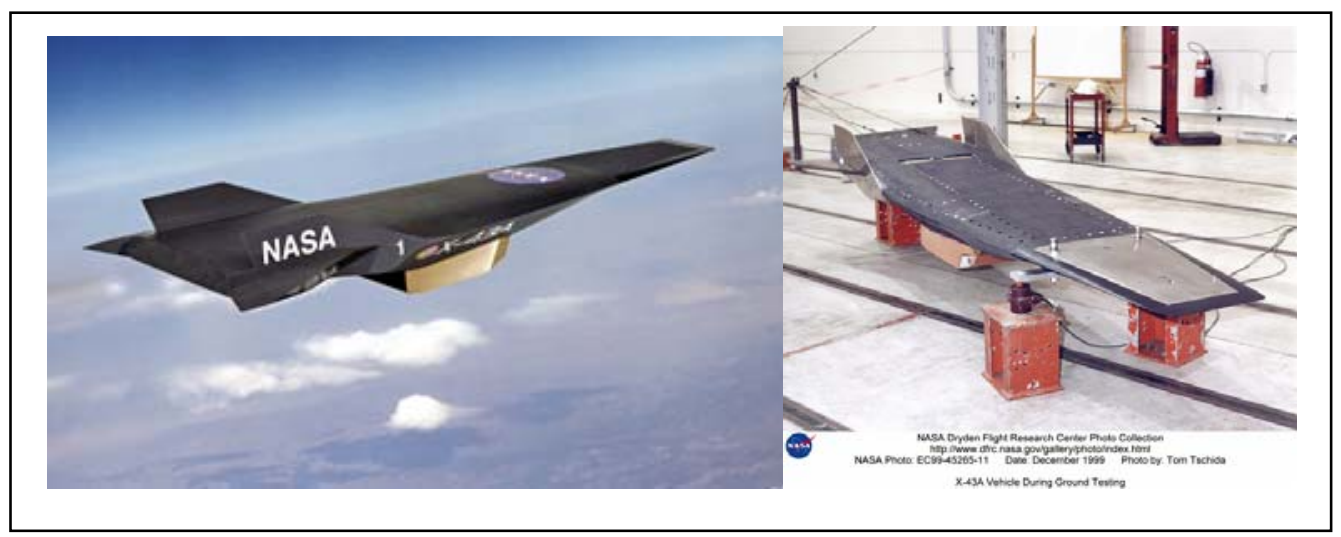

Figure 1.1. Artist rendering (left) and actual picture (right) of X-43A space-plane [www.dfrc.nasa.gov] 
Chapter 1. Introduction

\subsection{Scramjet and Ramjet Engine Designs}

\subsubsection{The Ramjet Engine}

The ramjet engine is simple in design; it contains no moving parts, unlike a turbojet used in modern aircraft. The air is compressed through the intake by the supersonic speed of the vehicle. The supersonic air is slowed to subsonic speed by the diffuser through a shock system. The flow then enters the combustor, where fuel is injected and burned prior to accelerating the flow through the exit nozzle at a higher speed than the inlet, thus creating a positive thrust. A schematic of a ramjet engine is shown in Figure 1.2. The two main limitations of the ramjet are its inability to produce thrust at low speeds and performance drops at flight speeds above Mach 6. To overcome the problem of static thrust, most ramjets use a mixed-cycle ramjet as described by Waltrup et al. [1996] to boost the vehicle to a given speed where the ramjet engine can begin to operate.

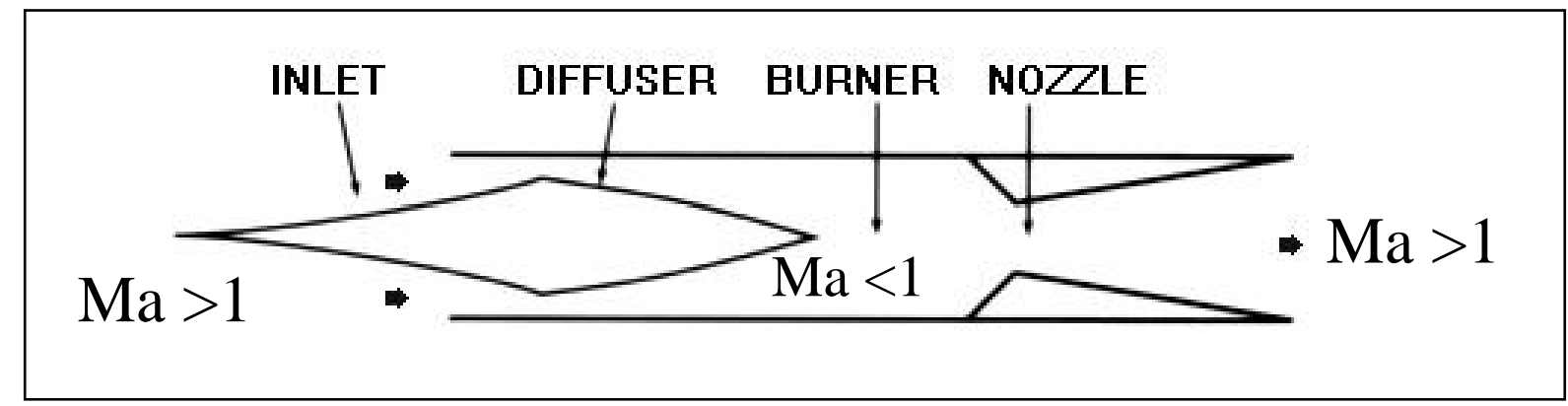

Figure 1.2. Schematic of a Ramjet Engine [www.avaition-history.com]

\subsubsection{The Scramjet Engine}

The first known scramjet engine was designed and tested by Dr. A. Ferri at the General Applied Science Laboratories in 1963. Scramjet engine development in the US has been supported by the U.S. Navy, U.S. Air Force and NASA [Waltrup et al. 1976, Waltrup 1987, and Andrews 2001]. Scramjet engines (Figure 1.3) are similar in design to ramjet engines where compression of incoming air is achieved using a supersonic diffuser, then the fuel and supersonic 


\section{Chapter 1. Introduction}

air are mixed and ignited in the diverging combustion chamber, forcing the hot gases through the exit nozzle, and producing thrust. However, a scramjet engine does not generate a normal shock system to decelerate the flow. The combined effect of heat addition and diverging area in a scramjet combustor with the absence of a geometric throat produces a shock train. This shock train strength will vary from a normal shock to no shock depending on the flight conditions, permitting efficient operation over a wide range of Mach number speeds.

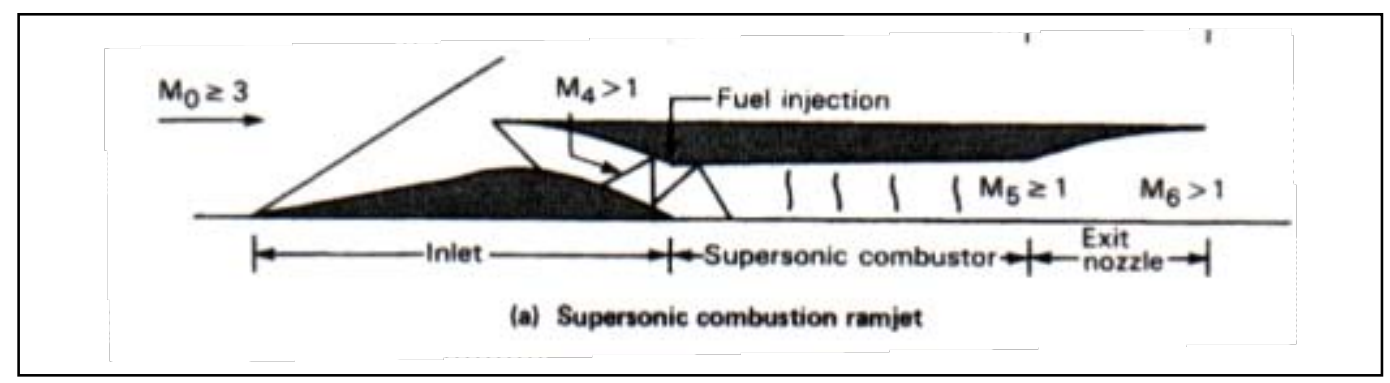

Figure 1.3. Illustration of a Scramjet Engine [Waltrup et al. 1996]

The dual-mode scramjet engine combines the advantages of both subsonic and supersonic combustion at low and high speeds. This is accomplished by fuel injection at different axial locations within the inlet. The supersonic section precedes the subsonic section and behaves like an inlet diffuser during subsonic mode. At low Mach number speeds, the strength of the shock train increases and subsonic combustion is achieved. The shock train strength then decreases at high flight Mach numbers and the combustion taking place is entirely supersonic.

The main limitation with the scramjet is its inability to produce both static and low speed thrust because the air needs to enter the inlet at supersonic speeds for proper operation. Moreover, scramjet engines require materials that are able to withstand high temperatures, and these materials are expensive to fabricate. Finally, the greatest problem that reduces the efficiency of the scramjet is mixing. If the fuel injected is not mixed with the air adequately ignition will not occur. Also, since the scramjet operates at very high internal velocities and D. Sanders 
short combustor residence times, the injected fuel tends to move towards the wall, reducing mixing. Pyrophoric additive fuels such as silane are used to achieve stable combustion. The disadvantage of using pyrophoric type igniters is they are dangerous to handle and store.

\subsubsection{The Dual Combustor Ramjet}

To overcome this issue the Dual Combustor Ramjet (DCR) engine has been developed which can operate with heavy liquid hydrocarbon fuels without the use of pyrophoric additives. The DCR was first tested in the mid 1970's at the Johns Hopkins University Applied Physics Laboratory [Curran, 2001]. All of the features of the scramjet are found in the DCR except a small subsonic combustor along with the conventional combustor is used. All of the liquid hydrocarbon fuel is injected and a pilot flame is added to this small subsonic combustor to further enhance combustion. Schematic of a DCR is shown in Figure 1.4 [Waltrup et al. 1996]. The one disadvantage is the added weight to the engine from the subsonic combustor.

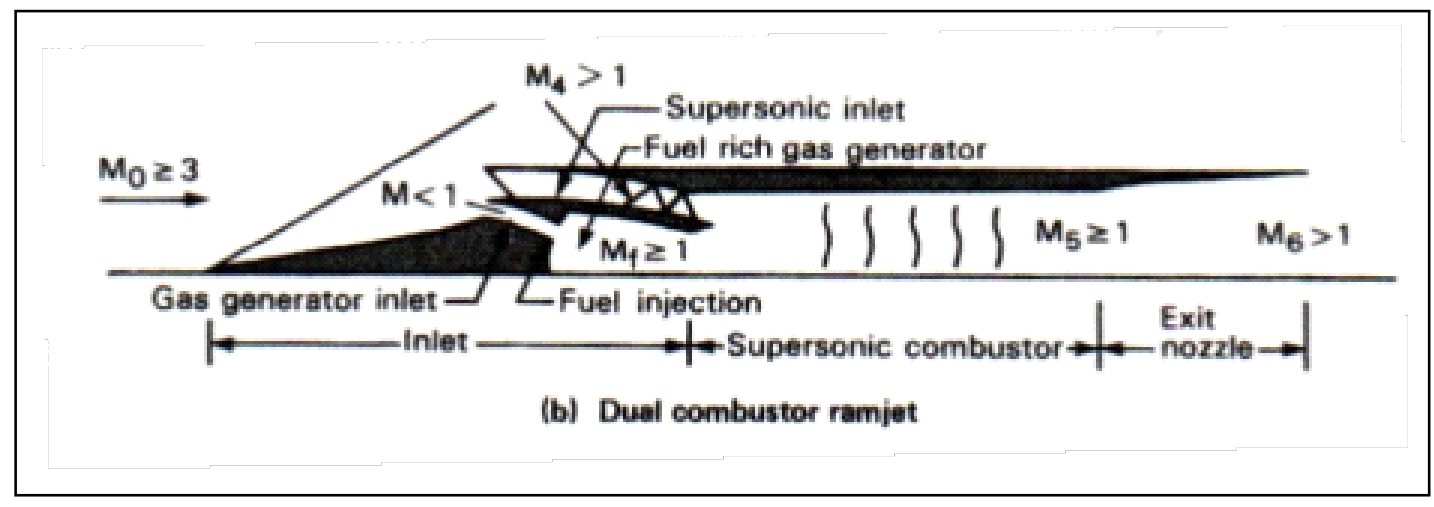

Figure 1.4. Illustration of a Dual Combustion Ramjet [Waltrup et al. 1996]

\subsection{The Plasma Torch}

A possible solution for the complex problems of scramjet propulsion is the implementation of a plasma torch as a pilot flame to ignite and enhance combustion. A plasma torch consists of an anode and cathode where flowing gas is fed between the anode and cathode. Then, a voltage is applied across the torch, producing an electric arc. This electric arc causes the 


\section{Chapter 1. Introduction}

feedstock gas to dissociate and form free radicals, producing ionized plasma. It has been observed that plasma torches are effective igniters and flame holders in scramjet engine applications. The plasma produces free radicals that enhance combustion and reduce the time for burning to take place in the combustor. The amount of power used to operate a torch requires only a few kilowatts, which would require a small amount of additional power from the flight vehicle system.

\subsubsection{The Electric Arc}

The electric arc has always existed in nature as the natural phenomenon known as lightning. The definition of an electric arc is a self sustained discharge having low voltage drop and capable of supporting large currents [Cobine, 1941]. The arc is a useful source of illumination and a high temperature source for industrial welding and chemical processes. They are characterized by a small intensity brilliant core surrounded by a cooler region of flaming gases called an aureole. An intense region of chemical activity is found in the aureole. The core inside the electric arc is at a high temperature at which gases are largely dissociated.

Arcs can exist as either free burning or constricted. A constricted arc passes from the cathode to the anode through a constricting channel. The temperature and stability of the arc is increased when constriction is used. Free-burning arcs exist between two electrodes without any type of restriction. Generally, free-burning arcs exist at atmospheric pressure at gas temperatures of $5000 \mathrm{~K}$ and above. The temperatures inside the electric arc depend on pressures of its surrounding medium. Temperature differences between low and high pressure arcs are shown in Figure 1.5. Thermodynamic equilibrium exists between ions, electrons, and gas atoms of the arc column in high pressure arcs. In low pressure arcs, the electron and gas temperature differ 
significantly, where the gas temperature is a few hundred degrees centigrade and electron temperature can be high as $40,000 \mathrm{~K}$.

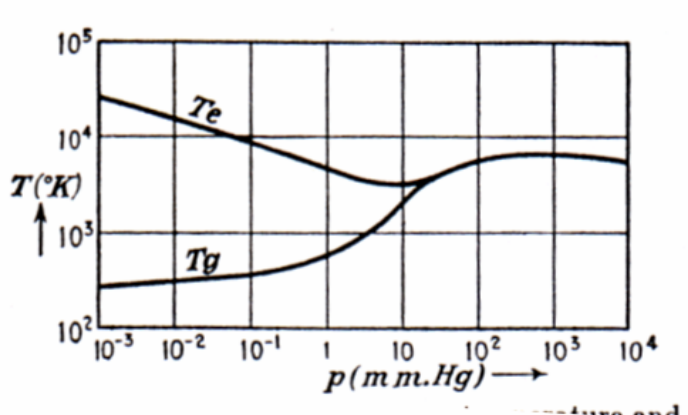

Figure 1.5. Gas and Electron Temperature vs. Pressure [Cobine, 1941]

The electric arc is physically divided into three regions: the positive column, and the anode and cathode drop regions (Figure 1.6). These regions are characterized by measurements of electric field and temperature distribution. A typical voltage potential along the axis of the electric arc is shown in Figure 1.6. The length of the arc mostly consists of the positive column. The voltage gradient along the positive column is low, producing electrically neutral plasma. The production of current inside the positive column differs between low and high pressure arcs. Most current is carried by electrons in low-pressure arcs. In a high pressure arc, the current is maintained by thermal ionization because of the high gas temperature in the arc column. The anode drop region can serve in an active or passive operation mode. In passive mode, the anode drop region collects electrons carrying current from the positive column to the anode surface. Sufficient ionization is achieved because a space charge region accelerates the electrons from the positive column. In active mode, the anode material evaporates and is ionized to supply ions to the plasma. The cathode drop region delivers current carrying electrons to the positive column. The current density found in the cathode is at least two orders of magnitude higher than the current density in the positive column. 
Chapter 1. Introduction

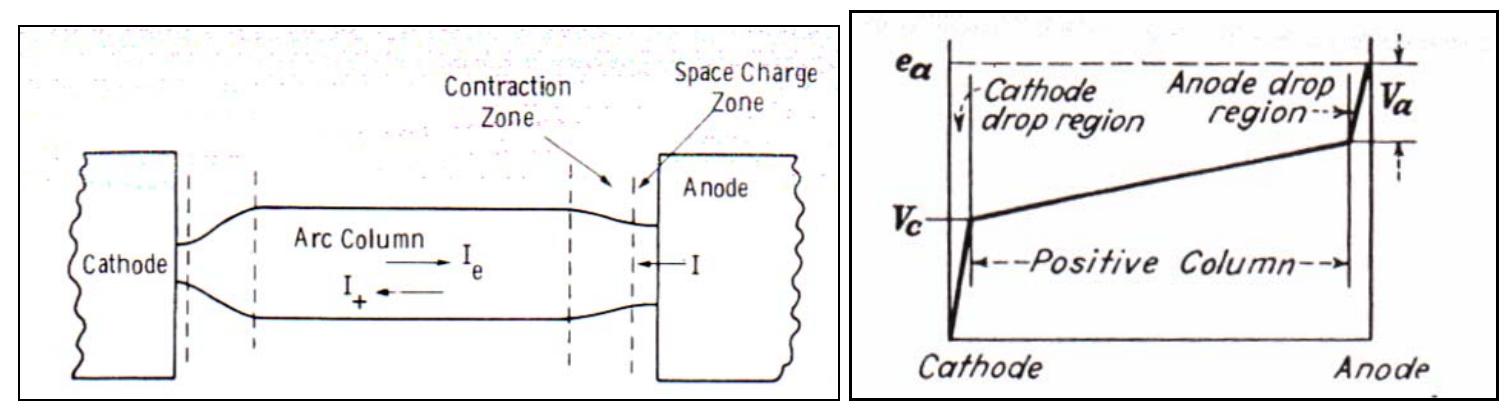

Figure 1.6. Schematic of an electric arc (left) [Brown, 1984] and voltage potential distribution in the arc (right) [Cobine, 1941]

\subsubsection{Circuit Behavior of the Electric Arc}

The electric arc as a circuit element behaves as a nonlinear resistor. The voltage across the arc is not only affected by current, but also by properties such as the arc length, properties of the surrounding medium, and cooling and deionization effects. A steady-state fixed length DC arc has a current-voltage behavior shown in Figure 1.7. There are two different distinct voltage behaviors. At low currents, the voltage rapidly decreases with current, approaching a constant power requirement. At high currents levels, the voltage remains constant practically independent of current. The positive column changes its physical state because of the two distinct voltage behaviors. Figure 1.7 shows the radial temperature distribution in the positive column associated with high and low current arcs. For low pressure arcs, the temperature and conductivity change primarily in response to the changing current in order to maintain a constant power requirement. At high currents, the arc column temperature is nearly constant within the positive column. The cross-sectional area responses only to the current changes thus, accounting for the constant voltage at high current levels. 

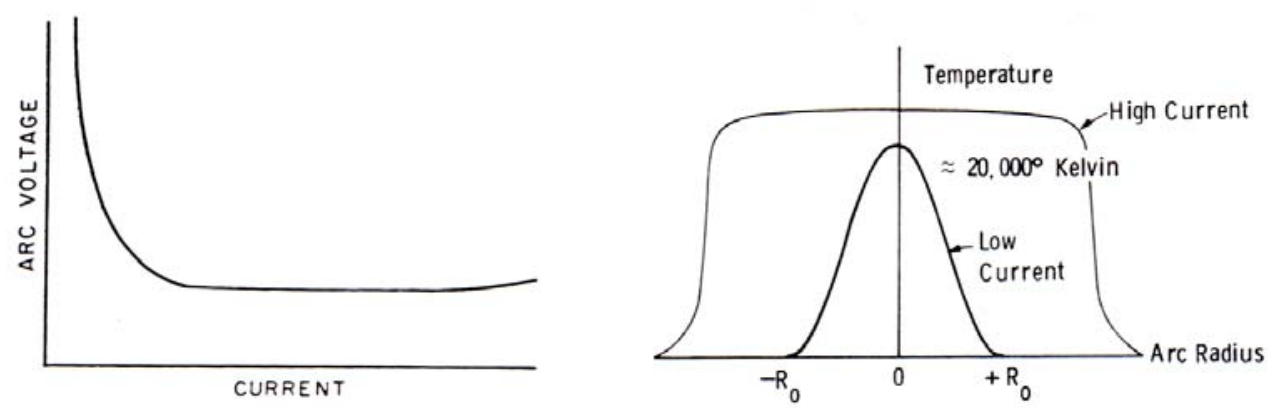

Figure 1.7. Static current-voltage characteristic (right) and the radial temperature distribution (left) of the electric arc [Brown, 1984]

The low current DC electric arc dynamics change according to frequency when driven with an alternating current. The conductance and the arc voltage lags behind any instantaneous current change. The amount of signal lag depends on the AC current frequency. This is illustrated in Figure 1.8 for the superposition of a limited amplitude alternating current on a low current DC electric arc. At low frequencies, $f_{1}$, the static characteristic is followed, while at higher frequencies, $f_{4}$, the conductance cannot follow the high frequency current and remains constant, and the static characteristic is the same as a pure resistance. Frequencies $f_{2}$ and $f_{3}$ have intermediate values between $f_{1}$ and $f_{4}$ indicating an oscillating arc voltage.

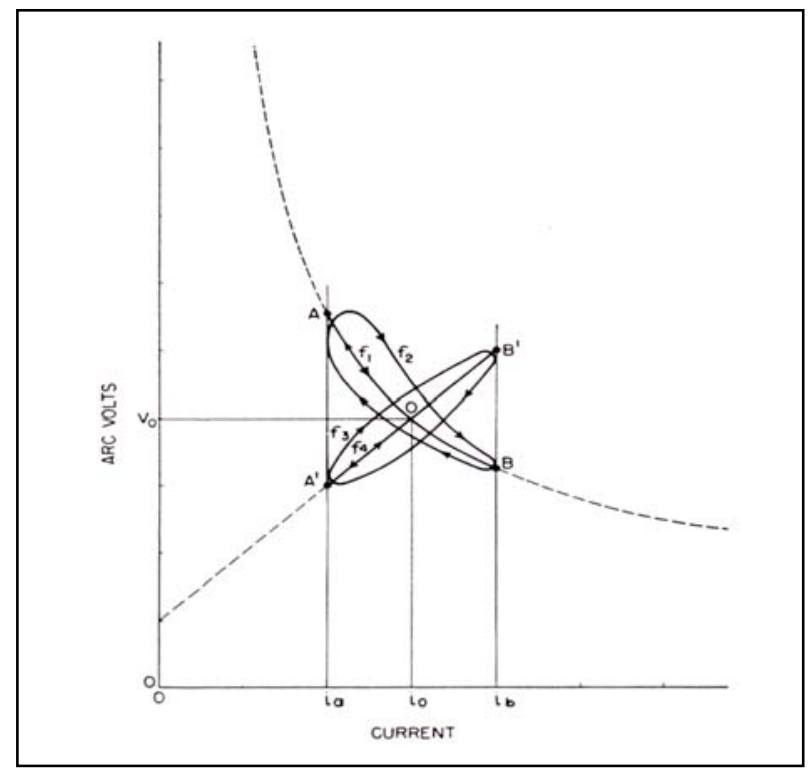

Figure 1.8. Dynamic characteristics of a low current arc with varying frequency [Brown, 1984] D. Sanders 


\section{Chapter 1. Introduction}

\subsubsection{Basic Plasma Theory}

Plasma exists as the fourth state of matter; plasma comprises approximately $99 \%$ of the visible universe. Plasmas are composed of conductive groups of particles, neutrals, and fields that exhibit collective effects which carry electrical currents and generate electrical fields. An equal number of positive and negative charged particles are found in plasma. The use of electric arc produces a type of artificially generated plasma. This type of plasma is not in thermal equilibrium due to the localized heating of the arc and the electrons, ions, and neutral atoms having different kinetic energies. Usually electrons are accelerated by an electric field and have larger kinetic energies than ions. So in a plasma, the electron temperature is usually higher than the ion temperature.

The formation of plasma occurs under the condition that the average kinetic energy of an electron substantially exceeds the average Coulomb energy needed for an ion to bind to the electron. The average Coulomb energy needed for an ion to bind the electron is represented by $\frac{e^{2}}{4 \pi \varepsilon_{0} d}$ where $d$ is the average distance between adjacent electrons and ions, $e$ is the elementary charge and $\varepsilon_{0}$ is the permittivity in a vacuum. The condition where plasma is formed can then be written as

$$
\left(\frac{4 \pi}{3} n_{0}\right)^{1 / 3} \frac{e^{2}}{4 \pi \varepsilon_{0} T_{e}}<<1
$$

where $n_{0}$ is the average number of electrons or ion per unit volume, and $T_{e}$ is the electron temperature. The Debye length is a parameter developed from the above equation which is the most fundamental property that characterizes plasmas. This is defined by

$$
\lambda_{\mathrm{D}}=\sqrt{\varepsilon_{0} T_{e} / n_{0} e^{2}}
$$


Several types of plasma are defined based on these parameters. The types are called: relativistic, classical, degenerate, and neutral gas plasmas. At very high temperatures, the electrons are governed by the laws of relativity, so plasma produced at this state is called relativistic plasma. Degenerative plasmas are known to have very high density states. Plasma is either a classical or a neutral gas plasma depending on whether the plasma condition is satisfied. Figure 1.9 shows the various plasma types as function of density and temperature. [Nishikawa, 1993]

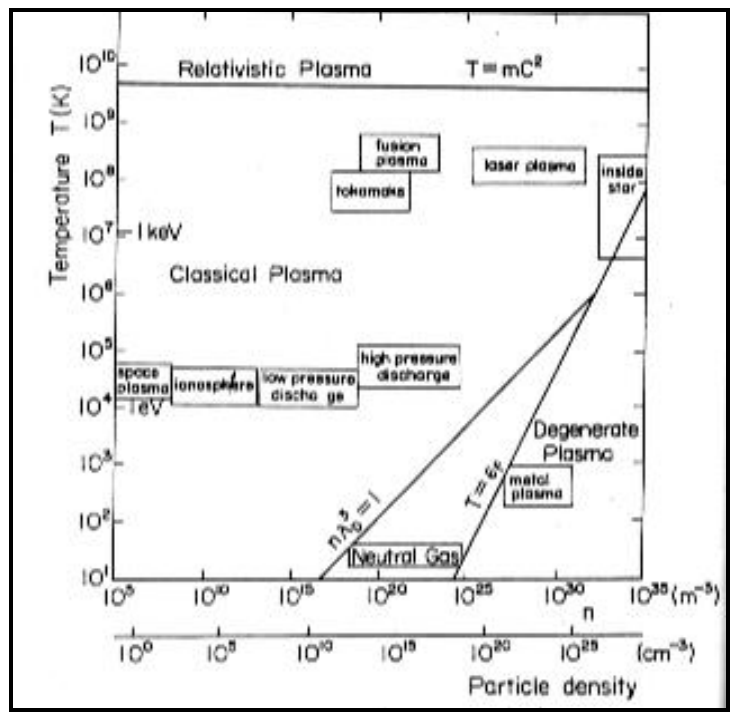

Figure 1.9. Types of plasma as function of temperature and density on a log-log scale [Nishikawa, 1993]

\subsection{Combustion Enhancement with a Plasma Torch}

The use of an electric arc discharge to aid combustion was first proposed by Southgate in 1924. Next, work did by Karlovitz, Weinburg, and others were the first to use a high voltage, low current arc discharge downstream of the combustion flame to generate specific radicals that increase flame reactions [Harrison et al. 1971]. Weinburg [Weinburg 1978] looked at using a plasma jet to improve the efficiency and emissions of internal combustion engines. The plasma jet was made from a modified spark plug and was tested with hydrogen, nitrogen, water, methane, and methane/air fuel mixture. All plasmas except water, performed considerably better than a normal spark ignition device by introducing an increased amount of hydrogen atoms. D. Sanders 


\section{Chapter 1. Introduction}

Harrison et al. [1971] noted the effect of radicals added to combustion have the potential to pilot a stable flame in a transient overloaded combustion chamber, such as jet engine at take off or following flame extinguishment at high altitudes. In these experiments a magnetic rotating plasma jet was used with fuel/air injection to stabilize combustion. The results showed that flame stability was greatly increased when a small amount of electrical energy is added. The combustion enhancement was due to the presence of combustion enhancing radicals and not the addition of thermal or electrical energy.

\subsubsection{Plasma Torch Radical Production}

In the literature there has been much debate on which radicals produced by plasma jets are the most effective for combustion enhancement. The production of hydrogen radicals by a plasma torch was observed to be effective in producing complete combustion [Weinburg, 1978]. A chemical kinetics code was used in a study by Wagner et al. [1989] to calculate whether production of hydrogen atoms produced by a plasma torch could reduce the ignition delay time of a hydrogen-air mixture. The results indicate that the presence of $0.1 \%$ hydrogen atoms are as effective as $20 \%$ silane in reducing ignition delay time at lower temperatures [Wagner et al., 1989 and Northam et al., 1984]. A rate of more than 68\% increase in combustion was observed by Kimura et al. [1981] when both hydrogen plasma torch and hydrogen fuel injection was introduced in Mach 2.1 airflow of low static temperature. The production of hydrogen atoms is essential to any combustion enhancement, providing a very basic element required in almost every combustion reaction. The chain branching reaction is:

$$
\mathrm{H}+\mathrm{O}_{2} \rightarrow \mathbf{O H}+\boldsymbol{O}
$$

Kimura et al. [1981] observed that the effectiveness of nitrogen plasma on the promotion of combustion is nearly equal to that of hydrogen plasma. Also, based on electrical input power, D. Sanders 
nitrogen is superior to hydrogen with about half of the electrical power needed to produce same amount of combustion as with hydrogen. Mitani [1995] using a linearized rate-equation analysis discovered that the addition of atomic oxygen was found to 1.5 more effective than $\mathrm{H}$ radicals for ignition applications involving a plasma torch. A study done by Takita, et al. [1993] differentiated between flame-holding and ignition limits with the addition of radicals from air, nitrogen, oxygen, plasma torches. They discovered that the difference in burning velocity, which related to flame-holding stability limit, was little between $\mathrm{N}$ and $\mathrm{O}$ radicals. Experiments on the ignition limit showed that both $\mathrm{N}$ and $\mathrm{O}$ radicals had the same effectiveness, but for plasma torches the nitrogen plasma jet is a better choice due to a high anode erosion rate by oxygen plasma. Kitagawa et al. [2003] found that the nitrogen plasma torch has a higher luminous burning region compared to the oxygen plasma torch. However, the shock wave formed by the heat release of combustion by the oxygen is stronger than the nitrogen plasma torch. These shock waves produced were observed to enhance mixing and combustion present downstream of the plasma torch. Nitrogen reacts with hydrocarbon fragments to produce HCN and hydrogen atoms in the following reaction [Hillard 1979]:

$$
\mathrm{CH}_{n}+\mathrm{N} \rightarrow \mathrm{HCN}+\mathrm{H}
$$

In general, the presence of hydrogen, oxygen, and nitrogen radicals are known to be important to combustion enhancement. The use of a plasma torch increases the reaction rate of combustion by locally increasing the amount of radicals available for combustion. These results were verified in a study by Gallimore et al. [2002] where an extensive spectroscopic study of the radical production of hydrocarbon and nitrogen based feedstock plasma jet was completed. This study states that hydrocarbon plasma jets contain greater amounts of hydrogen atoms within the jet at a given power because $\mathrm{C}-\mathrm{H}$ bond energies in hydrocarbons are weaker than the $\mathrm{H}-\mathrm{H}$ bond 


\section{Chapter 1. Introduction}

energies found in diatomic hydrogen. The spectroscopic measurements taken of ethylene, methane, propane, and propylene plasma jets indicate the presence of $\mathrm{C}_{2}, \mathrm{C}, \mathrm{H}_{2}, \mathrm{H}, \mathrm{CH}$, and $\mathrm{CH}_{2}$, the most important being atomic hydrogen. Nitrogen and air plasma spectrograms contained diatomic and atomic oxygen and nitrogen species along with the presence of excited NO and $\mathrm{NO}_{2}$, which are all useful for combustion enhancement [Gallimore et al. 2002]. A similar study done by Cross et al. [2003] used a feedstock gas of mixed hydrocarbons representing a cracked JP-7 surrogate consisting of 15/25/60 mixture of methane/ethane/ethylene. This tested the theory that heavy hydrocarbons should produce more atomic hydrogen than lighter hydrocarbons because the bond energy in hydrocarbons becomes weaker as the length of the hydrocarbon chain increases. This was verified in the results. The surrogate plasma jet plume relative spectrographic intensity for hydrogen ions was higher when compared to methane and ethylene plasma jets. [Cross et al. 2003]

\subsubsection{Virginia Tech Plasma Torch Ignition and Injection Experiments}

An extensive amount of work on plasma torch ignition systems has been done at Virginia Tech. Gallimore and Jacobsen developed and characterized an integrated fuel injector and plasma torch ignition system. The injector configuration called an aeroramp consisted of holes arranged in two rows and two columns spaced evenly apart. The aeroramp has the advantage of enhancing mixing by inducing vorticity without the associated blockage of injection with a physical ramp. A study by Jacobsen et al. [2001] evaluated the best geometrical configuration for plasma torch/aeroramp injector system. The torch was placed at three different downstream locations with respect to the aeroramp injector array in a cold Mach 2.4 flow. The best results were produced that when the torch was placed $47.6 \mathrm{~mm}$ from the injector with nitrogen feedstock. 
The nitrogen produced more excited C2 radicals, indicating more plasma-fuel interaction. [Jacobsen et al. 2001]

Based on the research of Jacobson et al. [2001], testing of the integrated aeroramp injector/plasma torch was done in a heated continuous Mach 2 flow combustion tunnel by Bonanos, et al. [2003]. The data collected from testing of the injection system with nitrogen feedstock and hydrogen through the injector was compared with a single 10 deg unswept ramp with a Ma $=1.7$ conical nozzle using hydrogen injection. Both supersonic and subsonic pressure data was collected and showed excellent agreement with the results from the unswept ramp at a total tunnel temperature of 1100K. [Bananos, et al. 2003] Anderson et al. [2003] designed a liquid kerosene aeroramp injector/plasma igniter consisting of a two-hole array of impinging jets. This system was tested in a cold Mach 2.4 flow, which might simulate a cold start scramjet engine combustion system. Based on the analysis of $\mathrm{OH}$ radical filtered photography, combustion was difficult to verify under the cold conditions of the tunnel. On the other hand, the liquid aeroramp injector did behave as planned with good penetration and atomization.

\subsection{Mixing Enhancement with Unsteady Shock Waves}

Methods for enhanced mixing are definitely important for scramjets because of the extremely low combustor fuel residence times of 1 millisecond or less. Studies indicate that as the scramjet combustor Mach number increases, the fuel-air mixing that can be naturally achieved is reduced, leading to an overall decreases in combustion efficiency and thrust [Drummond and Mukunda, 1988]. One technique that has been studied is the use of an oscillating shock to increase the amount of turbulence production in high speed flows. In addition, an oscillating shock would produce a fluctuating source of vorticity, another potential influential mechanism in the mixing process. 


\section{Chapter 1. Introduction}

Kumar et al. [1987] numerically studied the oscillating shock effect on a non-reacting perfect gas and reacting stoichiometric mixture of hydrogen-air under chemical equilibrium. The shock oscillations were introduced by imposing a periodic fluctuation on a shock produced from a 10-deg compression ramp. The results for both cases reported oscillating shock showed to increase the turbulence production in the flow field as predicted. The level of turbulence enhancement was seen to increase with decreasing frequency of shock oscillation.

An experimental study by Wood et al. [1990] used normal injection of a liquid jet from a opposing wall in Mach 3 airflow to generate shock oscillation of $60 \mathrm{kHz}, 120 \mathrm{kHz}$, and $240 \mathrm{kHz}$ to interact with high frequencies present in supersonic combustion on the order of $10^{5}-10^{6} \mathrm{~Hz}$. Concentration measurements and nanoshadowgraphs of helium injection using a singled-holed 15-deg injector located upstream of the liquid jet were used to study the effect of the oscillating shock on the mixing process. Changes in the eddy sizes produced from turbulence were observed with changing frequencies. Also, the maximum measured concentration and penetration of helium decreased with increasing frequency. Lower penetration is an indicator of increased efficiency of mixing of the helium and air.

Other techniques have been proposed by Kumar et al. [1987] for producing oscillatory shock waves. These techniques can be classified into two different approaches: an indirect approach using the flow field and a direct approach using mechanical and electromechanical systems. The use of cavities, forward injection, and normal injection are examples of indirect approach to producing oscillating shock waves. The direct approach example is to force shock oscillation using electromechanical systems such as a plasma torch. Plasma torches have the capability of producing oscillating shocks that can interact with the high frequencies associated with scramjet mixing and combustion. 


\section{CHAPTER TWO}

\section{Goals and Objectives}

The objective of this study was to thoroughly investigate the oscillation behavior of the plasma torch in the plan of ultimately controlling the oscillation at chosen frequencies. This is achieved by varying the frequency of the input voltage waveform applied to the torch. The modulated voltage will cause the luminous plasma jet plume area to change at the same frequency as the oscillating voltage. Shock structures produced by plasma jet will be affected by the dynamic change in the plasma jet plume. The unsteady plasma torch serves as a means of directly generating an oscillating shock. Oscillating shock interaction may provide the mixing augmentation needed to enhance the supersonic combustion [Kumar, et al. 1987]. Controlling the unsteady shock could allow for active control of the amount of flow blockage and the combustion process itself.

The goals associated with this work are as follows:

1. Develop and test a power system that will enable active control plasma torch oscillation.

2. Demonstrate that the plasma torch oscillations can be controlled at a given frequency by varying the input voltage waveform applied to the torch at wide range of frequencies and different types of electrical waveforms.

3. Develop an electrical arc model that simulates the electrical characteristics of the oscillating plasma torch and assess the model's performance based on the collected experimental data.

4. Use the electric arc model to predict the plasma torch electrical response at high frequencies associated with combustion. 


\section{Chapter 2. Goals and Objectives}

5. Investigate how the oscillating plasma torch affects the dynamic shock structure produced in a high speed flow.

6. Determine if the oscillating plasma torch enhances mixing and might allow active control of the combustion process.

This work will explore the possibility of controlled combustion enhancement by means of an oscillating torch. It is hoped that the use of an oscillating plasma torch will improve performance of the plasma torch as an ignition and combustion enhancer in supersonic combustion environments. 


\section{CHAPTER THREE}

\section{Experimental Set-up, Facilities, and Operation}

This chapter describes the lab equipment, facilities, and operation procedures used to collect data reported in this thesis. All equipment arrangements and procedures remained the basically the same for all tests. Any differences from the standard equipment and procedures will be discussed in their relevant sections.

\subsection{Lab Equipment}

The plasma torch operation requires several different systems working in unison. Each system has several pieces of lab equipment associated with it. Descriptions of the lab equipment used in each system are presented in this section and are named as follows: the plasma torch designs, oscillating plasma torch power system, electrical measurement system, flow system, data acquisition system, high speed imaging system, pressure system and instrument isolation system. A schematic of the entire system and how it is interconnected is shown in Figure 3.1.

\subsubsection{Plasma Torch Designs}

Two slightly different plasma torch designs were used in these experiments. The VTPT3 designed by Scott Gallimore [Gallimore, 2001] was used for both the quiescent environment and Mach 2.4 unheated supersonic conditions. A photograph and schematic of the cross section of the VTPT-3 plasma torch are shown in Figure 3.2. This design consists of twelve individual parts, which through development has improved the torch reliability, lifetime of the cathode and anode, and seal 


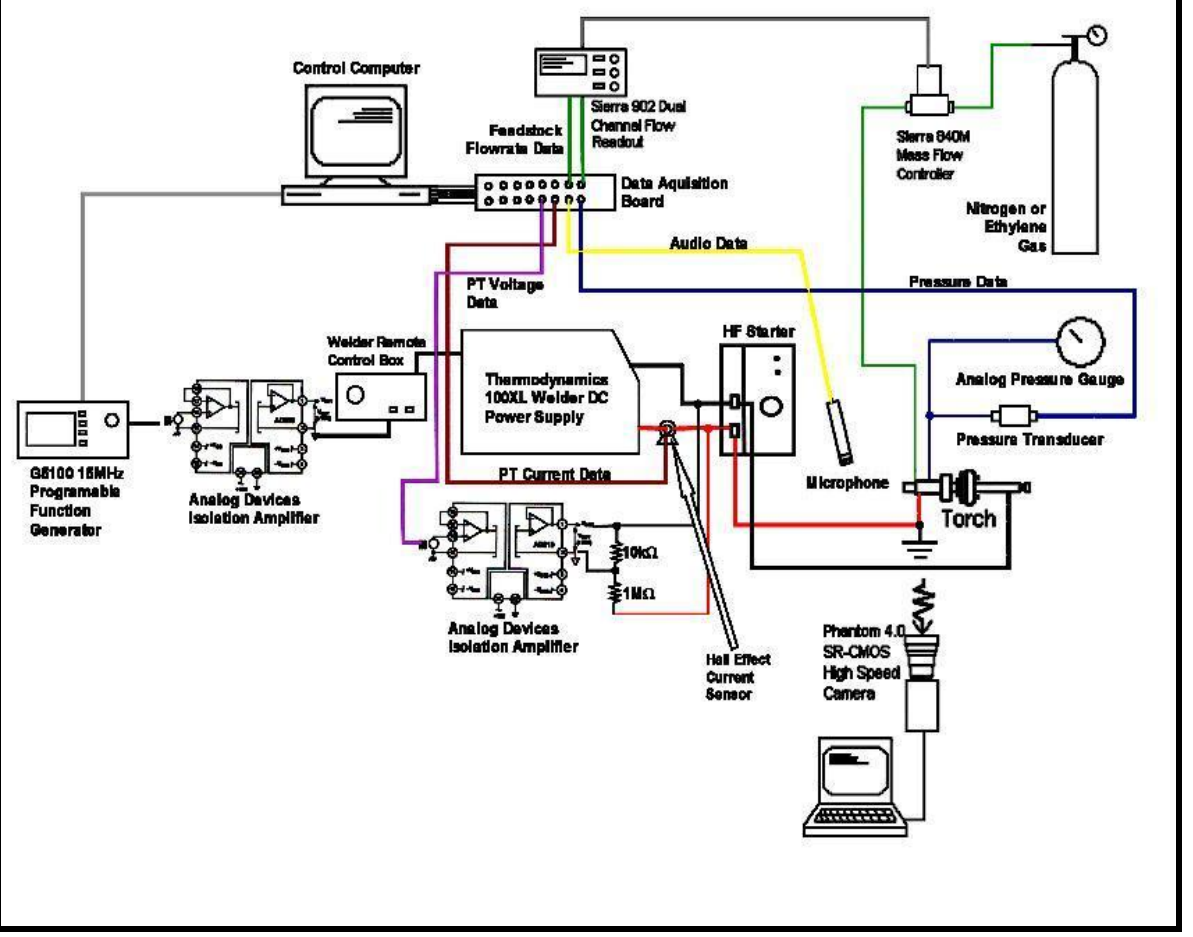

Figure 3.1. The Oscillating Plasma Torch Data Acquisition and Power Supply System

performance compared to previous designs. The anode is clearly shown in the front part of the plasma torch. The material used to make the anode depends on the feedstock gas used, molybdenum for hydrocarbons, and tellurium copper for nitrogen and air. The torch anode has a $1.59 \mathrm{~mm}$ diameter and $2.54 \mathrm{~mm}$ length constrictor. During operation the throat diameter gradually increases due to erosion. The cathode is manufactured from $2 \%$ thoriated tungsten with a $20^{\circ}$ half angle cone cut at the tip. Feedstock gas is channeled through the torch chamber with a flow swirler made from boron nitride. It consists of a hollow cylinder with 3 individual channels drilled on the outer surface. The flow swirler provides electric arc stabilization by inducing vorticity to the feedstock gas flow. The body insulator and support rod both provide electrical isolation between the anode and cathode. 


\section{Chapter 3. Experimental Set-up, Facilities, and Operation}
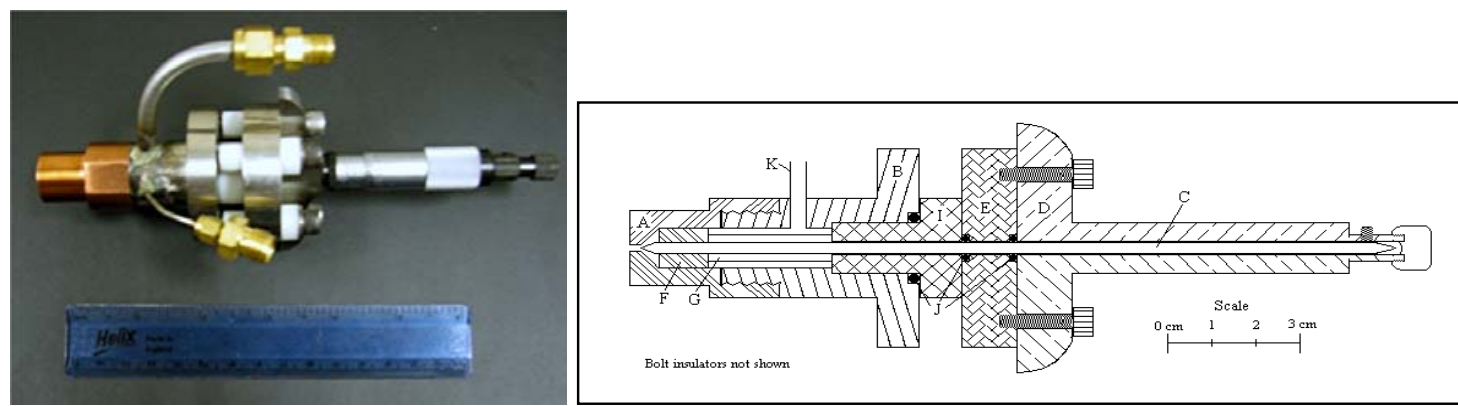

Figure 3.2. Schematic and Picture of VTPT-3 (A: Anode, B: Torch Body, C: Cathode, D: Micrometer Drive, E: Cathode Bracket, F: Flow Swirler, G: Support Rod, H: Bolt Jackets, I: Body Insulator, J: ORings, K: Feedstock Lines)

A modified version of the VTPT-3 plasma torch was used for testing in the heated Mach 2 continuous flow supersonic wind tunnel at the University of Virginia. This torch utilizes industrial torch components, and the distance is fixed between the copper anode and the hafnium tipped cathode. It was especially designed for increased torch lifetime using nitrogen and air feedstocks. A schematic of the modified plasma torch is shown in Figure 3.3. The operation of this design is nearly similar to the original VTPT-3. The feedstock gas enters the torch axially and is redirected tangentially through holes in the cathode. Subsequently, the gas flow passes through the flow swirler where vorticity is introduced to the gas flow to provide arc stabilization. Lastly, the ionized gas exits through the choked anode throat after passing through the electric arc.

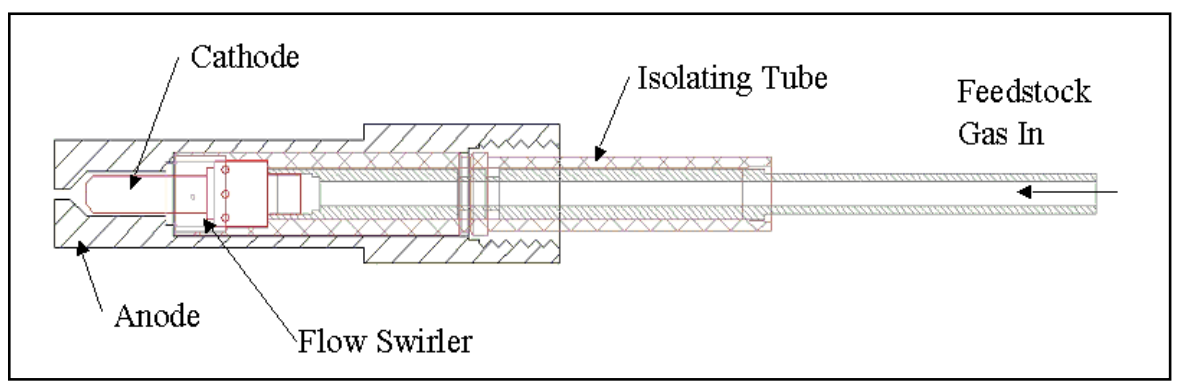

Figure 3.3. Schematic of the modified VTPT-3 [Bonanos et al. 2005] 
Chapter 3. Experimental Set-up, Facilities, and Operation

\subsubsection{Oscillating Plasma Torch Power System}

The source of electrical power to the plasma torch is provided by a Thermal Dynamics 100XL Plus welder power supply (Figure 3.4). The welder provides an open circuit voltage of $260 \mathrm{~V}$ with a current level between 15 and 80 Amps. This current level can be remotely controlled using a 0-9V external voltage signal. A $0.5 \mathrm{sec}$ burst of high frequency current is provided to the plasma torch to initiate the electric arc using a Miller Electric HF-251D-1 high frequency starter (Figure 3.4). The starter is needed because a much larger voltage is required to initiate the arc across the gap. An oscillating voltage signal from the high frequency starter breaks down the gas in this voltage gap. Also, the starter is equipped with a high frequency intensity selection knob (0-100\%), remote switch, and start/continuous selection switch. The welder power supply is electrically connected in parallel to the high frequency starter.

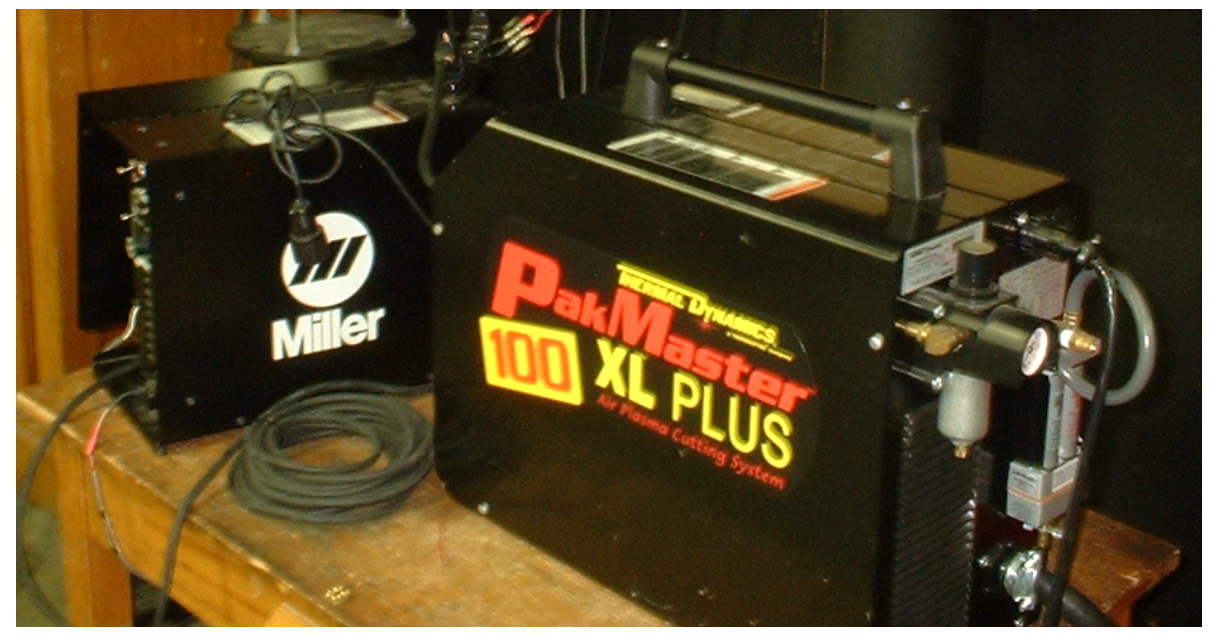

Figure 3.4. Miller HF Starter (left) and 100XL Thermal Dynamic Welder Power Supply (right)

Current modulation was produced by a remote control voltage through a fabricated Welder Remote Control Relay Box (Figure 3.5). This box allowed the control of the current level both manually or by the use of an external voltage power supply. The welder can also be triggered with a 5-12V voltage relay installed inside the Remote Control Relay Box. The oscillating control voltage is provided by a G5100 Sensotek ${ }^{\circledR} 15 \mathrm{MHz}$ programmable function 
generator (Figure 3.5). The function generator is programmable with a frequency range from $1 \mathrm{~Hz}-15 \mathrm{MHz}$ and is capable of producing sinusoidal, square, and triangle waveforms. It has a maximum amplitude of $20 \mathrm{~V}$ peak-to-peak and a DC offset voltage of $\pm 7.5 \mathrm{~V}$. In summary, oscillation of the plasma torch operation at any given frequency within the range capability is achieved with this system. A modulating voltage is sent from the function generator to the Remote Control Relay Box which modulates the current level to welder power supply, thus oscillating the plasma torch output voltage waveform.

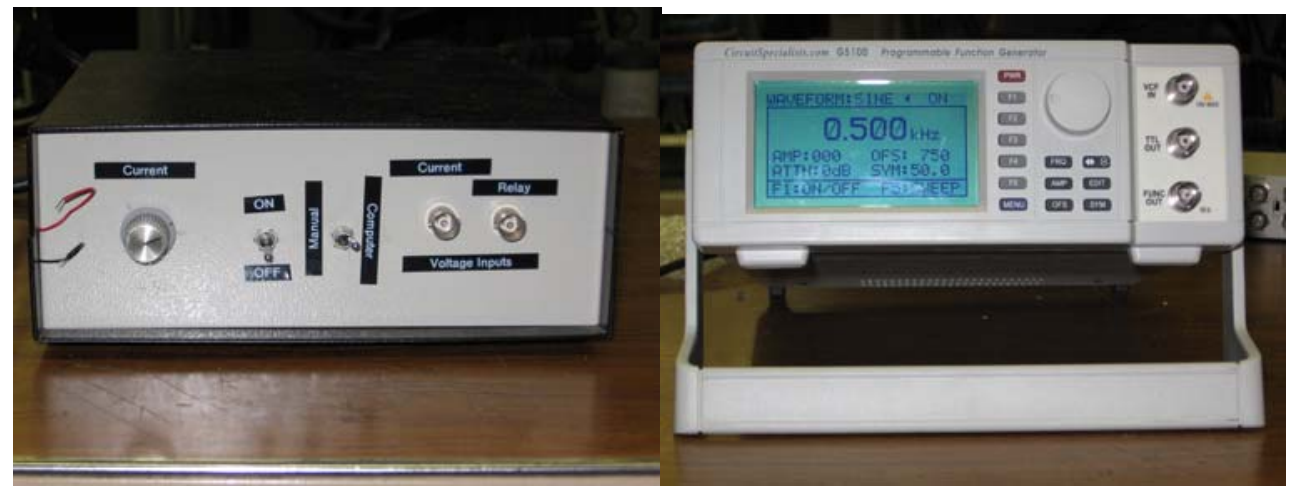

Figure 3.5. Welder Remote Control Relay Box (left) and G5100 Function Generator (right)

\subsubsection{Electrical Measurement System}

The plasma torch voltage and current were measured during torch operation. The plasma torch voltage was measured using a 100 to 1 resistive voltage divider which contains both a $10 \mathrm{k} \Omega$ and $1 \mathrm{M} \Omega$ resistors connected in series. The plasma torch voltage is applied across both resistors and the voltage is measured across a $10 \mathrm{k} \Omega$ resistor with the data acquisition system. The appropriate voltage is scaled to get an estimate of the plasma torch operating voltage. Current levels of the plasma torch are measured with a Honeywell ${ }^{\circledR}$ Hall Effect current sensor. The function of the Hall Effect sensor is based on a physical principal discovered by Edwin $\mathrm{H}$. Hall. This principal says if electric current flows through a semiconductor in a magnetic field, that magnetic field generates a voltage that is perpendicular to the direction of the current. The 


\section{Chapter 3. Experimental Set-up, Facilities, and Operation}

Hall voltage is linearly proportional to the amount of current flowing through it. The Hall Effect sensor is powered with an external $6 \mathrm{~V}$ power supply and has a response time of $3 \mu \mathrm{sec}$.

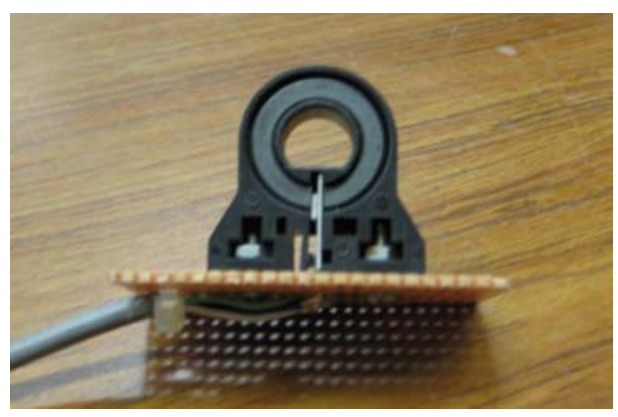

\section{Figure 3.6. Hall Effect Current Sensor}

\subsubsection{Flow Control System}

The flow rate of the feedstock gas was controlled using a Sierra 840M mass flow controller and 902C Dual Channel Digital Readout. The mass flow controller uses a built in electromagnetic servo-control value to set the precise value of mass flow. A photograph of the flow controller is shown in Figure 3.7. The flow controller was factory calibrated for use with methane gas at a range of 0 -30slpm. So, a calibration factor is needed for use with other feedstocks to account for the different material property of the chosen gas. Calculation of the calibration factor is shown with the following equations,

$$
\begin{aligned}
& Q_{2}=K^{*} Q_{1} \\
& K=\left(\frac{N_{1}}{\rho_{1} C_{p 1}}\right)\left(\frac{N_{2}}{\rho_{2} C_{p 2}}\right)
\end{aligned}
$$

where $\mathrm{Q}_{2}$ is the actual gas flow rate, $\mathrm{Q}_{1}$ is the mass flow rate reading from the controller, and $\mathrm{K}$ is the provided calibration factor from Sierra Instruments. Nitrogen and air feedstocks have a calibration factor of $\mathrm{K}=1.389$.

The 902C Digital Readout (Figure 3.7) is used to adjust and read the flow rate of the mass flow controller. Parallel cables are used to send signals from the digital readout to the mass flow controller. The face of the digital readout consists of a digital display, display select switch, 


\section{Chapter 3. Experimental Set-up, Facilities, and Operation}

flow control potentiometers, channel select knob, and power switch. The potentiometers are used to adjust the amount of flow going through the flow meters. The display select switch toggles between flow rate display and the flow rate value set point for the channel selected by the channel select knob. Electrical 20-pin connectors on the back of the digital readout allow for remote control and flow rate measurement using a data acquisition system.

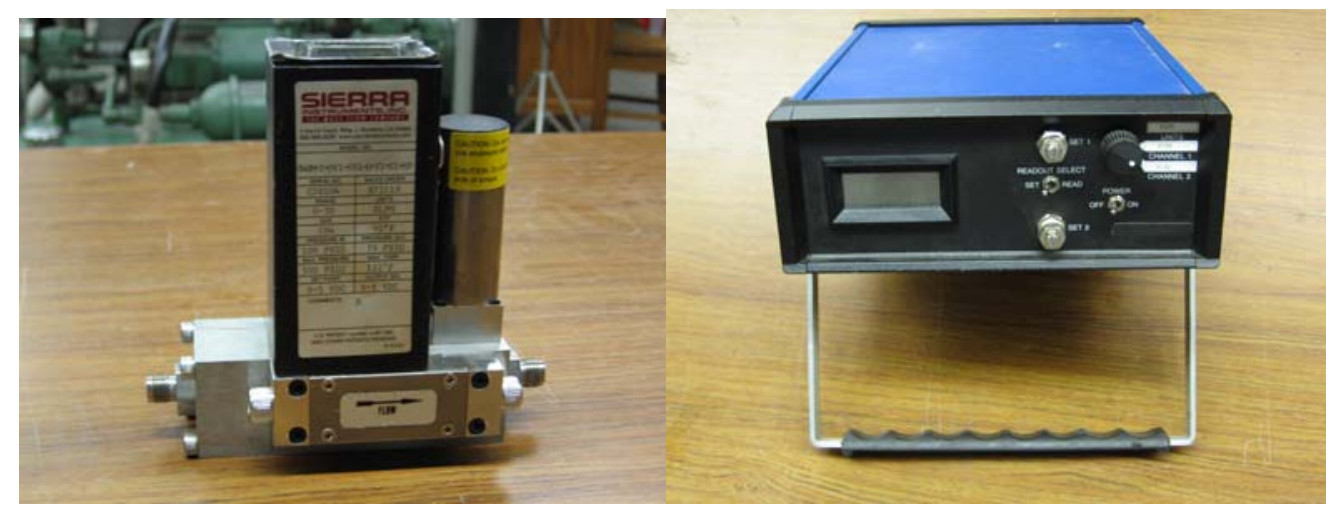

Figure 3.7. Sierra 840M Mass Flow Controller (left) and Dual Channel Digital Display (right)

\subsubsection{Data Acquisition System}

Plasma torch measurements and the control sequence were automated using software and hardware from National Instruments ${ }^{\circledR}$. A control computer used a NI PCI-6036E data acquisition (DAQ) card containing 16 analog inputs, 8 digital I/0, and 2 analog outputs with a 16-bit resolution capable of sampling up to $200 \mathrm{kHz}$. The DAQ card was connected to a BNC2090 Shielded BNC Adaptor Chassis with a 68-pin connector cable. Signals from all other operating equipment were connected to the BNC-2090's seven BNC connectors, and three digital I/O spring terminals. A program using LabVIEW 7.0 software was coded to control plasma torch operation and collect data measurements. The plasma torch operation sequence using LabVIEW is discussed later in Section 3.2.

\subsubsection{High Speed Imaging System}

High speed observation of the plasma torch operation was made using a Visible Solutions ${ }^{\circledR}$ Phantom 4.0 SR-CMOS camera (Figure 3.8). The camera has a resolution of D. Sanders 


\section{Chapter 3. Experimental Set-up, Facilities, and Operation}

512x512 pixels at 1000 frames/sec but is also capable of recording with sampling rates over $10 \mathrm{kHz}$ with reduced image formats. Typically, a resolution of $128 \mathrm{x} 128$ pixels at 10,000 frames per sec was used to view the plasma torch oscillation. The camera was connected to an external laptop using IEEE 1394 Firewire $^{\circledR}$ cable and PCMCIA card. Software provided by Visible Solutions controls the images playback, exposure time, and frame rate.

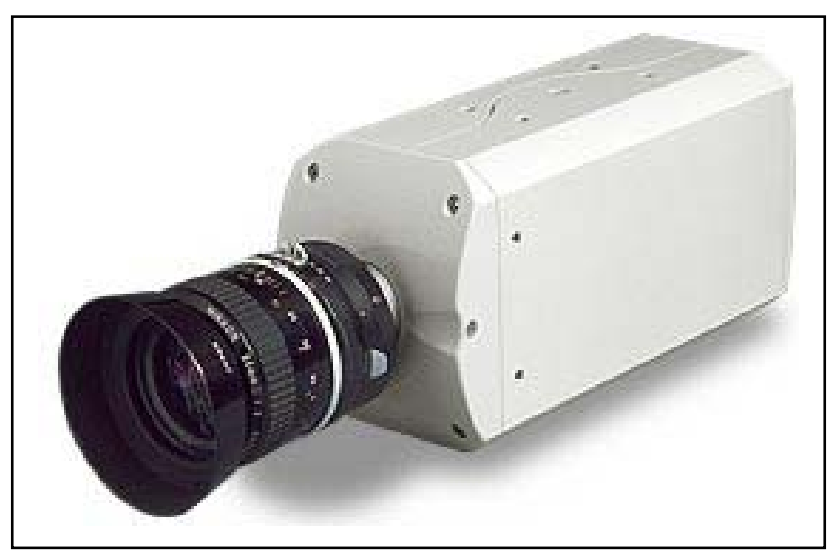

Figure 3.8. Phantom 4.0 SR-CMOS High Speed Camera [www.visionresearch.com]

\subsubsection{Pressure System}

The feedstock gas for the plasma torch is supplied from a high pressure cylinder fitted with dual-stage regulators. This allowed for the feedstock pressure to be adjusted from 0-4MPa (0-600psig). The plasma torch chamber pressure was usually set to $345 \mathrm{kPa}$ (50psig), adequate to choke the torch flow orifice during all the tests. All feedstock gas connections used $6.35 \mathrm{~mm}$ (0.25in) Nycoil ${ }^{\circledR}$ tubing with 0.25 in Swagelok gas compression fittings. Pressure measurements were recorded using a Gensico Tech 0-0.69MPa (0-100psi) pressure transducer and Measurements Group 2310 signal conditioning amplifier. A dead weight tester was used to calibrate the pressure transducer before each series of tests.

\subsubsection{Instrument Isolation System}

Isolation of all sensitive electrical equipment was achieved using Analog Devices ${ }^{\circledR}$ isolation amplifiers (Figure 3.9). One of these amplifiers was placed between the function 


\section{Chapter 3. Experimental Set-up, Facilities, and Operation}

generator and the Remote Control Relay Box as well as between the resistive voltage divider and the data acquisition system. These amplifiers provide protection from transient voltages up to $3500 \mathrm{~V}$. One of the features of the amplifier is a three-port design where power, input, and output signals are isolated from each other. This provides additional system protection should a fault occur in the power source. Also, the amplifier features a wide frequency response bandwidth of up to $20 \mathrm{kHz}$.

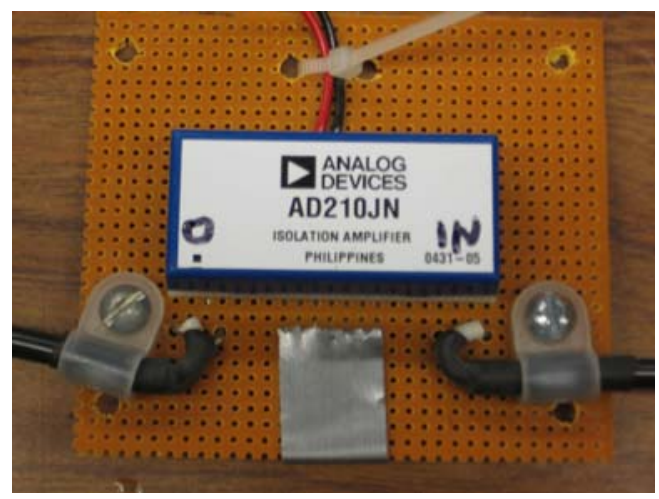

Figure 3.9. Analog Devices Isolation Amplifier

\subsection{Experimental Facilities}

Experiments were completed at three different testing facilities consisting of the quiescent test cell, the unheated supersonic wind tunnel at Virginia Tech, and the supersonic combustion tunnel at the University of Virginia. Facilities used for testing of the oscillating plasma torch are described in this section.

\subsubsection{Quiescent Test Cell}

The quiescent test cell (Figure 3.11) consists of an optical table that is used for alignment of the plasma torch with other optical measurement equipment. This optical table is fixed to a track that allows the plasma torch to be moved between the inside and outside lab environments. The plasma torch is mounted on the optical table with a bracket and oriented so the plasma torch is inside a horizontal $25 \mathrm{~cm}$ OD x $0.953 \mathrm{~cm}$ thick steel pipe that is used for ventilation. A window D. Sanders 


\section{Chapter 3. Experimental Set-up, Facilities, and Operation}

covered with a $1.25 \mathrm{~cm}$ thick piece of Lexan $^{\circledR}$ glass separates the inside and outside lab environments. An aluminum sheet and fire retardant fabric is placed over the ventilation pipe to shield the test area from precipitation and excess light.

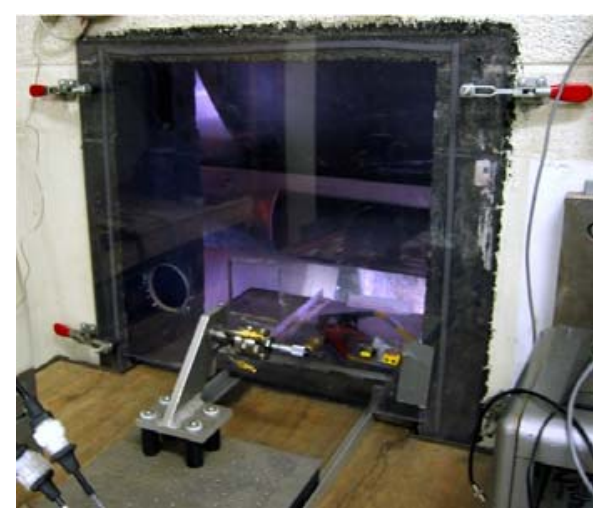

Figure 3.10. View of Quiescent Test Cell

\subsubsection{Virginia Tech Unheated Supersonic Wind Tunnel}

The unsteady plasma torch was tested in a blow-down, unheated wind tunnel at Mach 2.4 flow conditions (Figure 3.12). Mach 2.4 cross-flow is used because it is the minimum operating range of the combustor in practical scramjets. However, because the flow is unheated, it does not simulate the flow conditions found in scramjet combustors. At Mach 2.4, the plenum total pressure and total temperature is $378 \mathrm{kPa}$ and $271 \mathrm{~K}$, respectively. The test section dimensions were $23 \mathrm{~cm}$ wide $\mathrm{x} 23 \mathrm{~cm}$ high $\mathrm{x} 30 \mathrm{~cm}$ long in the streamwise direction. The average tunnel run time with the oscillating plasma torch is $8-10$ seconds. The plasma torch was mounted through the floor of the tunnel test section. Fused silica windows on each side of the test section allowed for set up of high speed Schlieren videos. 
Chapter 3. Experimental Set-up, Facilities, and Operation
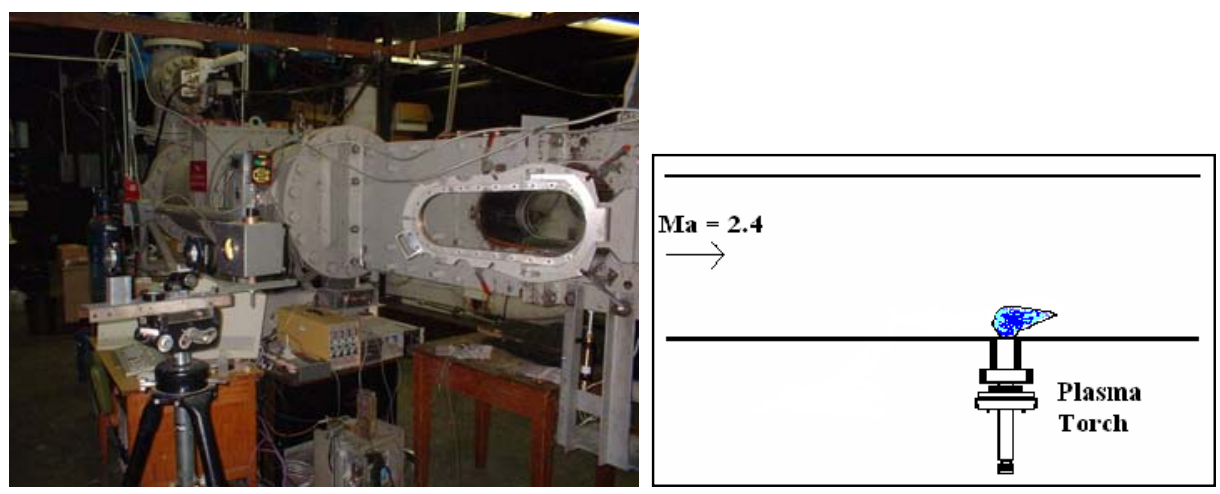

Figure 3.11. Virginia Tech Supersonic Wind Tunnel (left) and illustration of plasma torch in Virginia Tech Tunnel Setup (right)

\subsubsection{UVA Supersonic Combustion Tunnel}

Experiments were conducted at the University of Virginia Aerospace Research Lab (ARL) in Charlottesville, VA, shown in Figure 3.13. The facility produces a Mach 2 heated continuous flow which simulates Mach 5 enthalpy flight in a dual mode scramjet. The wind tunnel configuration consists of two stage compressor, 14-stage electrical resistance heater, ceramic flow straightener, supersonic nozzle, constant area isolator, test combustor, and exhaust duct. The heater provides a flow total temperature of near $1100 \mathrm{~K}$ that free of contamination. The test static and total pressure is $40 \mathrm{kPa}$ and $300 \mathrm{kPa}$, respectively.

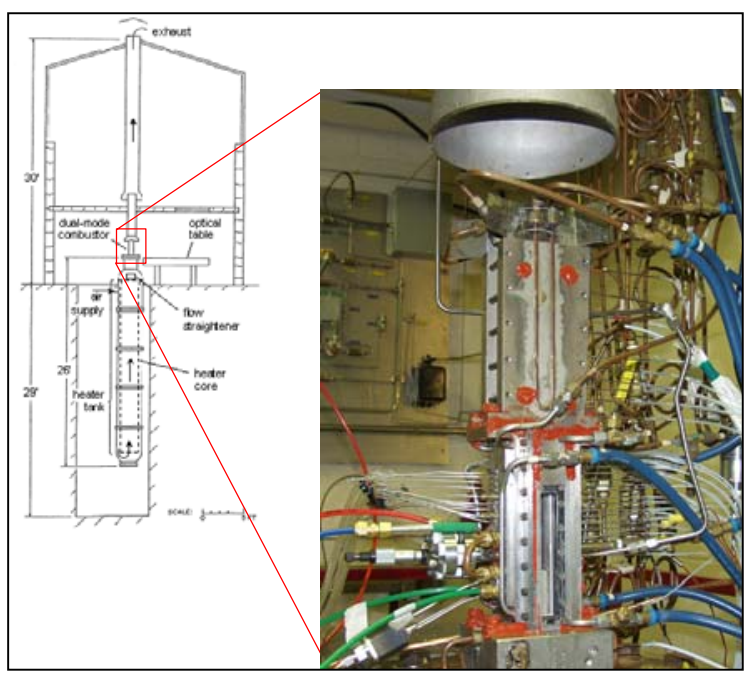

Figure 3.12. UVA ARL Supersonic Combustion Tunnel Schematic (left) and plasma torch injector array setup (right). 


\section{Chapter 3. Experimental Set-up, Facilities, and Operation}

The test section dimensions are 1 in. by 1.5in. A schematic of the combustion duct is shown in Figure 3.14. The center of the aerodynamic ramp injectors (aeroramp) is defined as the reference dimension. Approximately 2.5in downstream of the aeroramp/plasma torch injector center, a 2.9 degree divergence begins on the opposite wall. The flow then exhausts to the atmosphere $40 \mathrm{~cm}$ downstream of the injector center. The constant area isolator begins 12in. upstream of the injector center and is approximately 10in long. Optical access to the combustion duct is gained with two fused silica windows. Along the injector center there are 32 individual static pressure taps, where 28 of pressure taps are located in combustor section. Also, Kulite ${ }^{\circledR}$ pressure transducers are recess-mounted on the opposite wall of the injector array inside the isolator section of the tunnel.

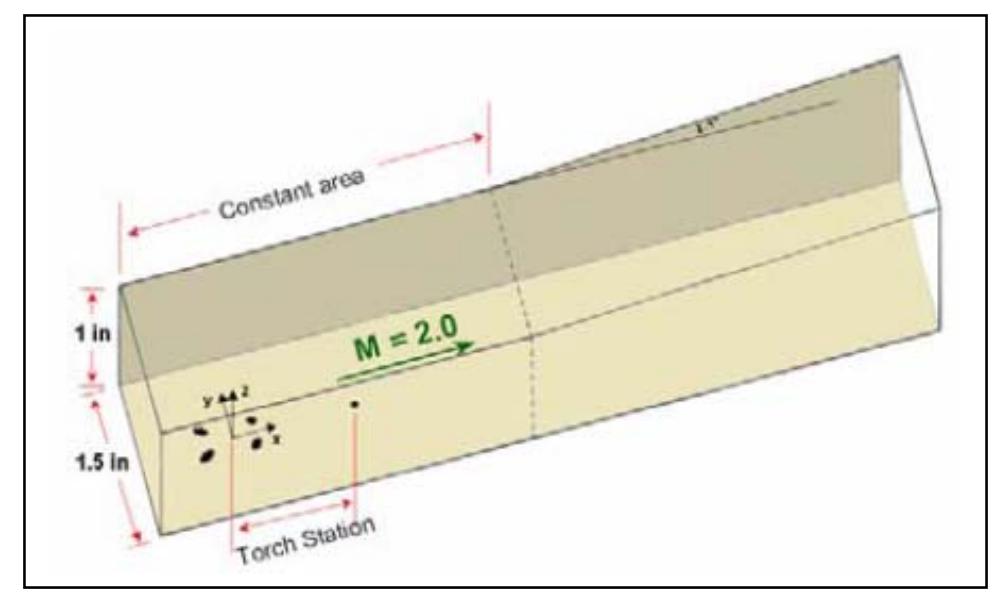

Figure 3.13. Schematic of UVA Combustion Tunnel Geometry [Bonanos et al. 2005].

\subsection{Oscillating Plasma Torch Operation}

The entire operation of the plasma torch is fully automated using a control sequence from LabView $^{\circledR}$ program. The control sequence block diagram is shown in Figure 3.15 and each step in the sequence is clearly labeled. The feedstock gas is triggered on for about 5 seconds to make sure proper feedstock flow is established. The plasma torch operation begins when the welder is 


\section{Chapter 3. Experimental Set-up, Facilities, and Operation}

remotely turned on and the high frequency starter is triggered for 0.5 seconds. Data from the oscillating plasma torch is collected for 4 seconds. A small delay is introduced, then the welder power and feedstock flow is triggered off. Raw voltage data saved to a file in LabView format for later viewing and calibration using the "PT Data Display” sub program.

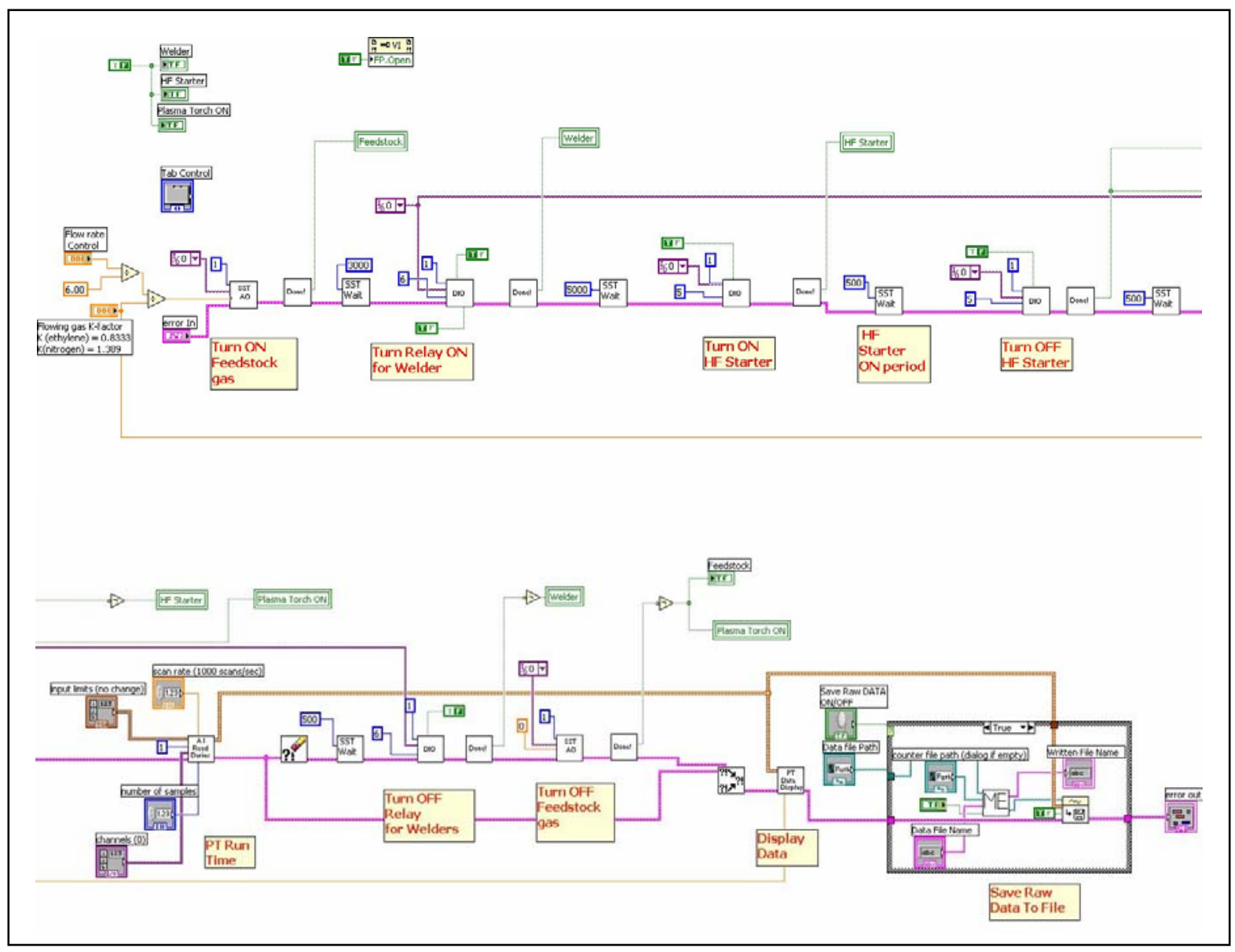

Figure 3.14. Plasma Torch Control Sequence Block Diagram

The front panel of the plasma torch control program (Figure 3.16) uses a set of LED lights to indicate which part of the control sequence the program has completed. Also, the feedstock flowrate with the corresponding gas conversion factor can be set depending on the test conditions. The sample rate and number of samples can be controlled but is limited due to the sample rate of the DAQ card and the size of the memory buffer. Another feature of the front 


\section{Chapter 3. Experimental Set-up, Facilities, and Operation}

panel control is an independent file counter that appends an incrementing number to each data file after each successful run.

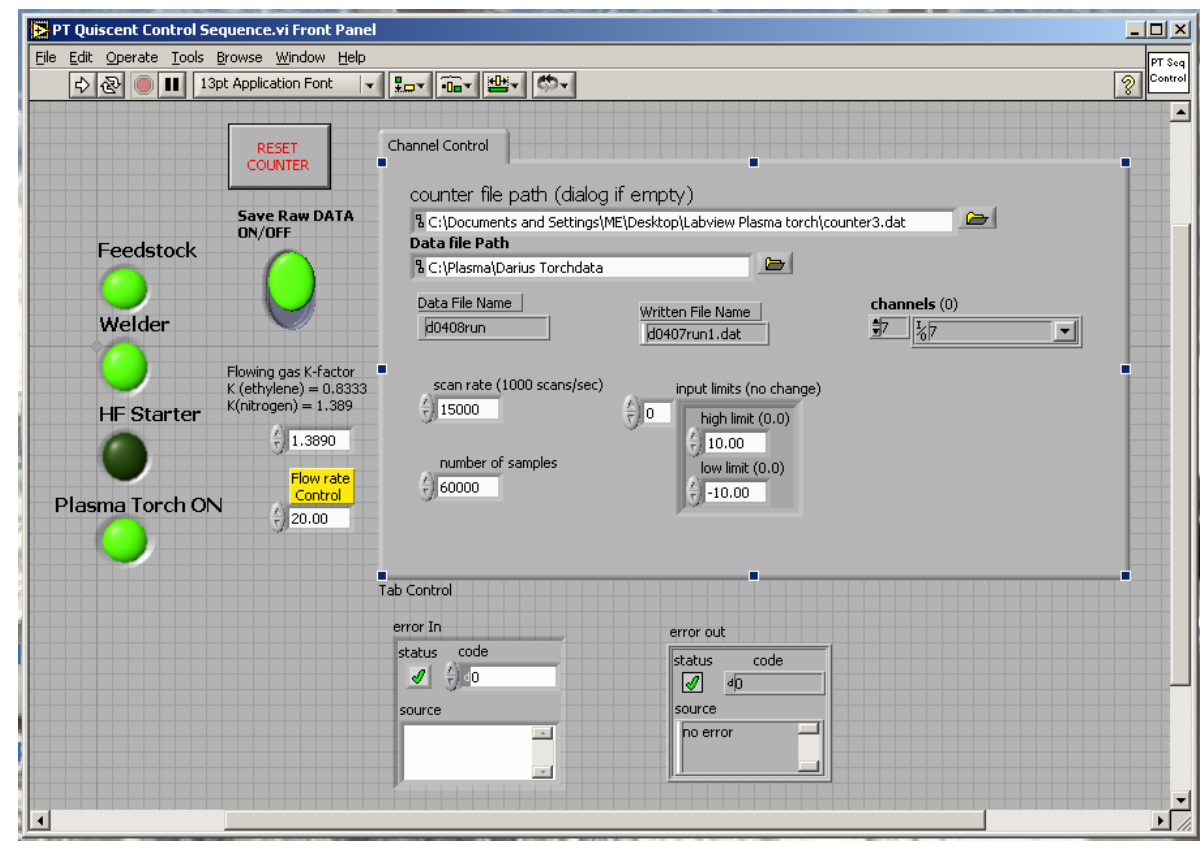

Figure 3.15. LabVIEW PT Control Program Front Panel 


\section{CHAPTER FOUR}

\section{Experimental Testing Procedures}

\subsection{Quiescent Testing}

The purpose of the quiescent testing was to test the oscillating plasma torch and current modulation power system for operability and to determine the ideal parameters for stable torch operation. Nominal DC power ranges of 1800-2200W with 45-50\% amplitude modulation were selected. The plasma torch was operated at individual oscillator input frequencies from $2 \mathrm{~Hz}-$ $4 \mathrm{kHz}$ with sinusoidal, triangle, and square waveforms. A nitrogen feedstock was used at flow rate of 25slpm. Electrical waveforms of the oscillator control voltage, plasma torch output current, and plasma torch output voltage were collected. The dynamic response of the plasma jet was recorded using high speed video imaging. Figure 4.1 shows the oscillating plasma torch operating in the quiescent test cell with nitrogen feedstock.

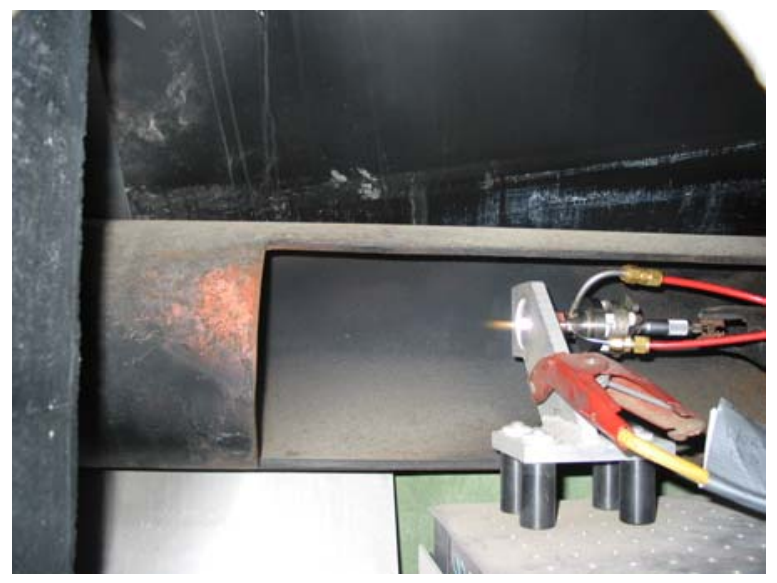

Figure 4.1. Oscillating plasma torch operating in quiescent test cell

\subsection{Virginia Tech Supersonic Tunnel Testing}

The oscillating plasma torch was tested in a supersonic cross-flow to characterize its shock structure. The same individual frequencies and parameters were used as in the quiescent D. Sanders 


\section{Chapter 4. Experimental Testing Procedures}

experiments. The plasma torch was operated at 2000W and above to ensure that the plasma jet was large enough to produce unsteady shock movement. The stable operation of the tunnel was achieved before the plasma torch is triggered on. The tunnel uses a PID (Proportional-IntegralDerivative) controller to set the correct total pressure in the tunnel for Mach 2.4 flow. The tunnel takes 2-3 seconds to stabilize the main flow before plasma torch is turned on. Electrical measurements of plasma torch and tunnel conditions are collected during the entire time the tunnel is running.

\subsubsection{High Speed Schlieren Image Set-up}

High speed Schlieren images were used to view the oscillating plasma jet and the shock structure produced from the plasma jet in supersonic flow. The set-up of the high speed Schlieren imaging system is shown in Figure 4.2. The light source was a halogen $15 \mathrm{~V}$ clear light bulb with a horizontal filament. The diverging light from the light bulb is converted to a parallel column of light using a concave mirror. The parallel light is directed through the test section to another concave mirror, where the converging light is reflected with a flat mirror towards the high speed camera. A knife edge is placed at the focal point between the flat mirror and the high speed camera to produce a Schlieren image. The best resolution and focus is obtained by adjusting the position of the camera and the focusing lens of the camera. 


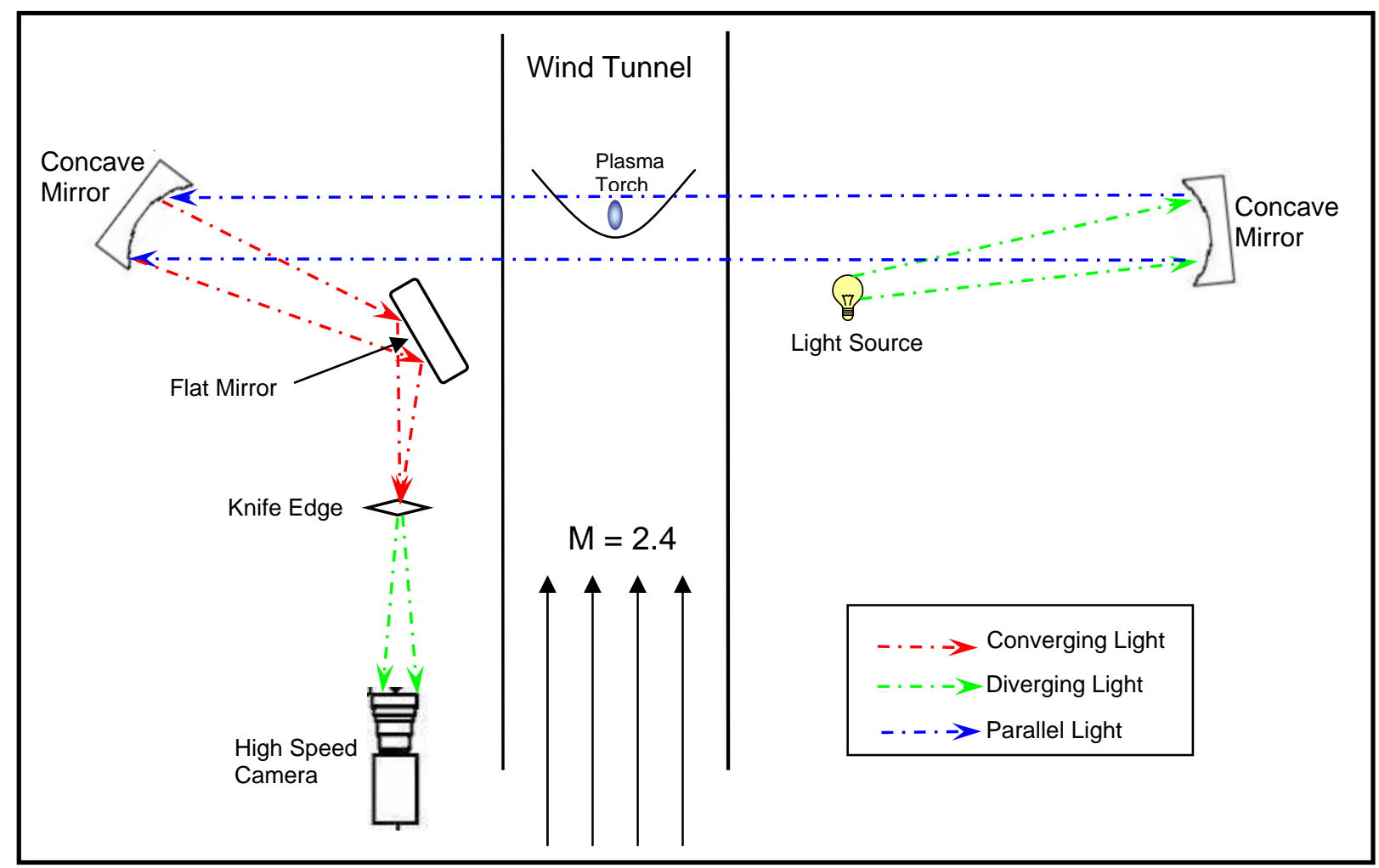

Figure 4.2. High Speed Schlieren Set-up

\subsection{University of Virginia Supersonic Combustion Tunnel Testing}

\subsubsection{Aerodynamic Ramp Injector}

Testing of the oscillating plasma torch was completed at the University of Virginia ARL. The unsteady plasma torch was integrated with the flush-walled 4-hole aerodynamic ramp injector (aeroramp) used in Bonanos et al. [2005] and Jacobson et al. [2001]. A schematic of the aeroramp is shown in Figure 4.2. Each of the four injector jets have a diameter, $d_{j}$, of $1.59 \mathrm{~mm}$ and an equivalent jet diameter, $d_{e q}$, of $3.18 \mathrm{~mm}$. The definition of an equivalent jet diameter is the diameter a single-holed injector that would have the same area as the total area of all the aeroramp jets. It is calculated with the equation:

$$
d_{e q}=d_{j} \sqrt{n}
$$




\section{Chapter 4. Experimental Testing Procedures}

where the $n$ is the number of injector jets. The aeroramp is arranged in two rows and two columns array spaced $4 d_{e q}$ apart in streamwise direction and $2 d_{e q}$ between the holes. The first pair (Section A-A of Fig 4.2) and second pair (Section B-B of Fig 4.2) of holes are transversely angled 20 and 40 degrees and toed-in 15 and 30 degrees, respectively. One advantage of using an aeroramp is that it enhances mixing by inducing vorticity without the associated blockage and total pressure loss of a physical ramp.

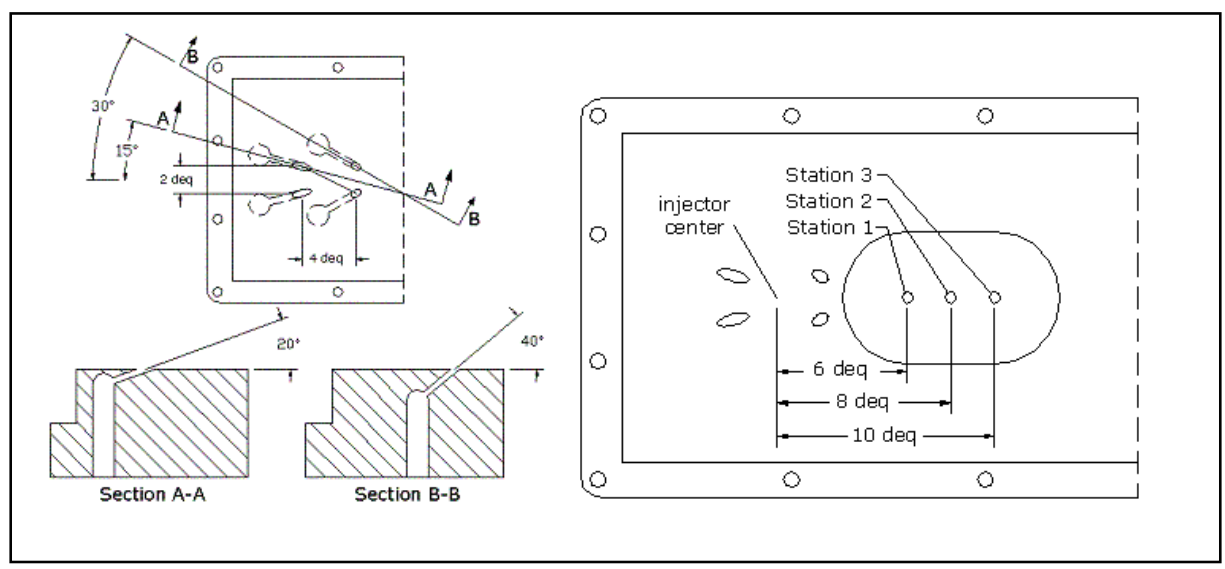

Figure 4.3. Schematic of 4-holed aerodynamic ramp injector array (left) and the three plasma torch locations tested shown in relation to the aeroramp fuel injector (right) [Bonanos, et al. 2003].

\subsubsection{Test Conditions}

The oscillating plasma torch/aeroramp ignition system was operated at a number of different test conditions. The combination of hydrogen-fueled aeroramp with nitrogen-fed plasma torch and ethylene fueled aeroramp with air-fed plasma torch were both tested in scramjet combustor conditions. The plasma torch used was the modified industrial plasma torch mentioned previously, because of its greater continuous operational life. Torch location with respect the aeroramp injector was anticipated to be very important for successful ignition. The torch was tested at three possible downstream locations from the aeroramp shown in Figure 4.2. For the hydrogen aeroramp/nitrogen-fed plasma torch test, the fuel flow rate was varied until a varying pressure signal was sensed by one of the three Kulite pressure transducers located in the 


\section{Chapter 4. Experimental Testing Procedures}

isolator section of the tunnel. Next, the overall effect of the oscillating plasma torch on the static pressure profile along the length of the combustor was tested with the ethylene aeroramp/air-fed plasma torch. 


\section{CHAPTER FIVE}

\section{Oscillating Plasma Torch System Electrical Response}

\subsection{Electrical Waveform Results}

\begin{tabular}{|c|c|c|c|}
\hline $\begin{array}{c}\text { Frequency } \\
(\mathrm{Hz})\end{array}$ & $\begin{array}{c}\text { Sinusoidal } \\
\text { Waveform }\end{array}$ & $\begin{array}{c}\text { Triangle } \\
\text { Waveform }\end{array}$ & $\begin{array}{c}\text { Square } \\
\text { Waveform }\end{array}$ \\
\hline 2 & $\sqrt{ }$ & $\sqrt{ }$ & $\sqrt{ }$ \\
\hline 128 & $\sqrt{ }$ & $\sqrt{ }$ & $\sqrt{ }$ \\
\hline 180 & $\sqrt{ }$ & $\sqrt{ }$ & $\sqrt{ }$ \\
\hline 256 & $\sqrt{ }$ & $\sqrt{ }$ & $\sqrt{ }$ \\
\hline 512 & $\sqrt{ }$ & $\sqrt{ }$ & $\sqrt{ }$ \\
\hline 1024 & $\sqrt{ }$ & $\sqrt{ }$ & $\sqrt{ }$ \\
\hline 2050 & $\sqrt{ }$ & $\sqrt{ }$ & $\sqrt{ }$ \\
\hline 4100 & $\sqrt{ }$ & $\sqrt{ }$ & $\sqrt{ }$ \\
\hline
\end{tabular}

Electrical waveforms of plasma torch were recorded for a range of dominant individual frequencies according to the test matrix shown in Table 5.1. The plasma torch was operated at the individual frequencies listed for triangle, sinusoidal, and square oscillator Table 5.1. Test Matrix for Quiescent Testing voltage waveforms. Typical waveforms of the oscillator voltage, plasma torch output current and voltage are shown in Figure 5.1, where it is observed that the plasma torch voltage and current is responding to the oscillator frequency of 128Hz. Also, a phase difference is seen between these time signals. The available equipment limited the frequency range of operation for the plasma torch. More analysis is needed to determine over what maximum frequency range the plasma torch is able to respond.

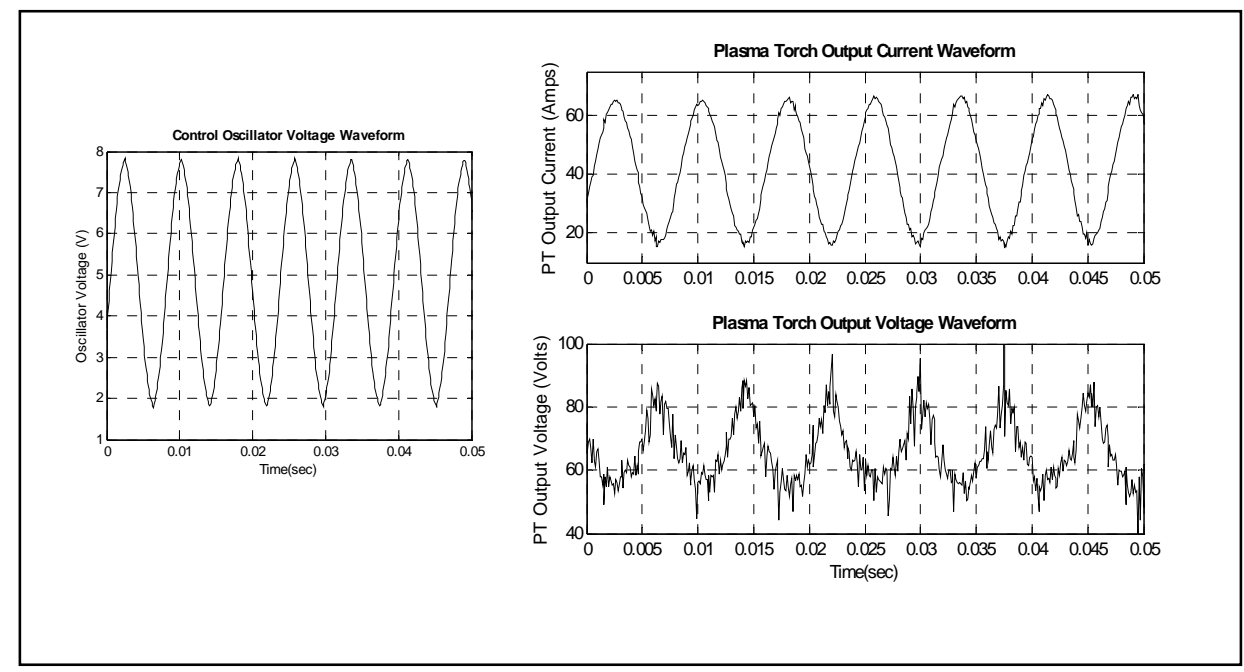

Figure 5.1. Plasma Torch Electrical Waveforms. The Control Oscillator Voltage (left), Plasma Torch Output Current (top right), and Plasma Torch Output Current (lower right)

D. Sanders 


\section{Chapter 5. Oscillating Plasma Torch System Electrical Performance}

\subsection{Signal Processing Calculations}

Signal processing methods were used to estimate the oscillating plasma torch frequency response. The frequency response function (FRF) was calculated assuming both the plasma torch output current and plasma torch output voltage with respect to oscillator control voltage can be expressed with a linearized input/output model described as:

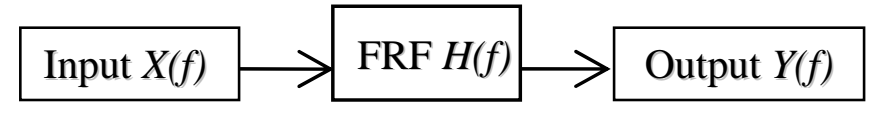

The frequency response function, $H(f)$, is calculated with the equation:

$$
H(f)=\frac{A_{X Y}}{A_{X X}}
$$

where $A_{X X}$ is the auto-spectrum of the input signal $(X)$ and $A_{X Y}$ is the cross-spectrum of the output signal $(Y)$ with respect to the input signal $(X)$.

\subsubsection{Auto-spectrum Estimation}

The auto-spectrum is described as the Fourier transform of the autocorrelation and is always a real valued function. It is obtained by first calculating the discrete Fourier transform (DFT) of a time signal and multiplying it by the complex conjugate. The equation of this description is as follows,

$$
A_{X X}=2\left[X^{*}(f) X(f)\right]
$$

where $X(f)$ is the DFT of the input time signal, $X$, and $X^{*}(f)$ is its complex conjugate. The DFT, $c_{m}$, is calculated as

$$
c_{m}=\frac{1}{N} \sum_{n=0}^{N-1} x(n) e^{-\frac{i 2 \pi n m}{N}}
$$

where $N$ is the total number of samples of the discrete time signal $x(n)$ and $n$ and $m$ is the data sample index and the assumed frequency index, respectively. The DFT contains both real and D. Sanders 


\section{Chapter 5. Oscillating Plasma Torch System Electrical Performance}

imaginary components. The highest frequency that can be examined is half the sampling frequency of the data acquisition system, or the Nyquist frequency. The frequency resolution of the DFT is equal to the number of samples divided by the sampling frequency.

\subsubsection{Cross-Spectrum and Coherence Function}

The cross-spectrum, $A_{X Y}$, is defined as the Fourier transform of the cross-correlation and is complex valued function consisting of both real and an imaginary values. So, the crossspectrum contains the phase information between the input signal with respect to the output signal. Similar to the auto-spectrum, the cross-spectrum is obtained by taking the complex conjugate of the calculated DFT of the assumed input, $X^{*}(f)$, and multiplying it by the DFT of the assumed output signal, $Y(f)$. The equation for calculation of the cross-spectrum is as follows

$$
A_{X Y}=2\left[X^{*}(f) Y(f)\right]
$$

Also, note that the first subscript in the $A_{X Y}$ notation is always assumed to be the complex conjugate.

The coherence function, $\gamma^{2}$, is calculated to determine how well the averaged frequency data fits the assumed linear input/output model.

$$
\gamma^{2}=\frac{A_{X Y} A_{Y X}}{A_{X X} A_{Y Y}}
$$

Coherence values range between 0 and 1 . A coherence value of one indicates that there is not any uncorrelated content in the output measurement. The signal output fits the assumed input/output model perfectly. A coherence value of zero implies that the output measurement is composed of uncorrelated content. The output signal is not linearly related to the input. Several ensembles of data must be averaged in the auto-spectrum and cross-spectrum calculations to obtain a correct value for the coherence. 


\section{Chapter 5. Oscillating Plasma Torch System Electrical Performance}

\subsection{Frequency Response Function Investigations}

The frequency response function was calculated at each of the dominant plasma torch oscillating frequencies. At least three ensembles of spectrum calculations were averaged at each plasma torch oscillation frequency for an accurate estimate of the coherence values. The FRF of the plasma torch power system and plasma torch operation was determined. The data presented is from quiescent testing, but it is assumed that the electrical behavior of the plasma torch is the same in all the testing environments.

\subsubsection{Frequency Response of Oscillating Plasma Torch Power System}

The control oscillator voltage is assumed to the input signal and the plasma torch output current is the assumed model output. The graphs in Figure 5.2 shows the FRF gain and FRF phase plotted as a function of plasma torch oscillation frequency. The gain and phase plot indicates that as plasma torch oscillator frequency increases the gain and phase difference decreases. This decrease becomes more significant at frequencies above $1 \mathrm{kHz}$. A similar behavior is found in DC amplifiers with frequency roll-off. The roll-off frequency or corner frequency is the frequency which the gain drops by a factor of $\sqrt{2}$ relative to the DC gain, or a $3-\mathrm{dB}$ reduction in the relative gain. At the corner frequency the phase is $-45^{\circ}$. A corner frequency of $1 \mathrm{kHz}$ with a DC gain of $8.8 \mathrm{~V}$ is estimated for plasma torch power system. All coherence values calculated were above 0.95 . Therefore, a linear relationship exists between the assumed input and output signals. 


\section{Chapter 5. Oscillating Plasma Torch System Electrical Performance}

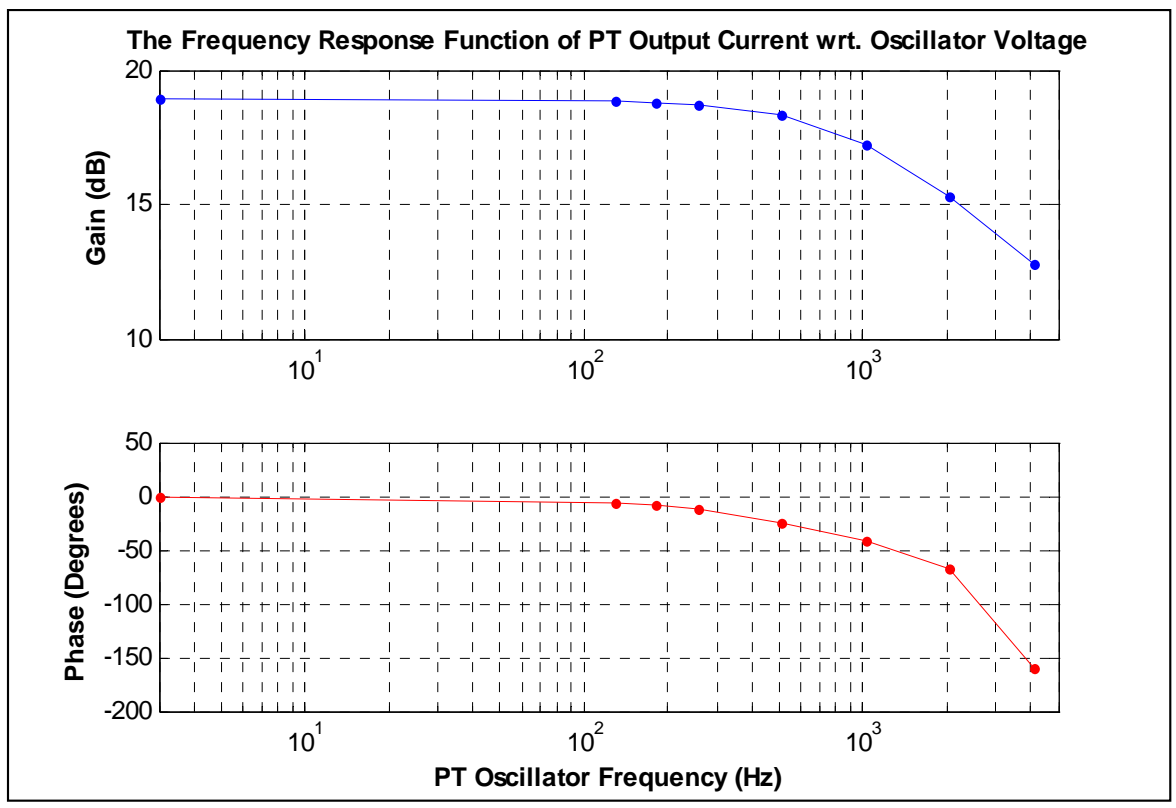

Figure 5.2. The Frequency Response Function of Oscillating Plasma Torch Power System

\subsubsection{Frequency Response of the Plasma Torch}

Similarly, the control oscillator voltage was assumed to be the input and the plasma torch voltage was the assumed output. The graphs in Figure 5.3 shows the plasma torch FRF gain and FRF phase plotted as a function of plasma torch oscillation frequency. The FRF gain plot indicates that the DC gain increases slightly with increasing frequency, but begins to roll-off at the estimated corner frequency of $2 \mathrm{kHz}$. The FRF phase plot shows a significant amount of lag between the two signals. The reason for the large signal lag is the presence of the phase difference from the plasma torch power system. The calculated coherence values were 0.85 and above. Therefore, the assumption that the control oscillator voltage input signal is linearly related to the plasma torch output voltage is considered valid. 


\section{Chapter 5. Oscillating Plasma Torch System Electrical Performance}

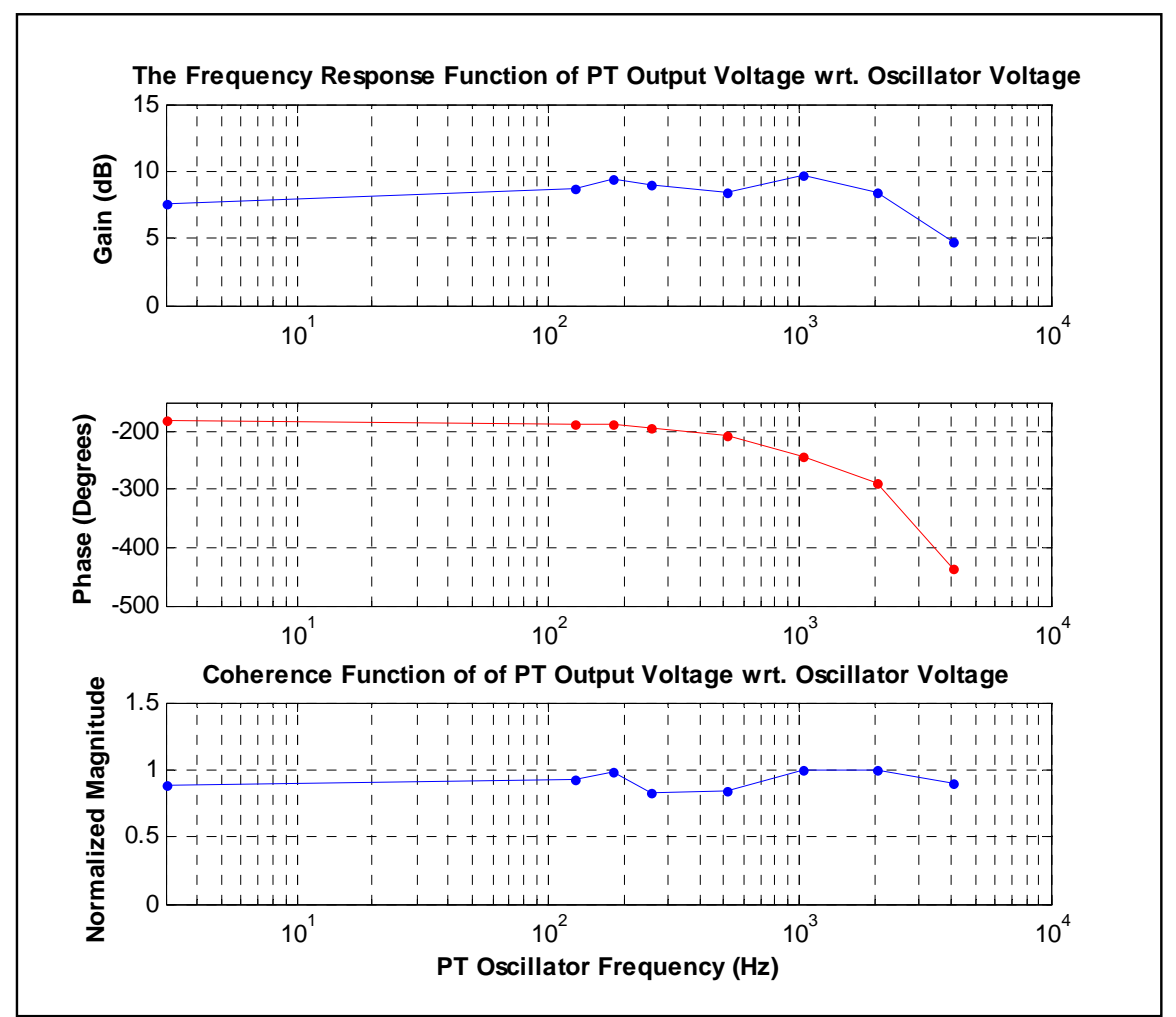

Figure 5.3. The Frequency Response Function of Plasma Torch Output Voltage 


\section{CHAPTER SIX}

\section{High Speed Images of the Oscillating Plasma Torch}

\subsection{Quiescent Environment High Speed Images}

The oscillating plasma jet at the individual frequencies given in Table 5.1 was optically recorded in a quiescent environment. The high speed imaging results are shown in Figure 6.1. The resolution of most of the high speed images recorded is $156 \mu \mathrm{m} /$ pixel at an image size of $128 \times 128$ pixel area. The high speed camera frame rate is 10,000 frames per second with at least 2 seconds of images recorded for later image processing. In order to obtain an estimate of the oscillation frequency of the plasma jet, the number of frames were counted between each successive oscillation and calculated with the following equation.

$$
\frac{\text { framerate }}{\# \text { frames }}=\frac{10,000 \mathrm{fr} / \mathrm{sec}}{39 \text { frames }} \approx 256 \mathrm{~Hz}
$$

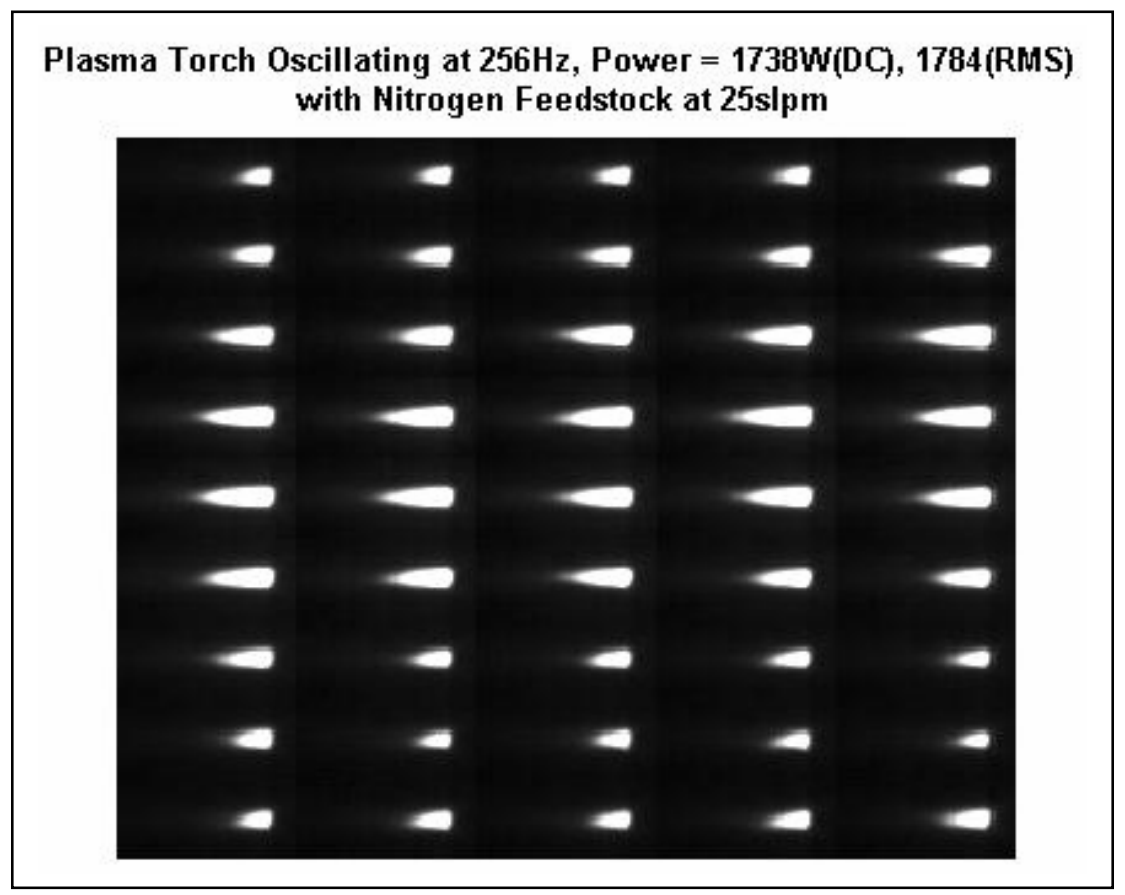

Figure 6.1. High Speed Images of Oscillating Plasma Jet

D. Sanders 


\section{Chapter 6. High Speed Images of Oscillating Plasma Torch}

\subsubsection{Area of Intensity Measurement Algorithm}

A method was developed by Ali Etebari to estimate the total pixel area of the brightest part of the plasma jet plume. The main tool used for analysis of the image data collected is the MATLAB 7.0 ${ }^{\circledR}$ Image Processing Toolbox. First, each recorded high speed video sequence is converted into individual grayscale intensity image (.tiff) files using the image software provided by the Vision Research ${ }^{\circledR}$. These grayscale intensity images have a scaled brightness level between 0 and 255, 0 being the darkest intensity level and 255 being the brightest intensity level. The algorithm makes an all black image of the same dimensions as the plasma torch original grayscale intensity image. Then it averages the grayscale intensity values in $3 \times 3$ pixel area portion of the plasma torch image. The algorithm moves the 3x3 pixel area box and averages the intensity throughout the whole torch image. If the intensity average is greater than the specified threshold of 89 , the center location of the $3 x 3$ box is set equal to 1 and is counted as a part of the plasma jet area. If not, the center location of the $3 \mathrm{x} 3$ box is set equal to 0 and is not counted as part of the plasma jet area. An illustration of this method is shown in Figure 6.2. The output image shown is a binary image with a total pixel area of 294.

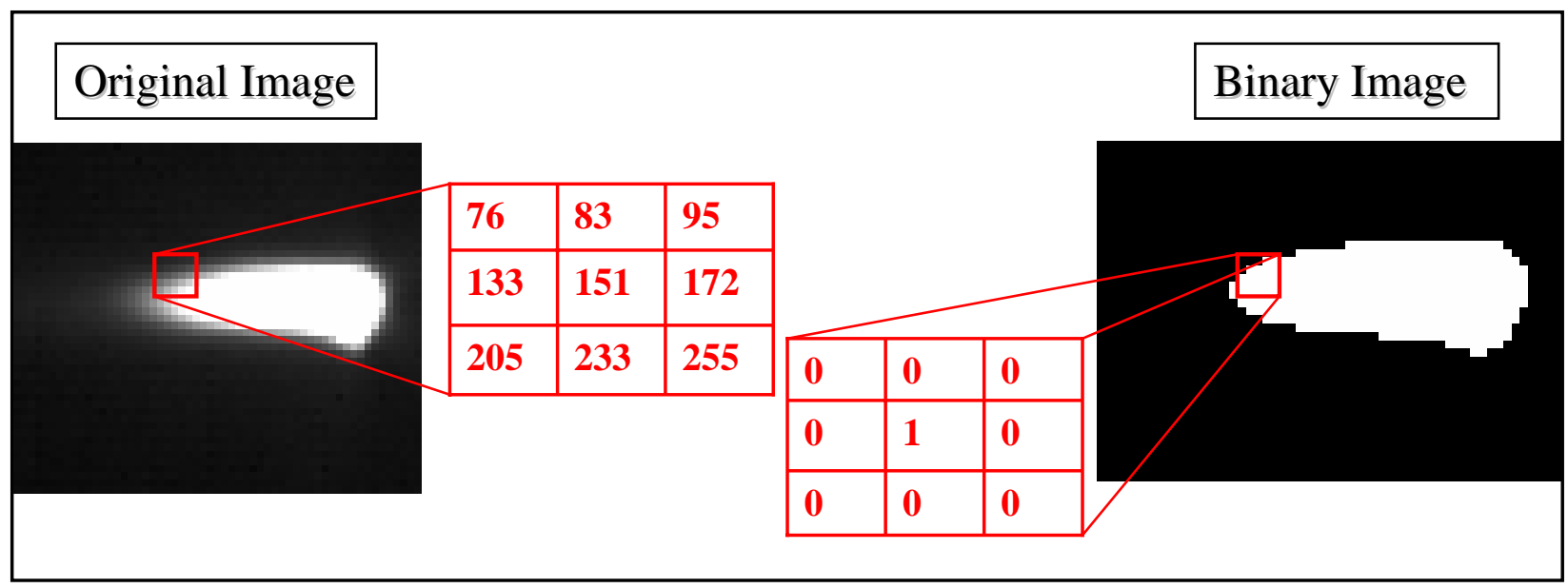

Figure 6.2. Illustration of Area of Intensity Algorithm 


\subsubsection{Response of the RMS Plasma Torch Brightness}

A time record of the modulated plasma jet plume area was generated to determine how the plasma jet area responds to the induced electrical oscillation. A typical area of intensity as a function of time measurement is shown Figure 6.3. The plasma torch RMS power is $1826.2 \mathrm{~W}$ with an RMS pixel area of 292.2. The plot indicates an oscillation is present in the area of the intensity measurements. Subsequently, the power spectral density is calculated and graphed versus frequency to measure the frequencies present in the area of intensity signal.

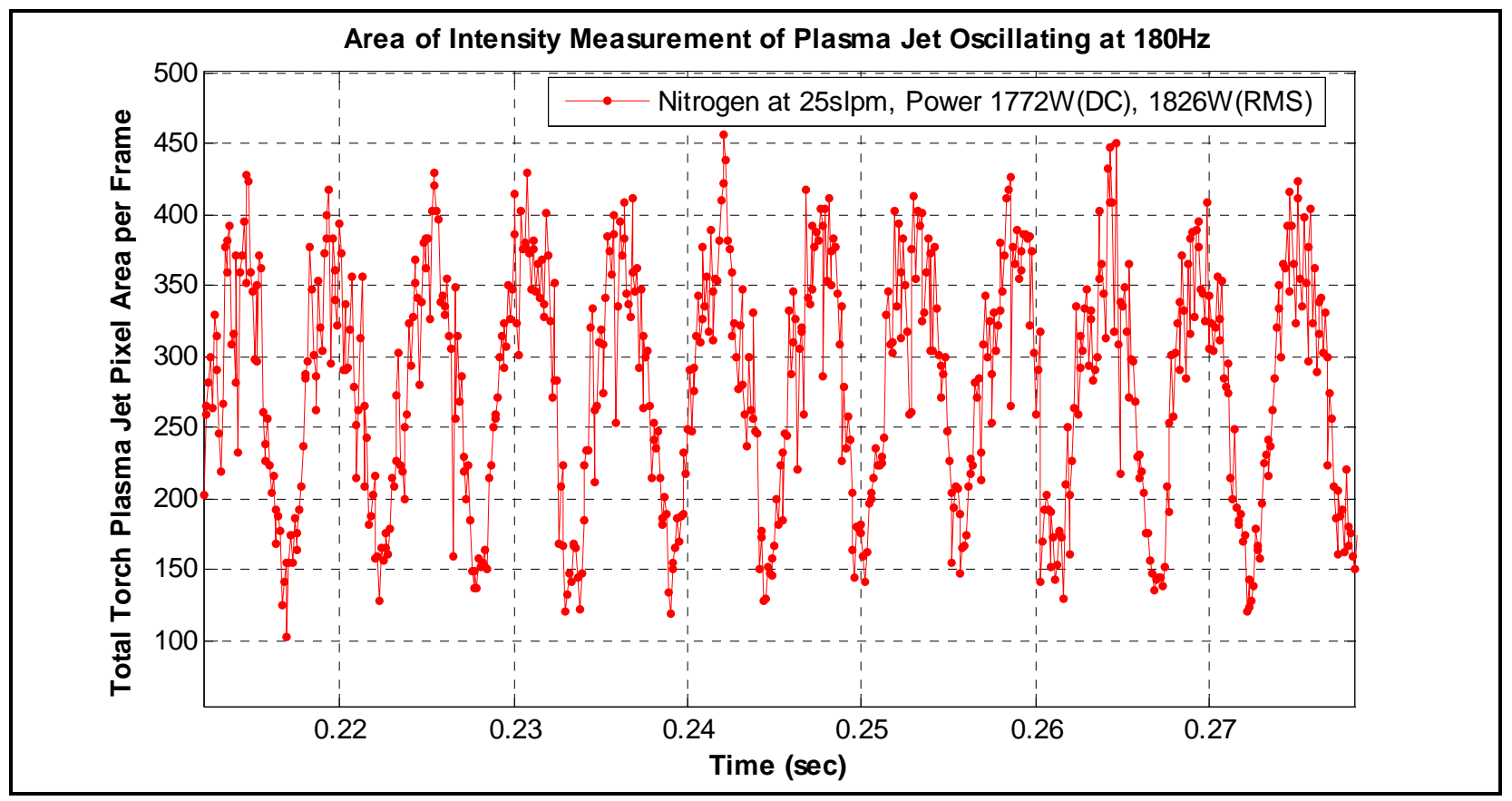

Figure 6.3. Time Record of Area of Intensity Measurement Oscillating Plasma Jet

The power spectral density (PSD) is used to describe the distribution of the energy contained in the signal over the sampled range of frequencies. A Welch Window with a $50 \%$ overlap was used to obtain a better estimate of the PSD. This method consists of dividing the data into eight segments with a 50\% overlap between them, and computing a modified PSD of each segment and then averaging the PSD estimates. The PSD (Figure 6.4) plot shows that the highest peak present is at $180 \mathrm{~Hz}$ and identifies higher order $180 \mathrm{~Hz}$ harmonics up to $540 \mathrm{~Hz}$. 
Chapter 6. High Speed Images of Oscillating Plasma Torch

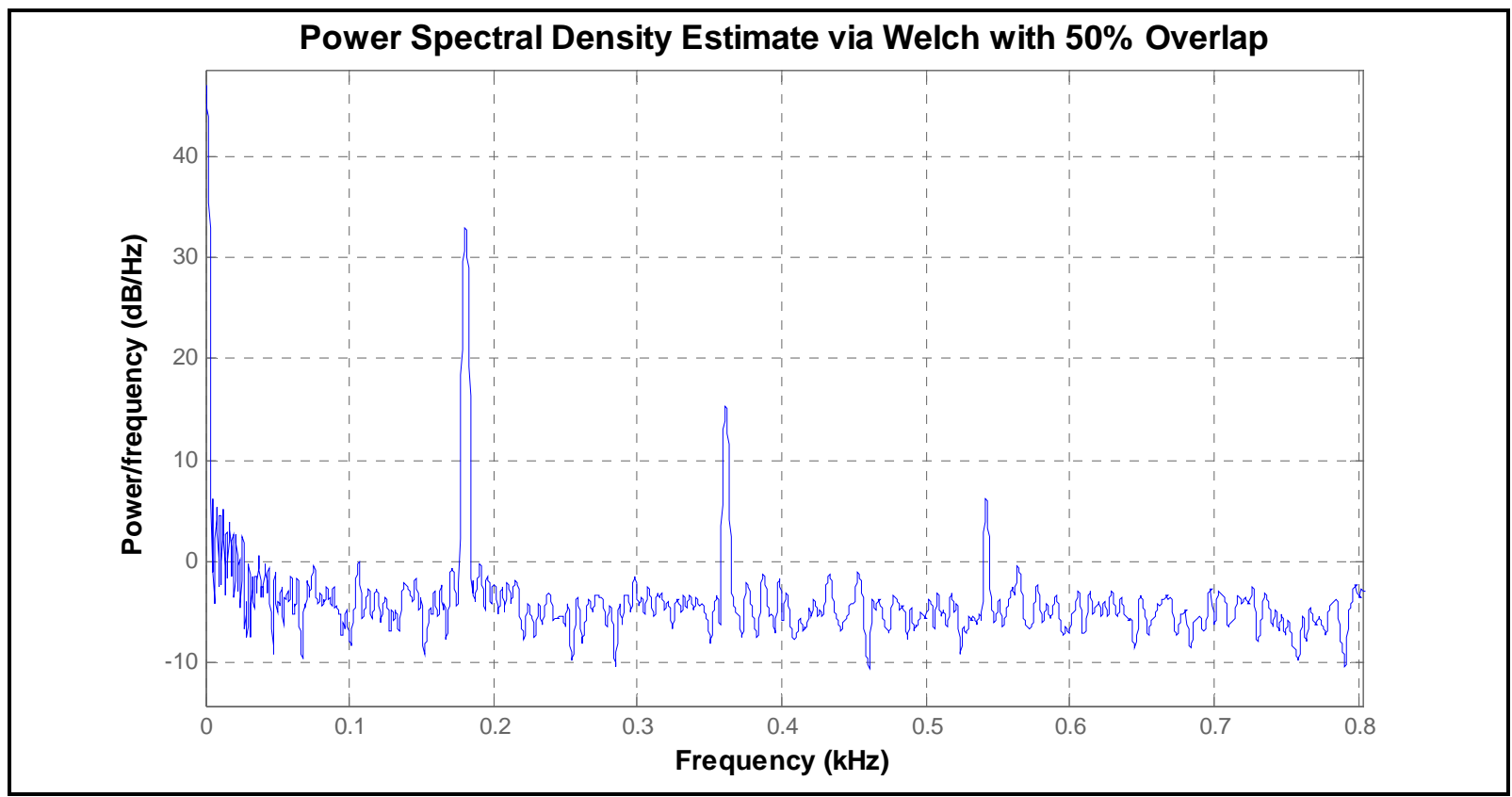

Figure 6.4. PSD Plot of Area of Intensity Measurement of Plasma Torch Oscillation of $180 \mathrm{~Hz}$

RMS pixel area values of the area of the intensity measurements was plotted verses the total RMS plasma torch power to determine if there was any relationship between the two. Figure 6.5 shows that the total pixel area increases linearly with torch power. The data shows that the greater amplitude modulation in the power, the larger the variation in the plasma jet pixel area. A similar frequency response calculation was done as in Section 5.3 with plasma jet total area of intensity as the assumed output and the plasma torch current and voltage as the assumed input. The results yielded no type of trend in the FRF for the assumed input and output as a function of plasma torch oscillation frequency. The calculated coherence values were all below 0.3, which indicate a random response to the torch oscillation frequency and assumed linear response model is not valid. 
Chapter 6. High Speed Images of Oscillating Plasma Torch

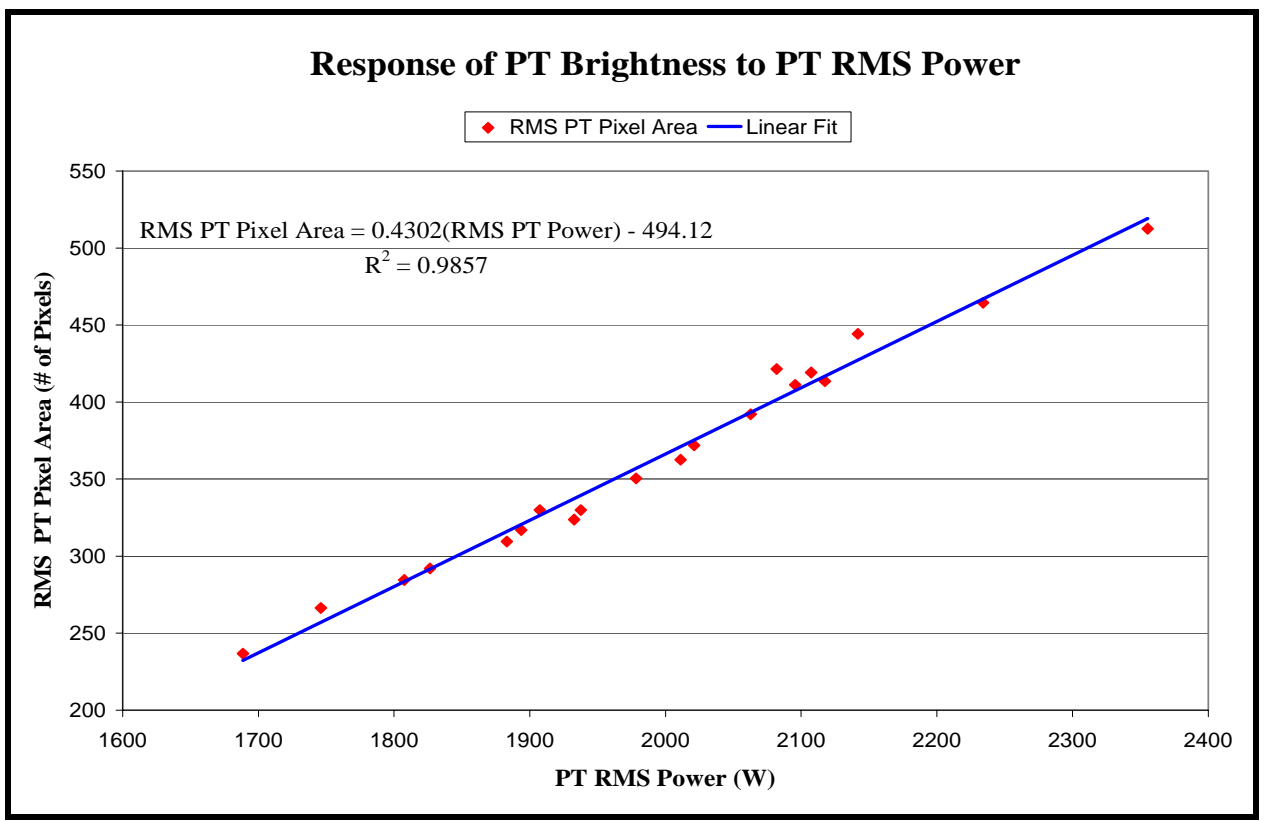

Figure 6.5. Graph of Response of RMS Plasma Torch Pixel Area vs. Plasma Torch RMS Power

\subsection{High Speed Schlieren Images}

High speed Schlieren images were obtained of the plasma torch oscillation in a Mach 2.4 crossflow. The plasma torch was oscillated at a frequency of $256 \mathrm{~Hz}$ with a RMS power of 2492W. Figure 6.6 shows the shock of interest caused by the plasma jet is as indicated. The location of the plasma jet is white circular region in the lower-center of the image. The other shocks present in the image are from surface imperfections from the tunnel floor plate and the

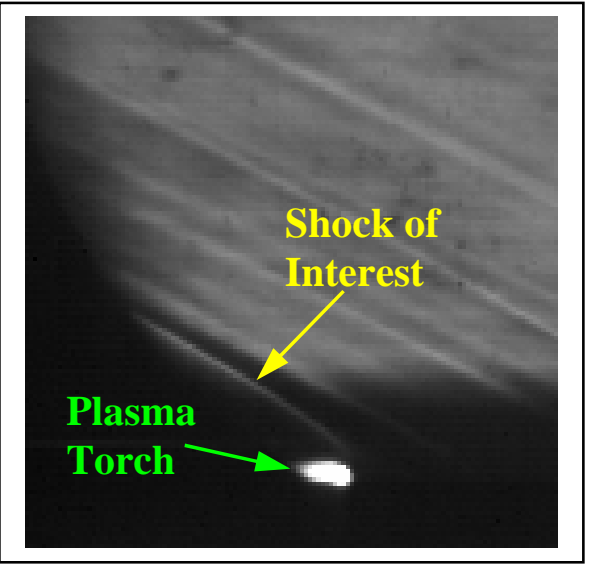

Figure 6.6. High speed Schlieren image of oscillating plasma torch indicating points of interest 


\section{Chapter 6. High Speed Images of Oscillating Plasma Torch}

plasma torch anode. Figure 6.7 shows 36 frames of plasma torch oscillation at a frame rate of 8000 frames per second. According to the images, there are approximately 31 to 33 frames in one plasma torch oscillation cycle corresponding to an oscillating plasma torch frequency range of $242-258 \mathrm{~Hz}$. Also, the shock produced by the plasma torch changes as the shape of the plasma jet plume changes. Therefore, the shock motion changes with the instantaneous torch power, as represented by the area of luminosity of the plume. The oscillating plasma torch thus causes an unsteady but controllable blockage in the flow. As noted before, this controllable unsteady blockage might provide a type shock interaction needed to increase turbulence and mixing augmentation [Kumar, et al. 1987].

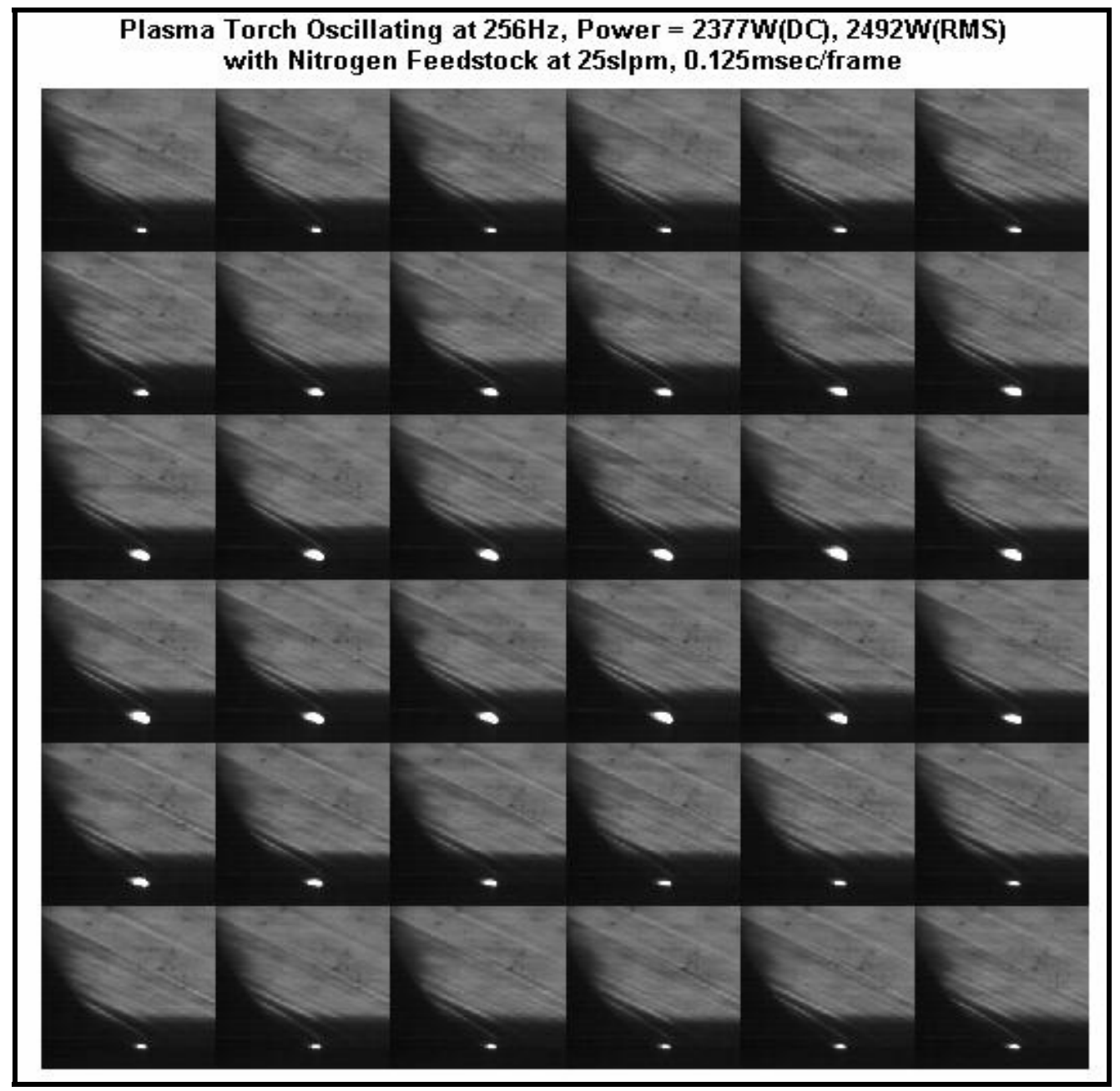

Figure 6.7. High speed Schlieren frame-by-frame display of plasma torch oscillation 


\section{Chapter 6. High Speed Images of Oscillating Plasma Torch}

\subsubsection{Image Analysis of Unsteady Shock Movement}

An image analysis method was developed to measure the unsteady shock movement associated with the torch oscillation. This process begins by cropping the Schlieren intensity images to a rectangular area where the plasma torch shock is located. Two points on a line segment of the PT shock are chosen, where the shock is assumed to be a straight line between these two points (Figure 6.8). Next, the horizontal intensity profile is obtained at each of these two points and the intensity gradient is calculated using a built-in numerical gradient function in Matlab $^{\circledR}$. Typical intensity and surface gradient profiles are shown in Figure 6.9.

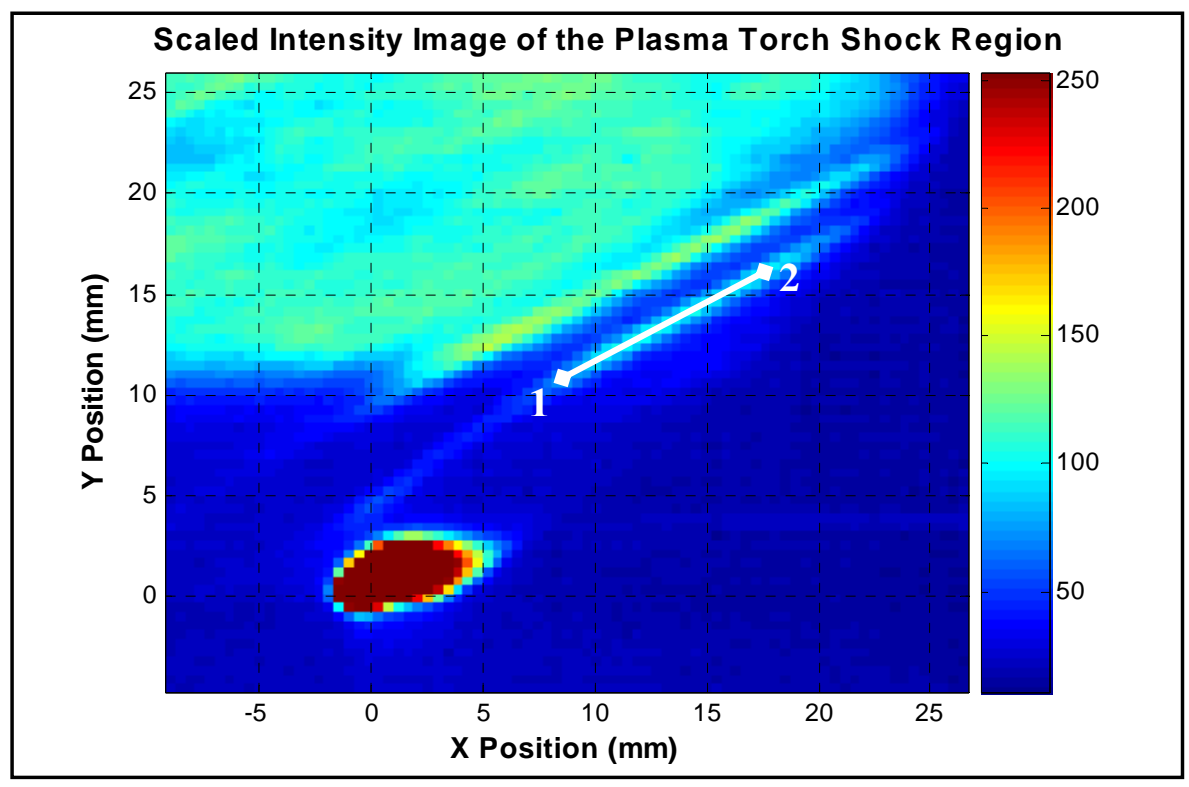

Figure 6.8. Scaled intensity image of plasma torch with chosen points of the PT shock line segment.

Performing this gradient operation on the chosen points allows for estimation of the shock location caused by the plasma torch. The peaks seen in the intensity profiles are caused by the large changes in the intensity due to the shock formation. The last strong peak in both profiles is caused by the flow blockage from the plasma torch. These peak intensities and their horizontal locations are found for each image using a relative maximum test within a predefined limit. This test compares the sign of the gradient to see if it changes from positive to negative. The starting 
and ending points of the relative maximum search algorithm are adjusted according to the location of the relative maximum in the previous image.

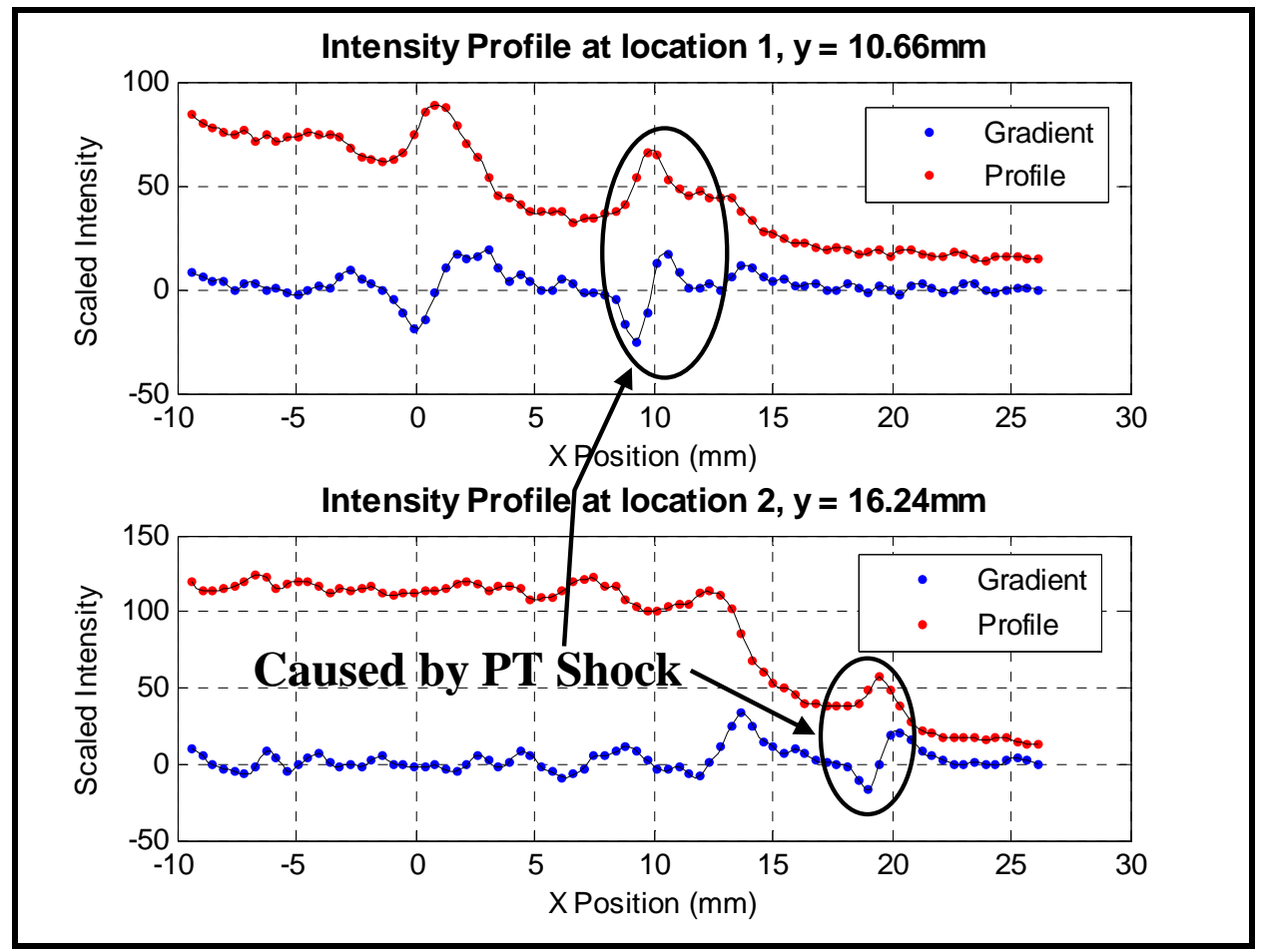

Figure 6.9. Interpolated horizontal intensity profile and surface gradient at the chosen PT shock locations.

\subsubsection{Shock Movement Results}

Success in locating the shock position using the above search algorithm was only achieved for a limited number of time-consecutive images. The plasma torch shock often moves into other shocks present in the images and the gradient test fails. To overcome this obstacle, the shock locations successfully found with the search algorithm were to be used to predict the shock locations at different times. An assumption is made that shock caused by the plasma torch will move to more upstream location as the plasma torch instantaneous power increases. The plasma torch causes additional flow blockage at higher power because the area of the plasma jet becomes larger. A mathematical relationship was obtained between the horizontal shock location and plasma torch instantaneous power. A linear fit test was done to obtain the equations to predict the shock movement. The result of this calculation is shown in Figure 6.10. The D. Sanders 


\section{Chapter 6. High Speed Images of Oscillating Plasma Torch}

equation used to predict the shock horizontal position at each shock location is shown on each plot with corresponding $R^{2}$ value. The $R^{2}$ value or coefficient of determination measures how successful the fit is in predicting the data and ranges from a value between 0 and 1 , with a value closer to 1 indicating a better fit. For shock locations 1 and 2 , the $R^{2}$ values were 0.45 and 0.39 , respectively. Though the $R^{2}$ values are below 50\%, the equations are considered adequate in predicting the horizontal location of the shock for two reasons. There is a significant amount of noise in the image because of the presence of other shocks in the image. Also, the plasma torch shock region is at more than one point along the intensity profile; the search algorithm only looks for the highest peak along that point.

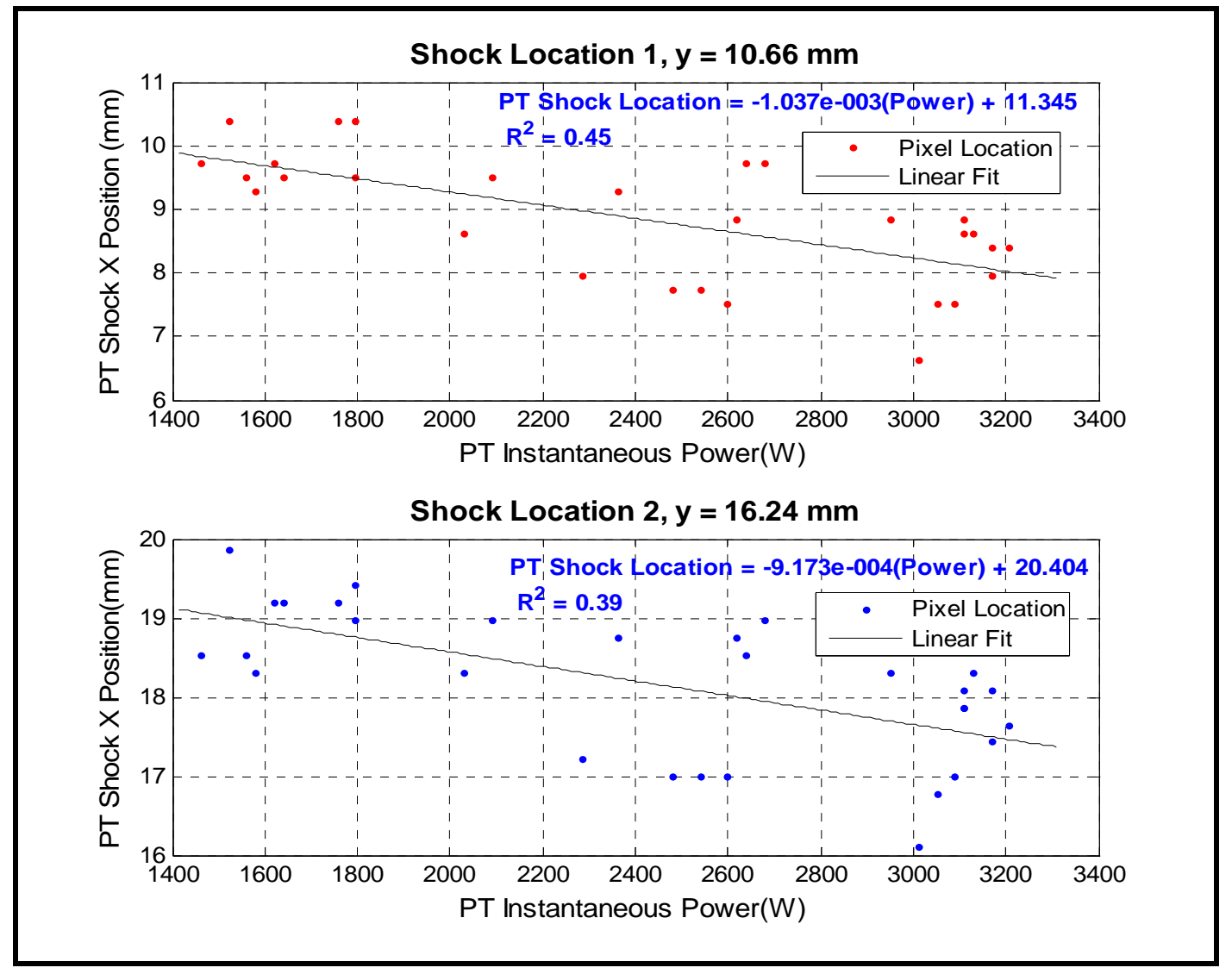

Figure 6.10. Graph of the PT horizontal shock position verses instantaneous power 


\section{Chapter 6. High Speed Images of Oscillating Plasma Torch}

\subsubsection{Plasma Torch Shock Animation}

An animation of the plasma torch with predicted shock movement was made to illustrate how the shock would move according to the prediction equations (Figure 6.11). Also, the shock angle was calculated and found to remain constant at about $31^{\circ}$ corresponding to an $8^{\circ}$ flow deflection angle for Mach 2.4 flow. Time records of the plasma torch instantaneous power and shock X position are also animated simultaneously with the predicted shock movement. The animation shows as the plasma torch power increases, the plasma jet plume increases in size, and the shock moves more upstream. Also, the animation illustrates that when the power decreases, the shock moves back to its original starting position. The position of the shock oscillates with the same frequency of $256 \mathrm{~Hz}$ as the plasma torch.

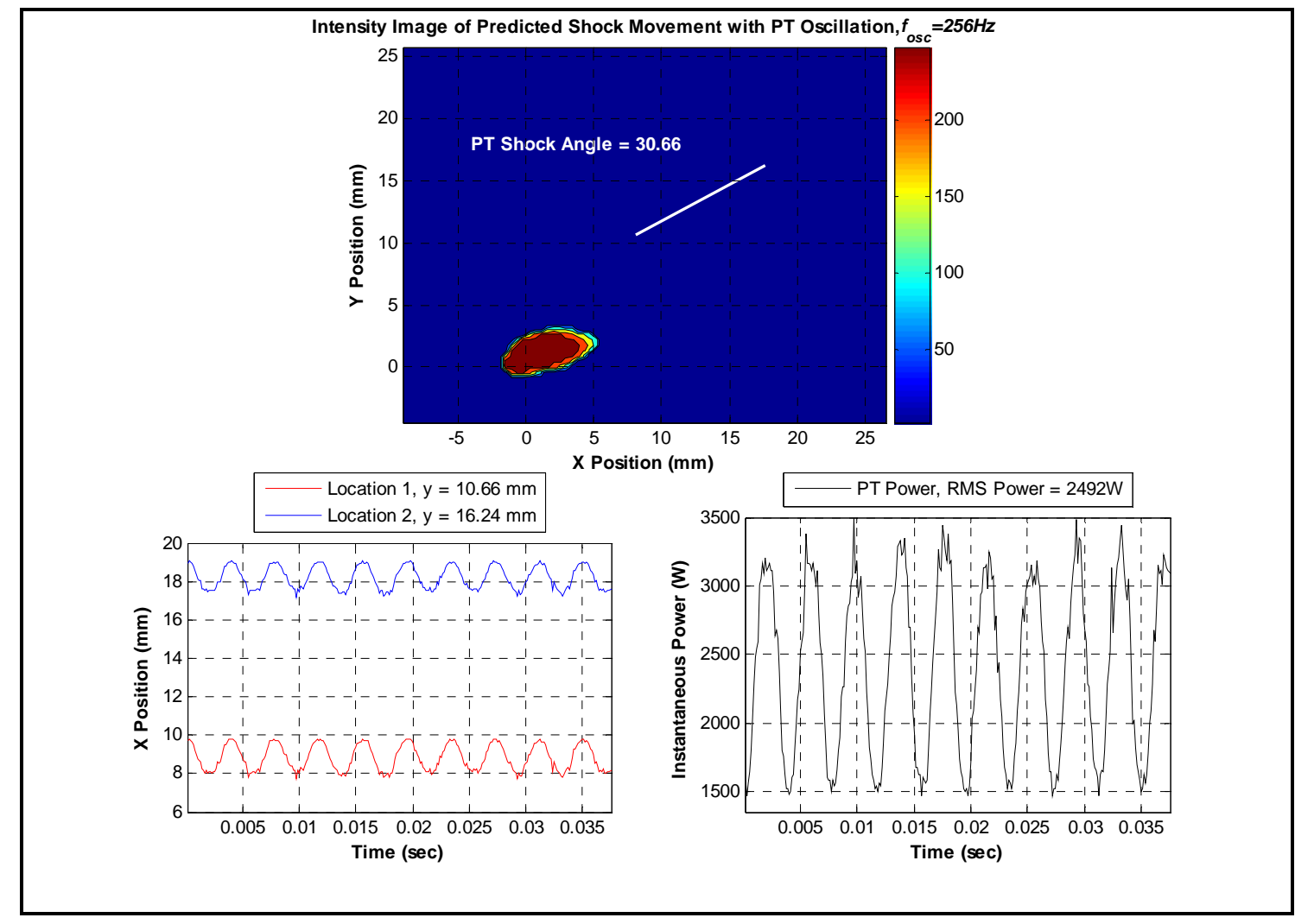

Figure 6.11. Animation of the plasma torch predicted shock motion (Click here to see animation). 


\section{CHAPTER SEVEN}

\section{Behavior at Supersonic Combustion Conditions (performed in the University of Virginia ARL)}

\subsection{Combustion Effects Due to Oscillating Plasma Torch}

The oscillating torch used in these series of tests is utilized as both an igniter and flameholder. It will both ignite and sustain hydrogen and hydrocarbon combustion. Testing conditions were as outlined in Section 4.3. Measurements of the unsteady pressure from the oscillating shock were made. Also, wall pressure profiles were taken to assess the effect the oscillating plasma torch had on the combustion process. The results and test conditions from each of these experiments are discussed in the following sections.

\subsubsection{Unsteady Pressure Measurements with Hydrogen Fuel}

At a global equivalence ratio $(\varphi)$ of 0.252 , a response of the Kulite pressure transducers to the torch oscillation was successfully measured. Hydrogen fuel was used in the aeroramp injector with the modified industrial plasma torch operating with nitrogen feedstock. The plasma torch was placed at "Station 2" or $8 \mathrm{~d}_{\mathrm{eq}}$ downstream of the aeroramp injector center and operated at power ranges between 4-6kW. Typical electrical waveforms of the modified industrial plasma torch are shown in Figure 7.1. The industrial torch has an operating voltage of 90-110V because of the fixed electric arc gap. This operating voltage is higher when compared to the VTPT-3 with operating voltages between $40-60 \mathrm{~V}$. The plasma torch was modulated at a frequency of $2 \mathrm{~Hz}$ and was operated at a total RMS power of 5641W. 


\section{Chapter 7. Behavior at Supersonic Combustion Conditions}

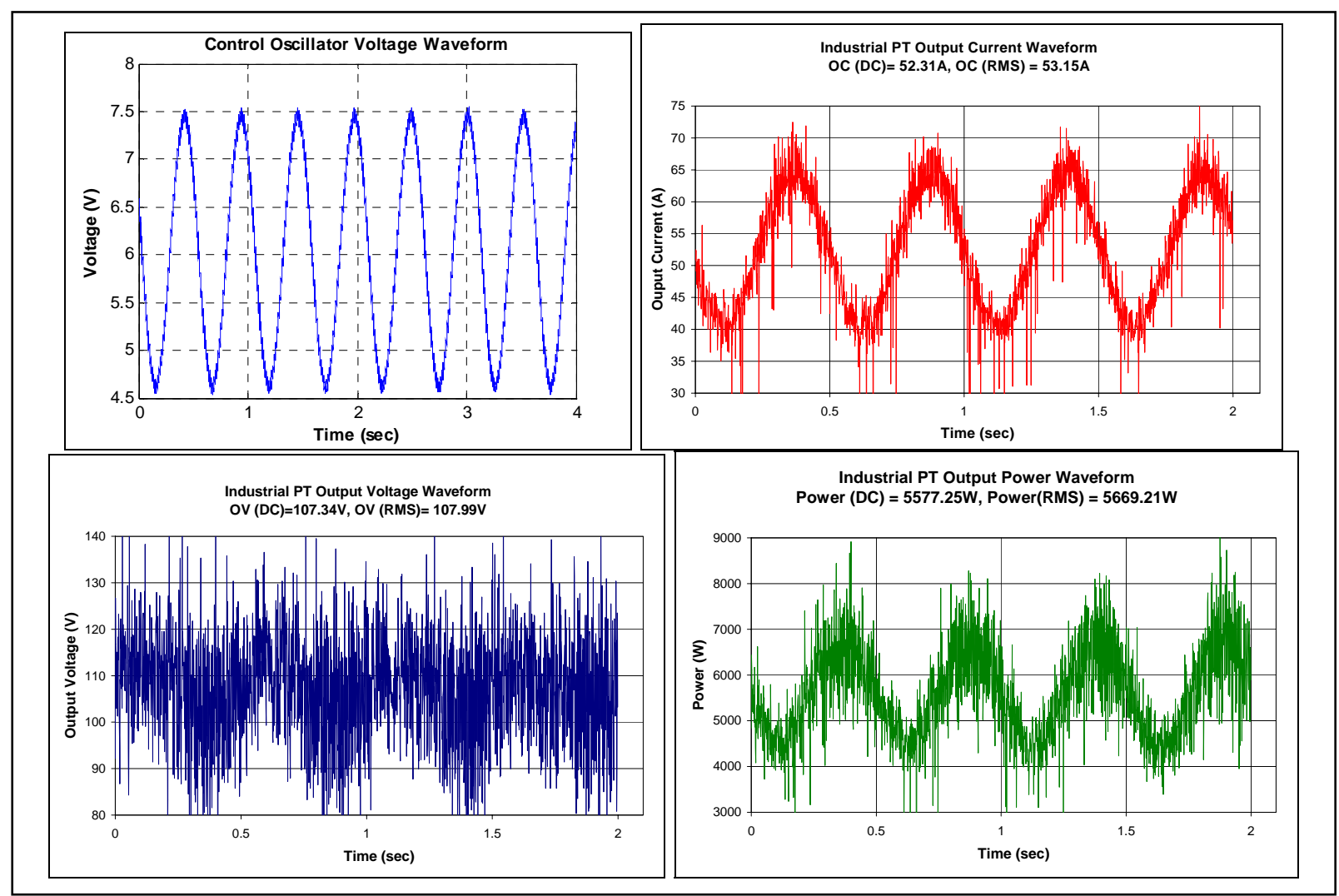

Figure 7.1. Modified Industrial Plasma Torch Electrical Waveforms Oscillating at $2 \mathrm{~Hz}$

The response of the Kulites is shown in the Figure 7.2 as K1, K2, and K3 with K1 being the most upstream pressure sensor, located in the isolator section of the tunnel (see section 3.2.3) All pressures are non-dimensionalized to the tunnel nozzle exit static pressure of $42 \mathrm{kPa}$. The plot indicates that K2 and K3 are responding to the unsteady pressure variation caused by the oscillating plasma torch, while K1 showed no response. To verify that the Kulites are responding to same modulation frequency as the plasma torch, a DFT calculation was performed for all three time signatures to determine the frequency content in each signal. The plot in Figure 7.3 indicates that the dominant frequency of $\mathrm{K} 2$ and $\mathrm{K} 3$ is the same as the plasma torch oscillation frequency, while K1 shows no response. This is also verified visually with digital video images taken of the oscillating plasma torch running in the tunnel (Figure 7.4). The video 


\section{Chapter 7. Behavior at Supersonic Combustion Conditions}

images show the combustion flame at the nozzle discharge exit is being influenced by the torch oscillation.

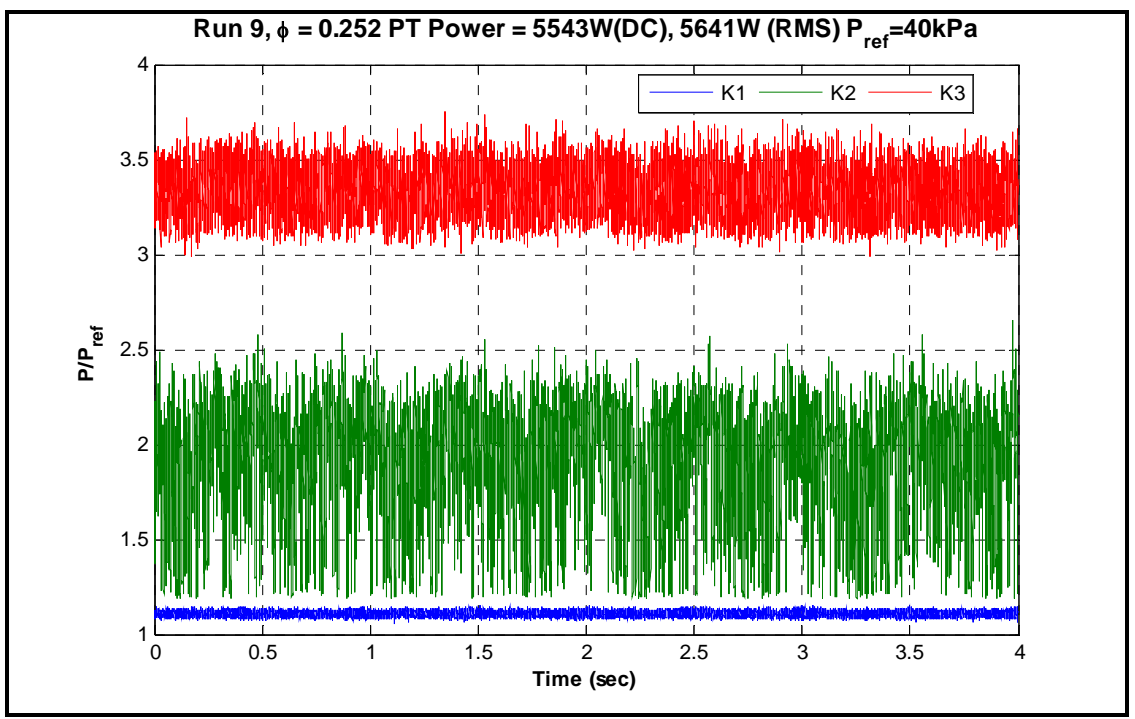

Figure 7.2. Kulite Pressure Response to Oscillating Plasma Torch

Therefore, it is concluded that the oscillating torch caused an unsteady pressure variation in the supersonic flow. This unsteady pressure variation was caused by the plasma torch creating an oscillating shock. Thus, the plasma torch demonstrated the ability to influence the combustion process.
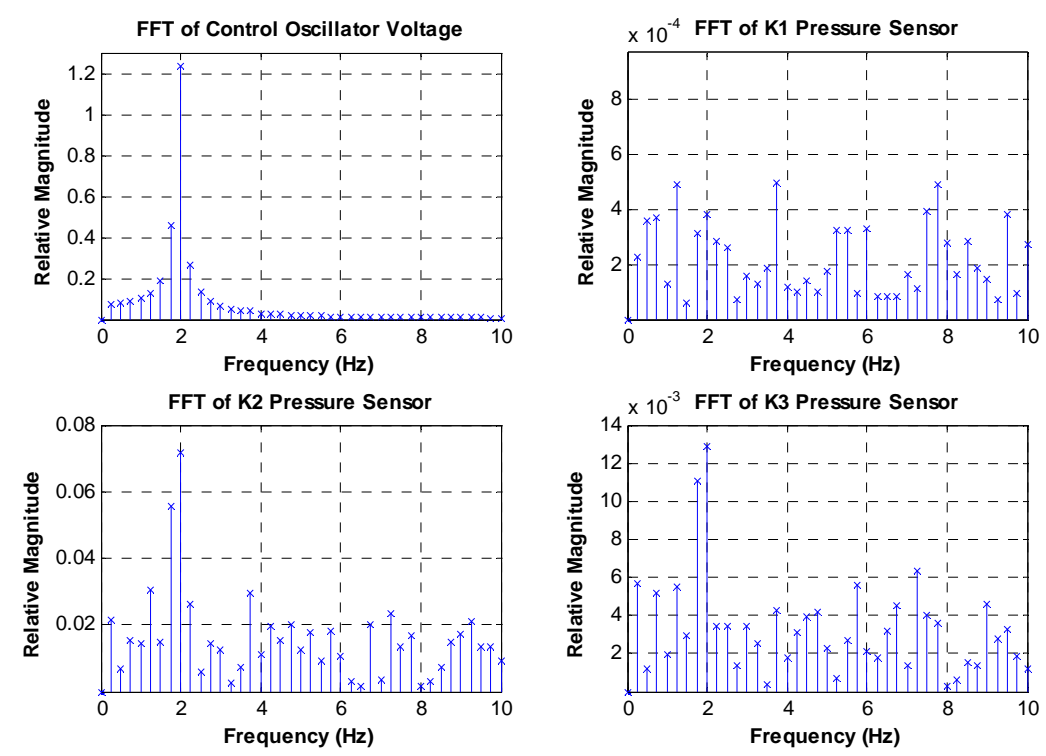

Figure 7.3. DFT Calculations of Kulite Pressure Measurements

D. Sanders

An Investigation of Controlled Oscillations in a

Plasma Torch for Combustion Enhancement 


\section{Chapter 7. Behavior at Supersonic Combustion Conditions}

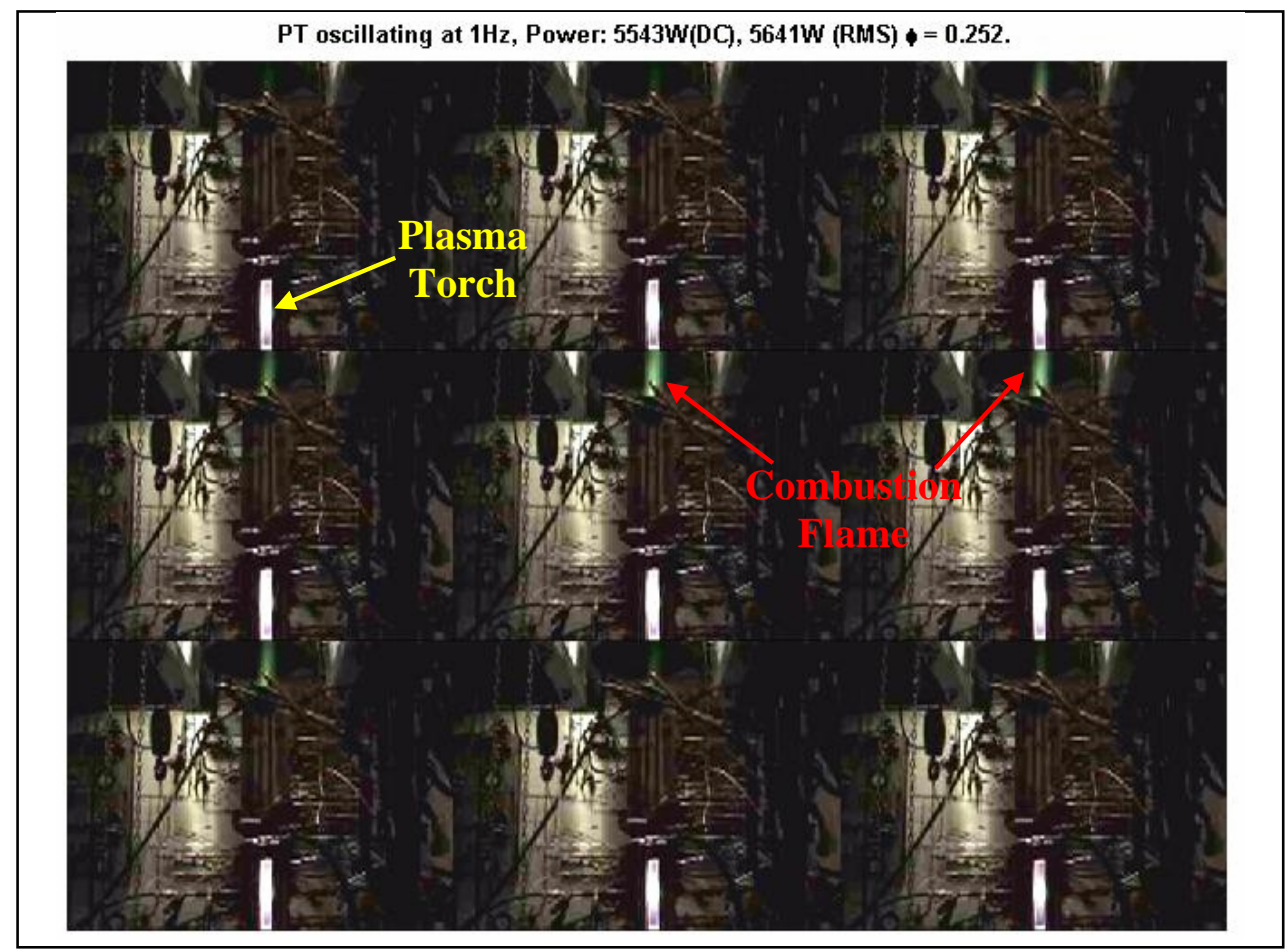

Figure 7.4. Video Images Oscillating Plasma Torch Running in Mach 2 Heated Wind Tunnel

\subsubsection{Combustor Pressure Profiles with Ethylene Fuel}

Wall static pressure measurements were obtained during testing with hydrocarbon (ethylene) fuel injection. There are 32 pressure taps located on the wall opposite of the injector, from the nozzle inlet to the exit of the duct. A Setra ${ }^{\mathrm{TM}}$ pressure transducer and a scanning Scanivalue $^{\circledR}$ were used to measure and record the pressure values. The pressure profiles obtained were used to compare combustion with an oscillating plasma torch versus a plasma torch operating with DC power. Ethylene fuel was used with an air-fed plasma torch. The plasma torch was located at "station 3" or $10 \mathrm{~d}_{\mathrm{eq}}$ downstream of the injector center. Figure 7.5 shows the pressure profiles along the length of the tunnel. The pressures and lengths are nondimensionalized with tunnel exit static pressure of $42 \mathrm{kPa}$ and the equivalent jet diameter, $\mathrm{d}_{\mathrm{eq}}$, respectively.

Air as a feedstock gas was used with ethylene combustion to enhance the ignition capability of the plasma torch. With the use of air as a feedstock, the oxygen from the air erodes D. Sanders 


\section{Chapter 7. Behavior at Supersonic Combustion Conditions}

the anode at much faster rate than nitrogen. The pressure profiles in Figure 7.5 indicate that for the DC powered plasma torch, subsonic combustion is achieved because the pressure is higher in the combustor section; the flow is now choked and pressure rise is sensed upstream.

Unfortunately, at the time of the oscillating torch teats, dynamic pressure transducers were not available at any of the 32 wall tap locations. The wall taps were connected to the low frequency transducers by long tubes, and the system was suitable only for steady state measurements. If is assumed that the pressure measurement system would correctly average the mean value of an oscillating pressure input, then at least the mean pressure measurements should be correct with a dynamic pressure input. Because of test limitations at the time, it was only possible to monitor a single location, pressure tap number 5.

With the sparse measurements available, the only recording of the effect of the oscillating plasma torch was the mean pressure at pressure tap number 5. In addition, visual (not recorded) monitoring of the chamber flame was possible, and the sound of the flame was evident, but not recorded. For a frequency range from dc to $100 \mathrm{~Hz}$, the combustion chamber flame was visually observed to oscillate at a frequency estimated to be the torch frequency. For a frequency range of dc to $3000 \mathrm{~Hz}$, the sound of the oscillating combustion could be heard, again at a frequency estimated to be that of the torch. The steady measurement of pressure at the tap location number 5 was not observed to change, indicating that the mean combustion pressures were steady over the entire range of torch frequencies (see Table 7.1). From the visual and auditory observations, it was clear that the combustion was influenced by, and responded to the unsteady torch. Since the measurement at tap 5 was the same as that for the steady torch, it may be assumed that the time-averaged combustion was the same as for the steady torch. 


\section{Chapter 7. Behavior at Supersonic Combustion Conditions}

It is unfortunate that dynamic instrumentation was not available for the reported oscillating torch tests with air feedstock and ethylene aeroramp fuel injection. However, the observations verify that a response did occur, and support a recommendation for additional investigation.

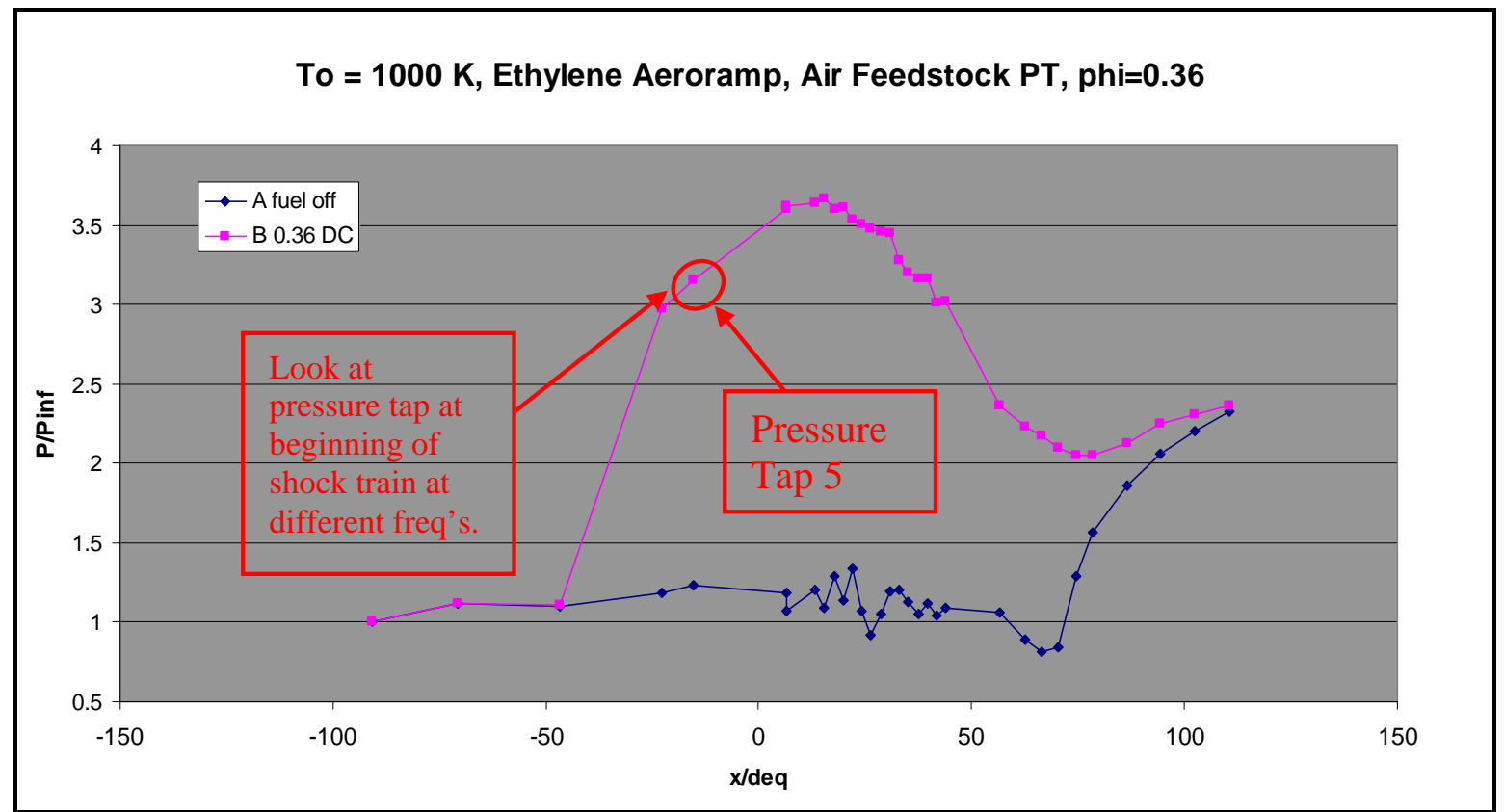

Figure 7.5. Ethylene fuel static pressure measurements with DC air plasma torch

\begin{tabular}{|c||c|}
\hline $\begin{array}{c}\text { PT Oscillation } \\
\text { Frequency (Hz) }\end{array}$ & $\begin{array}{c}\text { Static Pressure Ratio } \\
\left.\text { (P/P } \mathbf{P}_{\text {inf }}\right) \\
\text { at pressure tap 5 }\end{array}$ \\
\hline \hline DC & 3.21 \\
\hline 10 & 3.21 \\
\hline 50 & 3.19 \\
\hline 100 & 3.19 \\
\hline 250 & 3.19 \\
\hline 500 & 3.19 \\
\hline 750 & 3.19 \\
\hline 1000 & 3.21 \\
\hline 1500 & 3.19 \\
\hline \hline 3000 & 3.19 \\
\hline
\end{tabular}

Table 7.1. Static pressure ratio measurements near the beginning of shock train 


\section{CHAPTER EIGHT}

\section{Plasma Torch Electric Arc Model}

This chapter describes the development of a plasma torch electric arc model. A brief review of mathematical models for electric arcs is discussed. Detailed descriptions of the components that make up the plasma torch arc model are presented along with the simulation procedure. The plasma torch electric arc model is then compared to the experimental response of the plasma torch. Also, the model predicts the plasma torch response at high frequencies for the interaction of supersonic combustion.

\subsection{Electric Arc Models from Previous Studies}

Since the electric arc does not have a constant resistance with changing current, complex mathematical models must be used to predict current-voltage behavior. These models employ partial differential equations that are not easily solved. So, simplified electric arc models have been developed for use with engineering calculations. These models treat the arc as a circuit element, and use approximations to describe the resistance behavior found in the electric arc. Descriptions of four types of simplified mathematical models for the electric arc are discussed in the following sections.

\subsubsection{Nottingham Model}

An arc model by Nottingham [Cobine '41] discovered that an atmospheric arc of constant length can be represented by the equation

$$
v=A+\frac{B}{i^{n}}
$$




\section{Chapter 8. Plasma Torch Electric Arc Model}

for a great number of electrode materials, where $v$ is the arc voltage and $i$ is the arc current. The exponent $n$ is linearly dependent upon the absolute boiling temperature $T$ of the anode by the equation

$$
n=2.62 \times 10^{-4} T
$$

However, the boiling temperature cannot be accurately determined because boiling temperature depends on the gas the arc burns and its pressure.

\subsubsection{The Mayr Model}

O. Mayr based a model on simplified physics of the arc column of a fixed cross sectional area only losing heat through radial thermal conduction [Browne 1984]. The conductance of the arc, $G$, is varied as the energy stored in it. The Mayr equation is

$$
\frac{1}{R} \frac{d R}{d t}=\frac{1}{\theta}\left(1-\frac{v i}{P_{0}}\right)
$$

where $R$, is the arc resistance and $P_{0}$ is the constant power loss or the lowest steady state operating power. In steady-state conditions, when voltage and current is changing very slowly, $P_{0}=i v$. The arc time constant, $\theta$, is the energy stored per unit volume divided by the energy loss per unit volume. This model is a good representation for low current arcs because it assumes the arc is maintaining a constant power requirement [Tseng et al. 1997].

\subsubsection{The Cassie Model}

A. M. Cassie based his model on the arc that has a constant current density and fixed temperature, so the cross-sectional area varies with the current. This assumption is valid at high currents where the conductivity and power loss per unit volume is constant. The Cassie equation is given by 


\section{Chapter 8. Plasma Torch Electric Arc Model}

$$
\frac{1}{R} \frac{d R}{d t}=\frac{1}{\theta}\left(1-\frac{v^{2}}{E_{0}^{2}}\right)
$$

where $\mathrm{E}_{0}$ is the constant steady state arc voltage. This equation describes the behavior of the arc when the current is large.

\subsubsection{The Hybrid Mayr- Cassie Model}

An electric arc model was developed by Tseng et al. [1997] for use in commercial electrical circuit design. It combines the Mayr and Cassie Models for electric arcs for dynamic simulation purposes. The model relates the electric arc voltage, $v$, and current, $i$, to the arc conductance, $G$, with the equation

$$
i=G v
$$

where $G$ is described as

$$
G=G_{\min }+\underbrace{\left[1-\exp \left(\frac{-i^{2}}{I_{0}^{2}}\right)\right] \frac{v i}{E_{0}^{2}}}_{\text {Cassie Equation }}+\underbrace{\left[\exp \left(\frac{-i^{2}}{I_{0}^{2}}\right)\right] \frac{i^{2}}{P_{0}}}_{\text {Mayr Equation }}-\theta \frac{d G}{d t}
$$

and $\theta$ is described with the equation

$$
\theta=\theta_{0}+\theta_{1} \exp (-\alpha|i|)
$$

The Mayr part of the equation simulates low current arcs and the Cassie part of the equation simulates high current arcs. $G_{\min }$ is the minimum arc conductance and is dictated by the electric arc striking voltage. $I_{0}$ is the transition current that depends on the current value at which the arc will behave in high current or low current mode. The arc damping function, $\theta$, affects the transient arc voltage behavior, where $\alpha$ is set equal to the transition current, $I_{0}$. Then $\theta_{0}$ and $\theta_{1}$, the calibration constants, and are iteratively adjusted until the simulated waveform matches the experimental results. 


\section{Chapter 8. Plasma Torch Electric Arc Model}

\subsection{Plasma Torch Electric Arc Model Development}

Since the oscillating plasma torch power system has a limited frequency response range, a model was developed to predict the plasma torch response at higher frequencies for the interaction of supersonic combustion. The model attempts to duplicate the true electrical characteristics of the oscillating plasma torch system. The components of the power system that are mathematically modeled are the welder power supply, function generator, the plasma torch electric arc, and the losses associated with the plasma torch power supply circuit. The hybrid Mayr-Cassie mathematical model for the electric arc will be used to model the electric arc in the plasma torch.

\subsubsection{Welder Power Supply Model}

The welder power supply model is based on the electrical characteristics of the experimental response data discussed in Section 5.3.1. The welder is modeled as DC amplifier with a corner frequency of $1 \mathrm{kHz}$. The transfer function that represents this behavior is the equation

$$
I(s)=\frac{a_{0}}{1+\frac{s}{\omega_{0}}}
$$

where $\omega_{0}$ is the corner frequency in radians and $a_{0}$ is the DC gain of $8.8 \mathrm{~V}$. The welder in the model will be assumed as a constant current source where the current level, I(s), is controlled by the function generator. The function generator is modeled using a built-in signal generator simulation block with the appropriate multipliers to simulate the actual set point values of the G5100 function generator. 


\section{Chapter 8. Plasma Torch Electric Arc Model}

\subsubsection{Circuit Loss Model}

The losses in the plasma torch power supply circuit are modeled as a series RLC circuit (Figure 8.1). The inherent resistance in the welder power supply is calculated with the equation

$$
R_{\mathrm{int}}=\frac{V_{O C}}{I_{S C}}
$$

where $\mathrm{V}_{\mathrm{OC}}$ is the open circuit voltage of $240 \mathrm{~V}$ and $\mathrm{I}_{\mathrm{SC}}$ is the short circuit current of $80 \mathrm{~A}$. The circuit inductance is assumed to originate from the 8 AWG wire used to make the electrical connections. The capacitance of the circuit originates from electrodes and space charge effects of the electric arc. The inductance and capacitance value is measured as $\mathrm{L}=29.3 \mu \mathrm{H}$ and $\mathrm{C}=$ $10.4 \mu \mathrm{F}$, respectively. Kirchov's Voltage Law (KVL) is used to mathematically integrate all the circuit models together using the equation

$$
V_{\text {welder }}=V_{R_{\text {int }}}+V_{\text {ARC }}+V_{L}+V_{C}
$$

written in terms of the instantaneous current, $i$,

$$
V_{\text {welder }}=i R_{\mathrm{int}}+\frac{i}{G}+L \frac{d i}{d t}+\frac{1}{C} \int i d t
$$

where the hybrid Mayr- Cassie electrical arc equation is written in the form

$$
\frac{d G}{d t}=\frac{1}{\theta}\left(G_{\min }+\left[1-\exp \left(-\frac{i^{2}}{I_{0}^{2}}\right)\right] \frac{i^{2}}{G E_{0}}+\left[\exp \left(-\frac{i^{2}}{I_{0}^{2}}\right)\right] \frac{i^{2}}{P_{0}^{2}}-G\right)
$$


Chapter 8. Plasma Torch Electric Arc Model

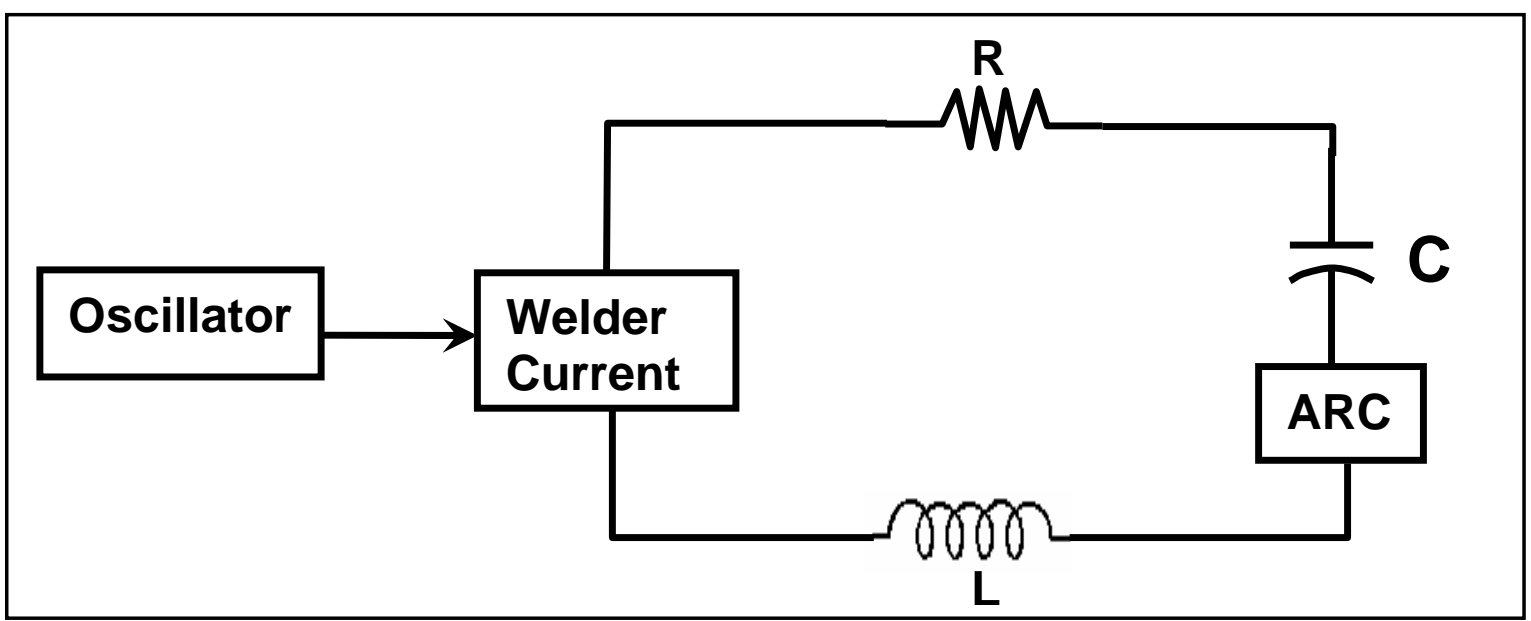

Figure 8.1. Plasma Torch Power Supply Circuit

\subsubsection{Simulation Model and Procedure}

The equations are dynamically solved using Matlab’s Simulink ${ }^{\circledR}$ (Figure 8.2), where each component equation is modeled with sub-simulation block with labeled input and output variables. The model parameters are defined using a Matlab program. The model is then tested for the ability to simulate the electrical waveforms produced by the plasma torch power system. The constant input parameters of each simulation are shown in Table 8.1. The variable parameters are based on the measured operating conditions of the plasma torch.

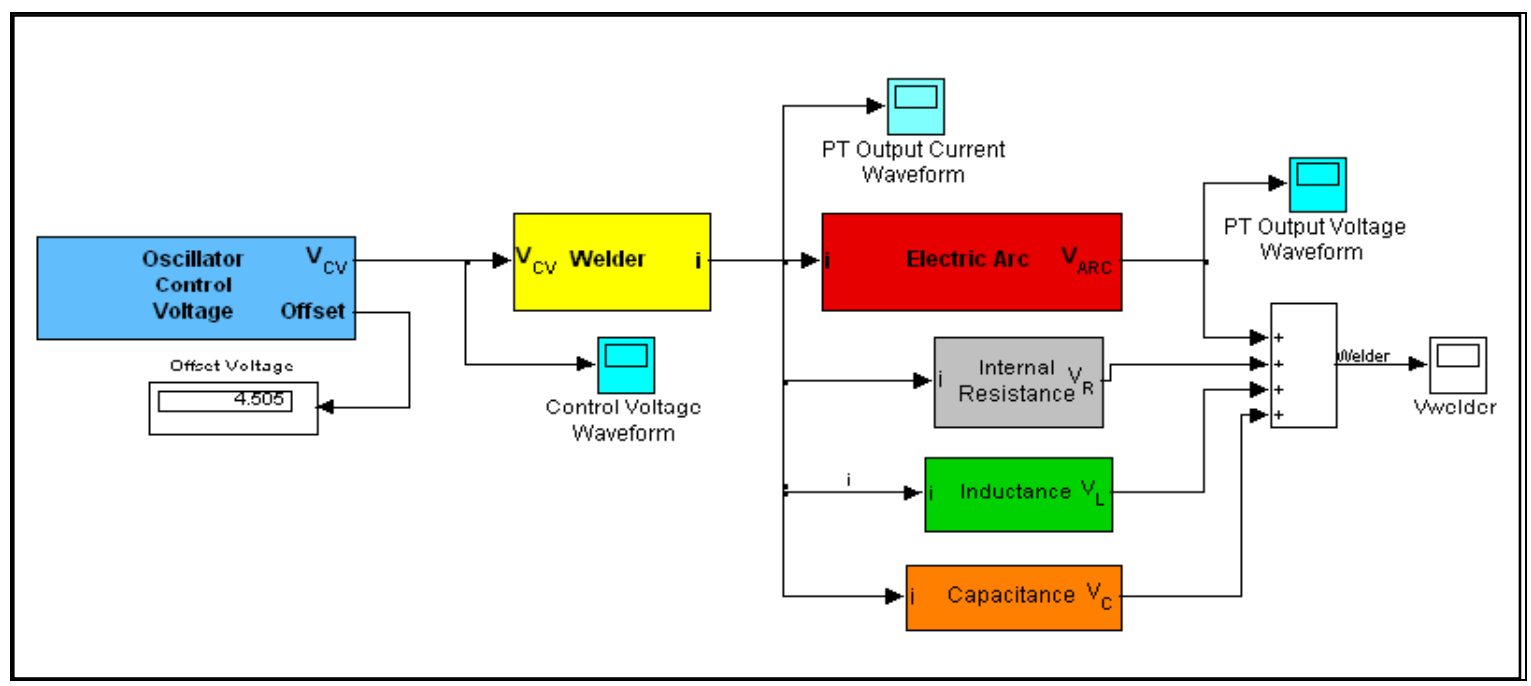

Figure 8.2. Simulink® Model of the Plasma Torch Power Supply System 


\section{Chapter 8. Plasma Torch Electric Arc Model}

\begin{tabular}{|c|c|}
\hline $\begin{array}{c}\text { Simulation } \\
\text { Parameters }\end{array}$ & Value \\
\hline $\mathrm{G}_{\min }$ & $4 \times 10^{-2}$ \\
\hline $\mathrm{I}_{0}$ & 50 \\
\hline$\alpha$ & 50 \\
\hline$\theta_{0}$ & $1 \times 10^{-5}$ \\
\hline$\theta_{1}$ & 100 \\
\hline $\mathrm{R}_{\text {int }}$ & $3 \Omega$ \\
\hline $\mathrm{L}$ & $29.3 \mu \mathrm{H}$ \\
\hline $\mathrm{C}$ & $10.4 \mu \mathrm{F}$ \\
\hline
\end{tabular}

Table 8.1. Simulation parameter inputs for plasma torch electric arc model

The electrical waveform results of the plasma torch power are shown Figure 8.3. The frequency, amplitude, and DC offset of the simulated signal generator were set to the same experimental input set points as the function generator. Model variables $E_{0}$ and $P_{0}$ are set to the measured DC plasma torch output voltage and total power, respectively. The simulated plasma torch electrical waveform results are good agreement with the electrical waveforms measured experimentally shown in Figure 5.1.
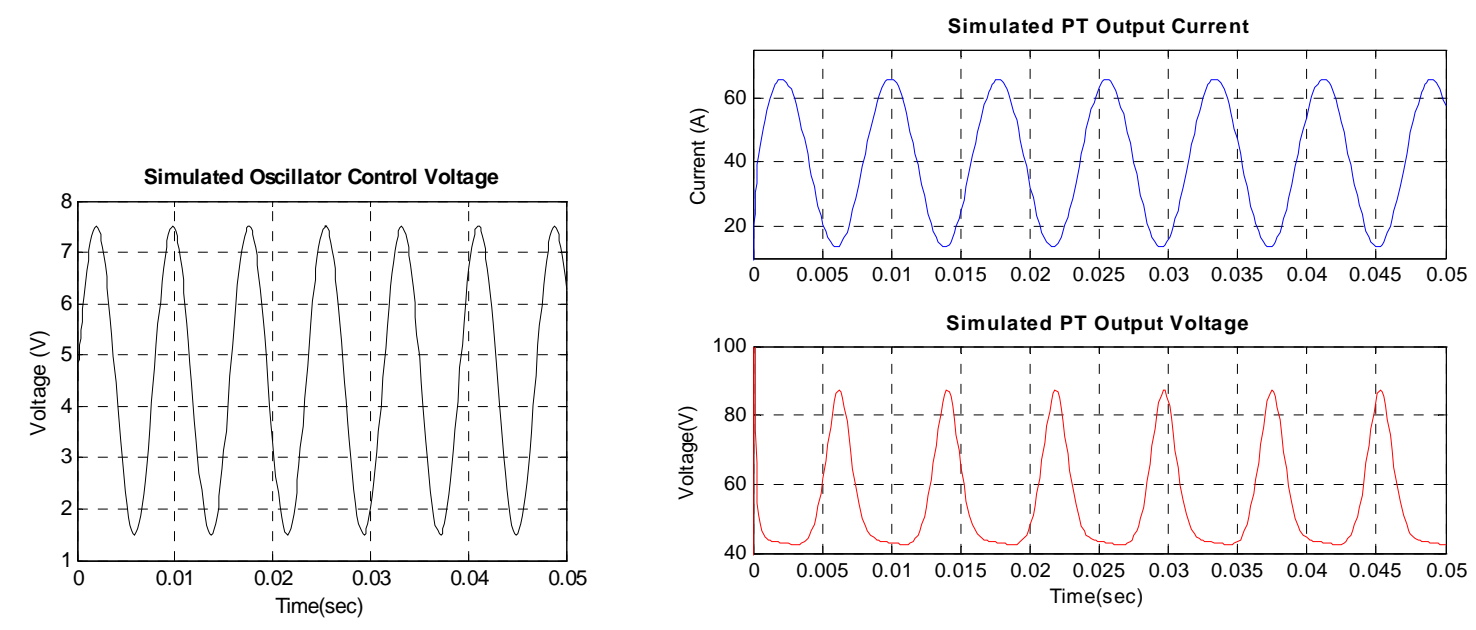

Figure 8.3. Simulated Plasma Torch Electrical Waveforms Oscillating at $128 \mathrm{~Hz}$

\subsection{Frequency Response Investigation of Plasma Torch Electric Arc Model}

A frequency response analysis discussed in Section 5.2 was completed with the simulated electrical data from the plasma torch electric arc model. The model simulated the same D. Sanders 


\section{Chapter 8. Plasma Torch Electric Arc Model}

oscillation frequency range from $2 \mathrm{~Hz}-4 \mathrm{kHz}$ with triangle, square, and sinusoidal control voltage waveforms. The FRF of the simulated data is calculated and compared to the FRF calculations based on experimental results. Three data ensembles at each oscillation frequency were averaged for an accurate estimate of the coherence values, which were above 0.89 for all calculations.

\subsubsection{Simulated Experimental Frequency Response Comparison}

The comparison of the simulated and experimental frequency response of the power supply is shown in Figure 8.4. The Gain verses PT Oscillator Frequency plot indicates the gain predicted with the simulation is the similar to the experimental result up to $512 \mathrm{~Hz}$. At frequencies higher than $512 \mathrm{~Hz}$, the roll-off slope in the gain is steeper in the simulated results. This indicates the corner frequency for the power supply is higher than predicted. The phase plot shows good agreement with experimental data up to $2 \mathrm{kHz}$. Therefore, the plasma torch power supply model adequately predicts the frequency response behavior of the welder power supply used in testing.

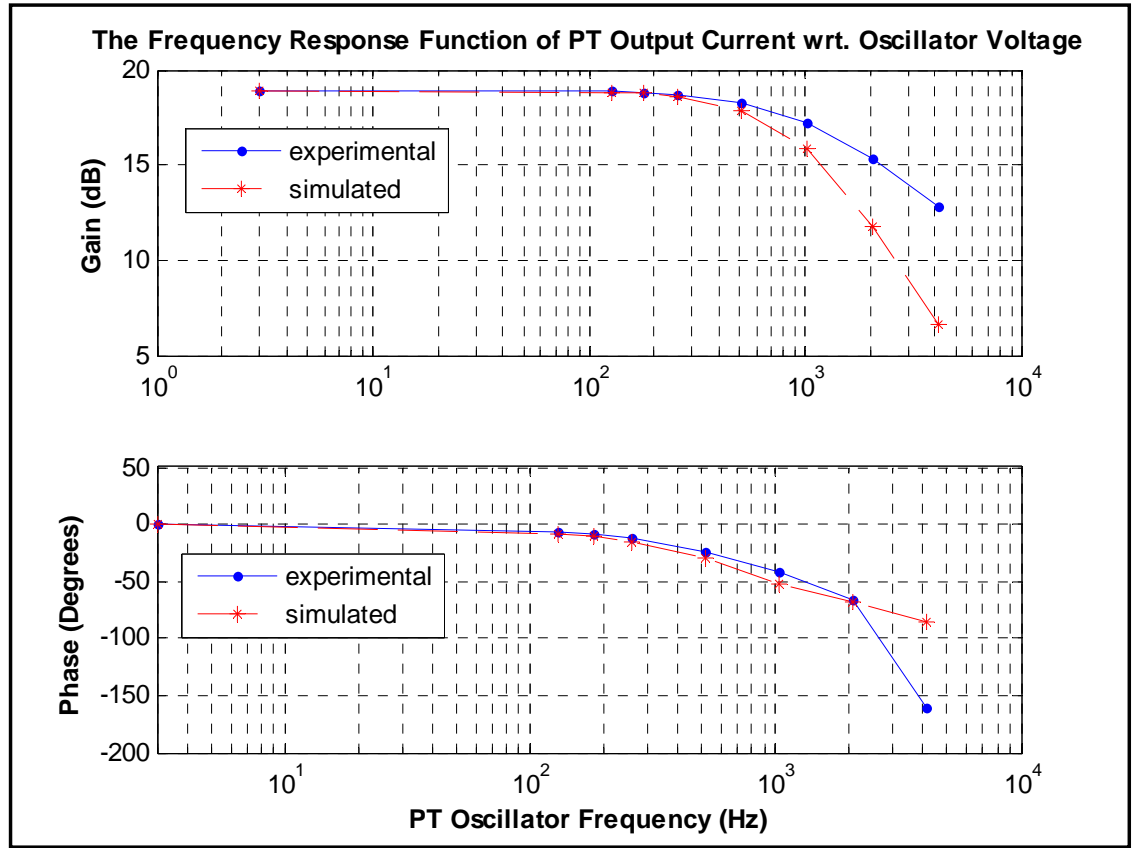

Figure 8.4. Simulated vs. Experimental FRF Plot of Power Supply 


\section{Chapter 8. Plasma Torch Electric Arc Model}

Next the simulated plasma torch electrical response was evaluated verses experimental measurements of the plasma torch output voltage. Figure 8.5 shows comparison of the simulated and experimental frequency response of the plasma torch. The gain plot shows differences in the gain for every PT oscillation frequency except $1024 \mathrm{~Hz}$. These gain differences are as high as 4.24dB or $1.5 \mathrm{~V} / \mathrm{V}$ magnitude and decreases as oscillation frequency increases until $1024 \mathrm{~Hz}$. The general shape of the gain plot is the same for both the simulated and experimental response data. The phase plot indicates good agreement with the experimental results up to $2 \mathrm{kHz}$. In summary, the plasma torch electric arc model appears adequate in predicting the plasma torch response even though there are some differences in the gain between the experimental and simulated results.

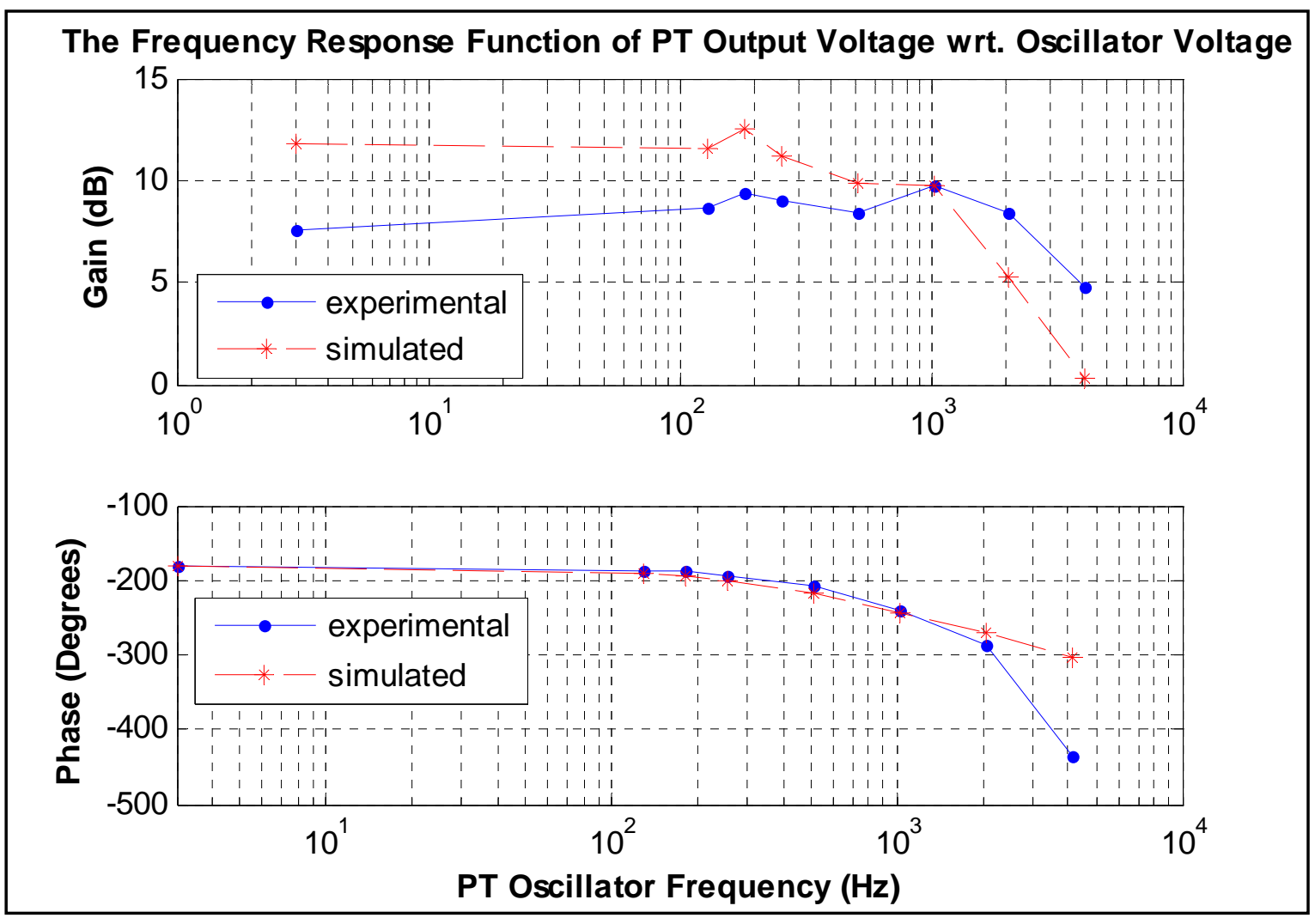

Figure 8.5. Simulated vs. Experimental FRF Plot of Plasma Torch 


\section{Chapter 8. Plasma Torch Electric Arc Model}

\subsection{Model Predictions at High Frequencies}

The plasma electric arc model was used to predict the plasma torch electrical response to high frequencies on the order of $50 \mathrm{kHz}$. These high frequencies are associated with supersonic flow combustion speeds. The model plasma torch power system must be adjusted to achieve ideal response at the set frequency range. The corner frequency for the welder power supply model will be set to $200 \mathrm{kHz}$ and oscillation frequencies of $50 \mathrm{kHz}$ at $P_{0}=2100 \mathrm{~W}$ and $E_{0}=55 \mathrm{~V}$. The result of this test is shown in Figure 8.6 and indicates the plasma torch can indeed be modulated at high frequencies if the power supply can respond adequately to high frequencies.

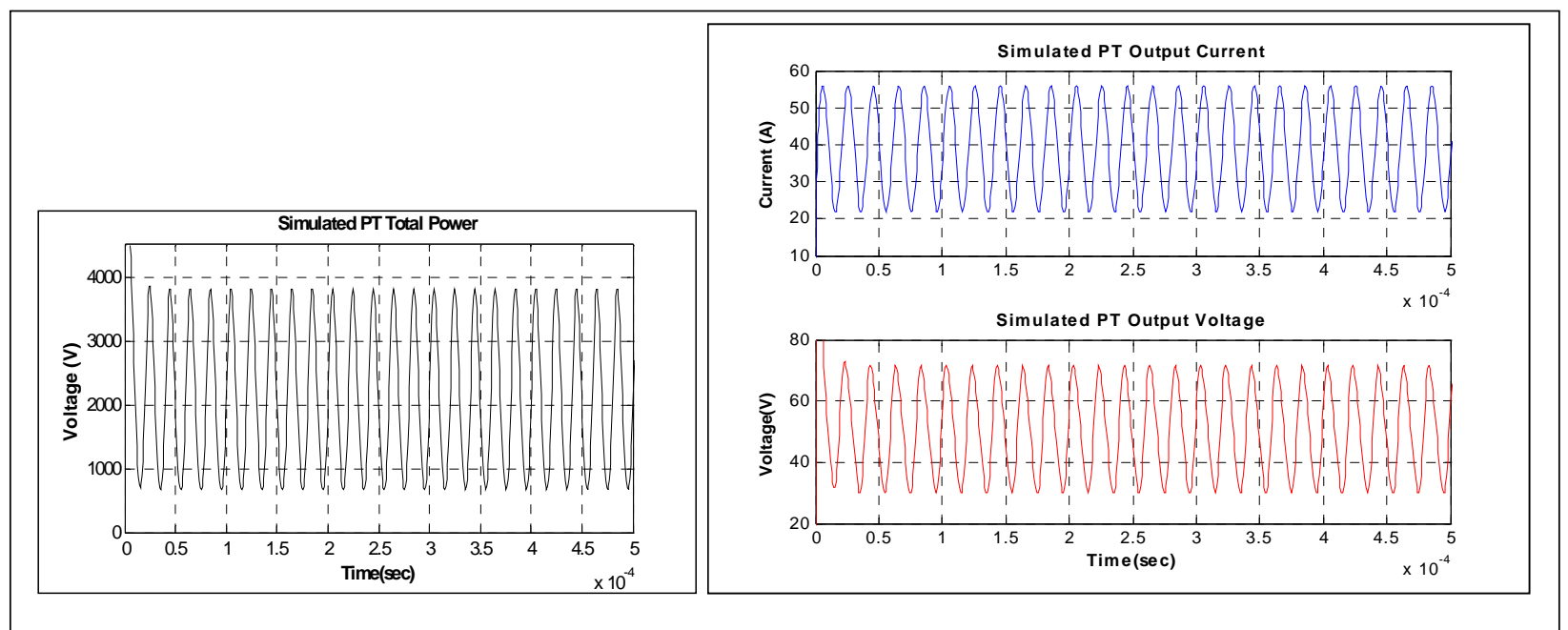

Figure 8.6. Simulated Plasma Torch Response at 50kHz 


\section{CHAPTER NINE}

\section{Conclusions and Recommendations}

This section will summarize the research completed and will present conclusions drawn from the results discussed in previous sections. Additionally, recommendations for future work on this research will be proposed.

\subsection{Conclusions}

In this study, the controlled oscillation behavior of a plasma torch was investigated for its potential to enhance mixing in supersonic combustion. A modulating power system used for dynamic control of the plasma torch oscillation was designed and tested in quiescent conditions, in Mach 2.4 cold supersonic flow, and in Mach 2 heated supersonic flow conditions. The oscillating plasma torch used nitrogen as a feedstock and operated at a power range 17002200W. Also, tests with the controlled plasma torch modulation were successfully completed over a frequency range of $2 \mathrm{~Hz}-4 \mathrm{kHz}$.

The frequency response of the modulated power supply and the plasma torch were characterized using signal processing techniques. The power supply used in the present experiments behaves as a DC amplifier with a corner frequency of $1 \mathrm{kHz}$. Also, the frequency response of the plasma torch was characterized with an amplitude roll-off greater than $2 \mathrm{kHz}$. Due to the limited response of the welder power supply, the response of the plasma torch is limited to this range. Analysis showed that the plasma torch has the potential to operate at higher frequency ranges for interaction with supersonic combustion.

The oscillating plasma torch was optically examined using high speed video imaging in a quiescent test environment. The images show that the plasma jet is responding to the modulating D. Sanders 


\section{Chapter 9. Conclusions and Recommendations}

current and voltage. Area of intensity measurements were made of the oscillating plasma jet plume to measure its oscillation frequency, but no linear correlation was found between the plasma torch electrical characteristics and plasma jet area as oscillation frequency was varied. A linear correlation was discovered between the RMS area of plume intensity and the total plasma torch RMS power. The correlation showed that the greater the plasma torch power is modulated, the larger the variation in the plasma jet plume area.

Tests in Mach 2.4 cold supersonic flow (blowdown) conditions qualitatively investigated the unsteady shock structure produced by the oscillating plasma torch, using high speed Schlieren images. The oscillating plasma jet produces an unsteady but controllable blockage in the supersonic flow. A method was implemented to measure the amount shock oscillation using an image gradient search algorithm. This algorithm was successful in identifying the position of the shock caused by the plasma torch for a limited amount of images of the plasma torch oscillation. A set of equations were found based on the assumption that a linear relationship exists between the plasma torch instantaneous power and the horizontal position of the shock caused by the plasma torch. These equations were used to predict the shock position at different times during the plasma torch oscillation cycle. An animation was made to illustrate the predicted unsteady shock position and how it moves with respect to the plasma torch oscillation.

The unsteady torch was successfully operated with an integrated aerodynamic ramp/plasma torch igniter in heated Mach 2 flow at the University of Virginia ARL. Unsteady pressure fluctuations caused by the torch flow blockage were measured and corresponded to the plasma jet oscillation frequency. Digital video images indicate that the torch oscillation influences the combustion flame produced. The single available measurement of the static 


\section{Chapter 9. Conclusions and Recommendations}

pressure indicated that the average combustion pressure was the same for the steady-state and oscillating plasma torch over the entire range of torch frequencies.

A dynamic torch model using a hybrid Mayr-Cassie electric arc model was implemented to predict the electrical characteristics of the oscillating plasma torch system. Frequency response analysis was done on the simulated electrical waveform data collected from the model. The response model compared very well to the plasma torch experimental response. Good agreement was shown between the experimental and simulated responses of both the welder power supply and the plasma torch. The plasma torch electric arc model was used to predict the plasma torch response at an oscillation frequency of $50 \mathrm{kHz}$. The model indicates that plasma torch power can be electrically oscillated at high frequencies, but whether the plasma jet plume will respond to the high frequency oscillation is still unknown.

In conclusion, the oscillating torch system performed well over a range of different flow conditions. It appears capable of implementing active control input to the combustion process. The controllable unsteady blockage has the potential to increase turbulence which should further enhance mixing in supersonic combustion [Kumar, et al. 1987].

\subsection{Recommendations for Future Research}

One idea to advance the progress reported in this thesis is to design or acquire a power supply that has a high frequency response on the order of $200 \mathrm{kHz}$, and to conduct combustion tests similar to work presented in the thesis at oscillation frequencies between $10-100 \mathrm{kHz}$. This type of research will directly test the potential of the oscillating plasma torch as an igniter with enhanced mixing efficiency.

Additional testing must be done using high-response pressure transducers that are able to measure the unsteady pressure fluctuations caused by the plasma torch. These measurements can 


\section{Chapter 9. Conclusions and Recommendations}

be complimented by optical temperature measurements to dynamically view unsteady combustion produced by the plasma torch. Also, monitoring combustion species production can be used to measure heat release and combustion efficiency of the oscillating plasma torch/aeroramp injector ignition system. The nature of how the oscillation affects the plasma jet structurally is also unclear. The high speed plasma jet plume images taken should be analyzed to obtain pressure wave propagation information.

Also, a flow control system should be developed using a plasma torch that controls flow blockage in supersonic flow. This could also be used to cancel out any combustion instabilities found in supersonic flow and to match the resonant frequency of the fuel injection system used with the plasma torch. This type of system is non-intrusive to the flow, and potentially could reduce torch power requirements, improve combustion stability, and reduce total pressure losses in the supersonic combustor.

The integration of the oscillating plasma torch with other injection systems should be tested. A recent development in the plasma torch ignition designs is a regenerative atomizerigniter [Billingsley et al. 2005]. This torch uses a heat exchanger fashioned around the anode to heat liquid fuel and inject the liquid fuel directly in the hottest region of the plasma jet. The oscillating plasma torch with the aeroramp injector could be easily integrated with the atomizerigniter. This system could provide reliable cold start ignition in supersonic combustion environments.

Finally, a power system using batteries should be designed to provide power to the plasma torch. Assuming no rotating machinery to be present, batteries are the only way plasma torches could be operated in an actual scramjet flight vehicle. Recent advances in radio- 


\section{Chapter 9. Conclusions and Recommendations}

controlled airplane (UAV) battery technology and flight demonstrations have made this idea plausible. 


\section{References}

1) Anderson, C., Schetz, J.A. and O’Brien W.F., "Integrated Liquid-Fuel -Injector/ Plamsa-Igniter for Scramjets," $12^{\text {th }}$ International Space Plasmas and Hypersonic Systems and Technologies Conference, AIAA 2003-6986, December, 2003.

2) Anderson, C., “The Development and Testing of An Integrated Liquid-Fueled-Injector/PlasmaIgniter for Scramjets,” Masters Thesis, Virginia Polytechnic Institute and State University, 2004.

3) Andrews, Earl H., "Scramjet Development and Testing in the United States," 10th International Space Planes and Hypersonic Systems and Technologies Conference, AIAA 2001-1927, April 2001.

4) Billingsley, M.C., Sanders, D.D., O’Brien W.F., and Schetz J.A., "Improved Plasma Torches for Applications in Supersonic Combustion," $13^{\text {th }}$ International Space Plasmas and Hypersonic Systems and Technologies Conference, AIAA 2005-3423, May, 2005

5) Bonanos, A.M., Sanders, D.D., Schetz, J.A., O’Brien, W.F., Goyne, C.P., Krauss, R.H., and McDaniel, J.C., "Hot-Flow Testing of an Integrated Aero-Ramp-Injector/Plasma Torch-Igniter for Scrmajets with Hydrogen and Hydrocarbon Fuels," $12^{\text {th }}$ International Space Plasmas and Hypersonic Systems and Technologies Conference, AIAA 2003-6987, December, 2003.

6) Bonanos, A.M., Schetz, J.A., O’Brien, W.F., "Scramjet Operability Range Studies of Multifuel Integrated Aeroramp Injector/Plasma Igniter," $13^{\text {th }}$ International Space Plasmas and Hypersonic Systems and Technologies Conference, AIAA 2005-3425, May, 2005.

7) Browne, Thomas E., “Circuit Interuption,” Marcel Dekker, Inc, New York, 1984.

8) Cobine, James Dillon, “Gaseous Conductors Theory and Engineering Applications,” Dover Publications, New York, 1958.

9) Cross, M.A., Sanders, D.D., O’Brien, W.F., and Schetz, J.A., "Operation of a Plasma Torch for Supersonic Combustion Applications with Simulated Cracked JP-7 Feedstock," $12^{\text {th }}$ International Space Plasmas and Hypersonic Systems and Technologies Conference, AIAA 2003-6935, December, 2003.

10) Cross M.A., "Operational Characteristics of a Plasma Torch for Supersonic Combustion Applications with Simulated Cracked JP-7 Feedstock," Masters Thesis, Virginia Polytechnic Institute and State University, 2004.

11) Curran, Edward T., "Scramjet Engines: The First Forty Years;" Journal of Propulsion and Power, Vol. 17, No. 6, November - December 2001.

12) Dowling, A.P., “Active Control of Combustion Oscillations”, $30^{\text {th }}$ Fluid Dynamics Conference, AIAA Paper 99-3571, July 1999.

13) Drummond, Phillip J. and Mukunda, H.S., "A Numerical Study of Mixing Enhancements in Supersonic Reacting Flow,” 24 ${ }^{\text {th }}$ Joint Propulsion Conference, AIAA-88-3260, July, 1988.

14) Etebari, A., Carneal, J., and Vlachos, P.P., "On the Accuracy of Wall Shear Stress Using DPIV," 2004 Heat Transfer/Fluids Engineering Summer Conference, HT-FED 2004-56839, July, 2004.

15) Gallimore, S.D., "Development and Operating Characteristics of an Improved Plasma Torch for Supersonic Combustion Applications,” Masters Thesis, Virginia Polytechnic Institute and State University, 1998. 
16) Gallimore, S.D., Prebola, J.L., O’Brien, W.F., Schetz, J.A., Hanus G., and Uznanski, K., "Operation of a High Pressure Uncooled Plasma torch with Hydrocarbon Feedstocks," $36^{\text {th }}$ JANNAF Combustion Meeting, 1999.

17) Gallimore, S.D., "A Study of Plasma Ignition Enhancement for Aeroramp Injectors in Supersonic Combustion Applications,” Ph.D. Dissertation, Virginia Tech, May 2001.

18) Gallimore, S.D., Jacobsen, L.S., O’Brien, W.F., and Schetz, J.A., “Spectroscopic Investingations of Hydrocarbon and Nitrogen-Based Plasmas for Supersonic Flow," $10^{\text {th }}$ International Space Plasmas and Hypersonic Systems and Technologies Conference, AIAA 2002-5247, October 2002.

19) Goyne, C.P., Rodrigeuz, C.G., Kruass, R.H., McDaniel, J.C., and McClinton, C.R., "Experimental and Numerical Study of a Dual Mode Scramjet Combustor", $11^{\text {th }}$ International Space Plasmas and Hypersonic Systems and Technologies Conference AIAA Paper 2002-5216, October, 2002.

20) Harrison, A.J. and Wienburg, F.J., "Flame Stabilization by Plasma Jets, "Proceeding of the Royal Society of London, Vol.321, pp.95-103, 1971.

21) Hilliard, J.C., "Methods of Improving Combustion by Electrical Means," Ph.D. Disseration, Imperial College of Science and Technology, London, November, 1979.

22) http://www.aviation-history.com/, Feb. 3.2004.

23) http://www.dfrc.nasa.gov, December, 1999.

24) http://www.plasmas.org/basics.htm, July 29, 2004.

25) http://www.visionresearch.com, July 13, 2005.

26) Jacobsen, L.S., Gallimore, S.D., Schetz, J.A., O’Brien, W.F., and Goss, L.P., “An Improved Aerodynamic Ramp Injector in Supersonic Flow," 39 ${ }^{\text {th }}$ Aerospace Sciences Meeting and Exhibit, AIAA 2001-0518, January 2001.

27) Jacobsen, L.S., Gallimore, S.D., Schetz, J.A., O’Brien, W.F., and Goss, L.P., “An Integrated Aeroramp Injector/ Plasma-Igniter for Hydrocarbon Fuels in a Supersonic Flow, Part A: Experimental Studies of the Geometric Configuration," $10^{\text {th }}$ International Space Plasmas and Hypersonic Systems and Technologies Conference, AIAA 2001-1766, April, 2001.

28) Kimura, Itsuro, Aoki, Hiroshi, and Kata, Manabu, "The Use of a Plasma Torch for Flame Stabilization and Promotion of Combustion in Supersonic Air Flows," Journal of Propulsion and Power, Vol. 19, No. 5, pp.853-858, 2003.

29) Kumar, A., Bushnell, D.M., and Hussaini, M.Y., "Mixing Augmentation Technique for Hypervelocity Scramjets,” Journal of Propulsion and Power, Vol. 5, No. 5, pp. 514-522, 1989.

30) Mitani, Tohru, "Ignition Problems in Scramjet Testing”, Combustion and Flame, Vol. 101, pp. 347359, 1995.

31) Nishikawa, K. and Wakatani, M., "Plasma Physics: Basic Theory with Fusion Applications," Springer-Verlag, Berlin, 1993.

32) Northam, G. Burton, McClinton, Charles R., Wagner, Timothy C. and O'Brien, W.F., "Development and Evaluation of a Plasma Jet Flameholder for Scramjets," 20th Joint Propulsion Conference, AIAA 84-1408, 1984.

33) Prebola, J.L., "Performance of a Plasma Torch with Hydrogen Feedstocks for Use in Scramjet Combustion,” Masters Thesis, Virginia Polytechnic Institute and State University, 1998.

34) Sitenko, A. and Malnev, V., "Plasma Physics Theory,” Chapman and Hall, London, 1995. 
35) Takita, K., Sato, T., Ju,Y., and Masuya, G., "Effects of Addition of Radicals Supplied by Plasma Torch on Burning Velocity,” 35 ${ }^{\text {th }}$ Joint Propulsion Conference, AIAA 99-2247, June 1999.

36) Tseng, K.J., wang, Y., Vilathgamuwa, D.M., "Cassie- Mayr Electric Arc Model for Power Electronic Simulations,” IEEE Transactions on Power Electronics, Vol. 12, No.3, pp. 429-436, May, 1997.

37) Wagner, T.C., O’Brien, Walter F., Northam, G. Burton and Eggers, James M., "Plasma Torch Igniter for Scramjets," Journal Propulsion and Power, Vol. 5, No. 5, pp. 548-554, September October 1989.

38) Waltrup , P.J., “Hypersonic Airbreathing Engines: Evolutions and Opportunities,” AGARD CP428, Paper 12, April 1987.

39) Waltrup, P.J., White, M.E., Zarlingo, F., and Gravelin, E.S., "History of U.S. Navy Ramjet, Scramjet, and Mixed-Cycle Propulsion Development," $32^{\text {nd }}$ Joint Propulsion Conference Exhibit, AIAA 96-3152, July 1996.

40) Waltrup, Paul J., Anderson, Griffin Y., and Stull, Frank D., "Supersonic Combustion Ramjet (Scramjet) Engine Development in the United States," Proceedings $-3^{\text {rd }}$ International Symposium on Air breathing Engines, Dietmar K. Hennecks and Gert Winterfield, eds. DFLR Fachbuchriehe Bd. 6, pp. 835-861, 1976.

41) Wienburg, F.J., Hom, K., Oppenhiem, A.K., and Teicham, K., "Ignition by a Plasma Jet,” Nature, Vol 272, pp. 341-343, 1978.

42) Wood, C.W., Thomas, R.H., and Schetz, J.A., "Effects of Oscillating Shock Impingement on the Mixing of Gaseous Jet in Mach 3 Airstream," $26^{\text {th }}$ Joint Propulsion Conference, AIAA 90-1982, July, 1990. 


\section{Appendix A}

\section{Audio and Video Media of Oscillating Plasma Torch}

This section is included to show slow motion videos of the oscillating plasma torch at various conditions. The image of the first frame of the video is shown. The media files are available from the http://etd.vt.edu website for downloading. To use the file, save the file at a specific location on your computer and click on the media file in this document to play it. It will ask you to point to the location of the media file on your computer to play it. The specified media file will open in a new window and play.

\section{Oscillating Nitrogen Plasma Torch in Quiescent Conditions}
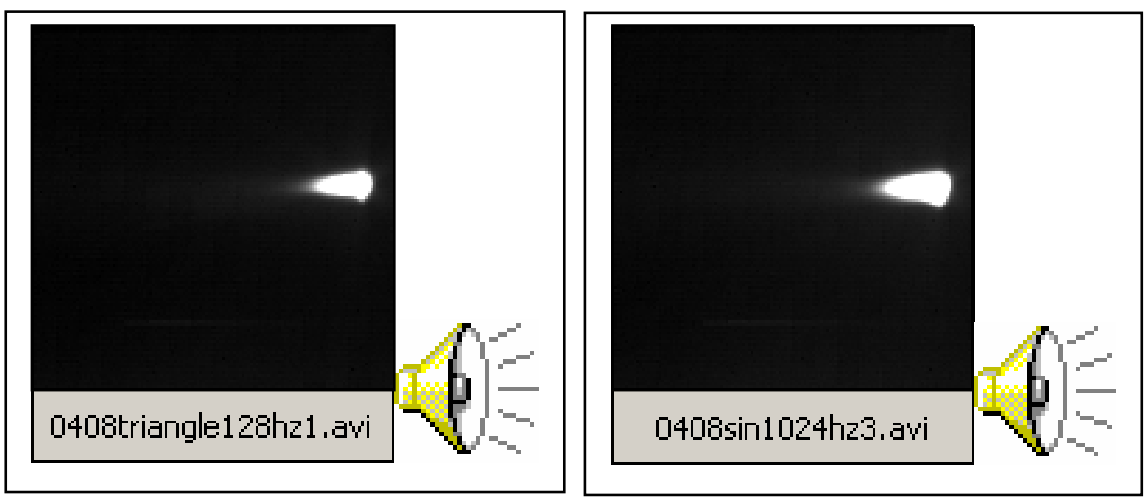

Figure A.1. Nitrogen Plasma Jet Movies Oscillating at 1024Hz (left) and $128 \mathrm{~Hz}$ (right)

These movies show how the nitrogen plasma jet plume responds to the modulating voltage using high speed video imaging and audio recordings. The plasma torch is operated at controller oscillator voltage frequencies of $128 \mathrm{~Hz}$ and $1024 \mathrm{~Hz}$ with triangle and sinusoidal waveforms at total power of $1866 \mathrm{~W}$ and $2037 \mathrm{~W}$, respectively. The feedstock flow rate is 25slpm of nitrogen. These videos were recorded at a frame rate of 10,000 frames per sec with a resolution of $156 \mu \mathrm{m} /$ pixel. The frame rate of the movies shown in Figure A.1 is 10 frames per second. 


\section{High Speed Schlieren Movies at Mach 2.4 Flow Conditions}

Figure A.2 shows two videos at different test conditions. The first video shown is the control case where the feedstock gas of the plasma torch is operating without any plasma ignition and the shock of interest, caused by the cold feedstock injection, moves very little. The next video shows the oscillating PT at a frequency of $256 \mathrm{~Hz}$ with an average total power of $2377 \mathrm{~W}$. The shock movement is caused by the plasma jet area changes with the total instantaneous power. The videos were recorded at a frame rate of 8000 frames per second. The frame rate of the videos in Figure A.2 is 2 frames per second.

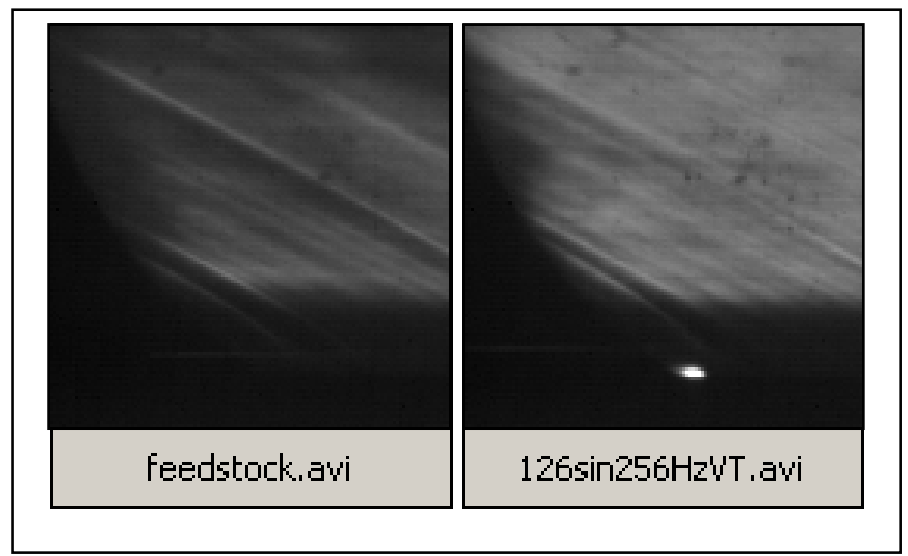

Figure A.2. High Speed Schlieren Videos of Control Case (left) and Nitrogen PT at 256Hz

\section{Oscillating Plasma Torch Operating at UVA in Mach 2 Heated Tunnel}

Figure A.3 is a video of the oscillating plasma torch operating at UVA Supersonic Combustion Tunnel (ARL). The plasma torch is oscillating at a frequency of $2 \mathrm{~Hz}$ at a RMS total power of 5669W with hydrogen aeroramp injection. The test conditions are the same conditions described in Section 7.1.1. The video was taken at 30 frames per second with a digital video camera. The video demonstrates in real time how the plasma torch is influencing the combustion produced at the nozzle discharge exit. 


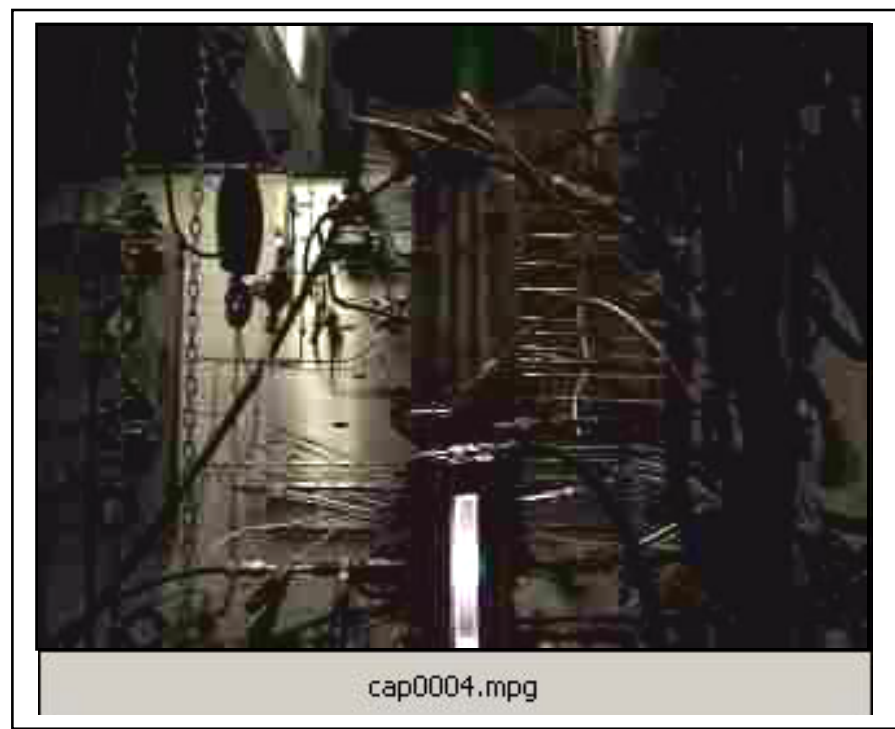

Figure A.3. Video of Oscillating Plasma Torch Operating at the UVA Supersonic Combustion Tunnel 


\section{Vita}

Darius Sanders, son of Edward Sanders and Alice Howard, was born in Washington, D.C. on February 2, 1980. His family eventually moved to Hyattsville, MD when Darius was at the age of eleven and he attended public schools in Prince Georges County, MD. He graduated top 3\% of his class from Northwestern High School in June, 1998. He then attended Delaware State University in Dover, DE with a full academic scholarship. There he was the Drum Major of the Delaware State University “Approaching Storm” Marching Band, played varsity tennis, and was a MARC (Minority Access to Research Careers) Scholar. He graduated Summa Cum Laude in May 2002 with a Bachelor of Science in Physics with Engineering Emphasis. Darius decided to pursue a Master's and Doctorate degree in Mechanical Engineering at Virginia Tech. He has remained active in the community at Virginia Tech through work as an officer in the Black Graduate Student Organization and the local chapter of Kappa Alpha Psi Fraternity Incorporated. Upon obtaining his Master's degree, Darius plans continue his education and obtain a Ph.D. degree in Mechanical Engineering. Also, Darius plans to participate in a cooperative research position at Wright-Patterson Air Force Base Air Force Research Lab to fund his doctorate work. 